\title{
DIFFERENCES IN ATRIAL FIBRILLATION PROPERTIES UNDER VAGAL NERVE STIMULATION VERSUS ATRIAL TACHYCARDIA REMODELING
}

\author{
par \\ Grigorios Katsouras MD \\ Programme en Sciences Biomédicales \\ Faculté de Médecine \\ Thèse présentée à la Faculté des études supérieures \\ en vue de l'obtention du grade de Maitrise \\ en Sciences Biomédicales
}

Août 2009

(C) Grigorios Katsouras, 2009 
Université de Montréal

Faculté des études supérieures

Cette thèse intitulée :

\title{
DIFFERENCES IN ATRIAL FIBRILLATION PROPERTIES UNDER VAGAL NERVE STIMULATION VERSUS ATRIAL TACHYCARDIA REMODELING
}

\author{
présentée par : \\ Grigorios Katsouras MD \\ a été évaluée par un jury composé des personnes suivantes : \\ Bruce Allen $\mathrm{PhD}$, président-rapporteur \\ Stanley Nattel MD, directeur de recherche \\ Teresa Kus MD, PhD, membre du jury
}




\section{Résumé}

Fond : Le substrat de fibrillation auriculaire (FA) vagale et celui secondaire à remodelage par tachycardie auriculaire (RTA) partagent beaucoup des caractéristiques : période réfractaire efficace $(\mathrm{PRE})$ réduite, hétérogénéité accrue de PRE et quelques mécanismes moléculaires communs. Cette étude a comparé les 2 substrats à une abréviation comparable de PRE.

Méthodes : Chez chacun de 6 chiens de groupe de stimulation vagal (SV), les paramètres de stimulation cervicale bilatérale de nerves vagaux ont été ajustés pour produire la même PRE moyenne (calculé à 8 sites des oreillettes gauche et droite) avec 6 chiens de groupe de RTA assorti à sexe et poids. Des paramètres électrophysiologiques, la durée moyenne de la fibrillation auriculaire (DAF) et les fréquences dominantes (FD) locales ont étés calculés.

Résultats : En dépit des PREs assorties (SV: 80 $\pm 12 \mathrm{msec}$ contre RTA: $79 \pm 12 \mathrm{msec}$ ) la DAF était plus longue $(*)$, l’hétérogénéité de conduction était plus élevée (*), la FD était plus rapide (*) et la variabilité de FD plus grande $\left(^{*}\right)$ chez les chiens SV. Les zones de maximum FD qui reflètent les zones d'origine de FA étaient à côté de ganglions autonomes chez les chiens SV.

Conclusions : Pour un PRE atriale comparable, la FA secondaire à SV est plus rapide et plus persistante que la FA avec un substrat de RTA. Ces résultats sont consistants avec des modèles de travail suggérant que l'hyperpolarisation SV-induite contribue de façon important à la stabilisation et à l'accélération des rotors qui maintiennent la FA. La similitude de la distribution de FD du groupe vagal avec la distribution des lésions 
d'ablation après cartographie des électrogrammes atriales fragmentés suggère des nouvelles techniques d'ablation. La distribution des FD entre le SV et le RTA fournit de nouvelles idées au sujet de possible rémodelage neuroreceptorial et indique des différences importantes entre ces substrats de FA superficiellement semblables.

Mots-clés : fibrillation auriculaire, période réfractaire effective, stimulation vagal, ganglion cardiaque, remodelage par tachycardie auriculaire, fréquence dominante, récepteurs muscariniques, vitesse de conduction. 


\section{Abstract}

Background: Vagal nerve stimulation (VS) and atrial tachycardia remodeled (ATR) atrial fibrillation (AF) substrates share many features: reduced effective refractory period (ERP), increased ERP heterogeneity and some common molecular mechanisms. This study compared VS and ATR substrates at comparable ERP abbreviation.

Methods: In each of 6 VS dogs, bilateral cervical VS parameters were adjusted to produce the same mean ERP as a sex and weight matched ATR dog. Electrophysiological parameters, mean duration of $\mathrm{AF}$ (DAF) and local dominant frequencies (DF) were determined (before (CTL) and after VS in VS dogs).

Results: Despite matched ERPs (VG: $80 \pm 12 \mathrm{msec}$ vs ATR: $79 \pm 12 \mathrm{msec}$ ) DAF was greater $\left(^{*}\right)$, conduction heterogeneity was greater $(*)$, DF was faster $\left(^{*}\right)$ and DF variability greater (*) in VS dogs. AF drivers reflected by maximum DF zones were adjacent to autonomic ganglia in VS dogs; there was a tendency $(\mathrm{p}<0.07)$ to faster driver zones in the left atrium comparing to the right in ATR dogs.

Conclusions: For a comparable atrial ERP, VS AF is faster and more persistent than AF with an ATR substrate. These results are consistent with modeling work suggesting that VS-induced hyperpolarization is an important contributor to AF-maintaining rotor stabilization and acceleration. Similarities in DF distribution in VS dogs with distribution of ablation lesions performed after Complex Fractionated Atrial Electrograms mapping suggests new curative ablation methods. DF distribution differences between VS and ATR 
provides new ideas about possible neuroreceptorial remodeling and indicates important differences between these superficially similar AF substrates.

Keywords: Atrial fibrillation, atrial tachycardia remodeling, vagal stimulation, dominant frequencies, effective refractory period, cardiac ganglia, muscarinic receptors, conduction velocity 


\section{Table of contents}

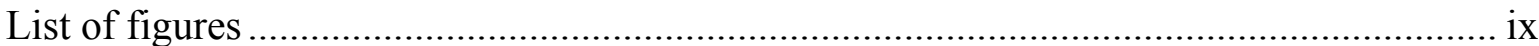

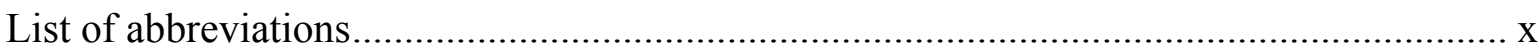

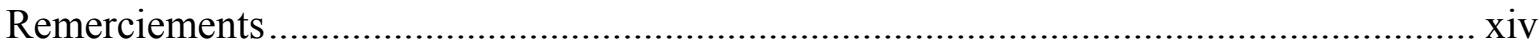

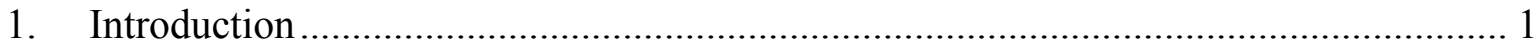

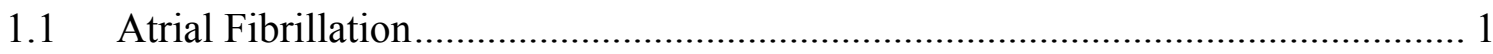

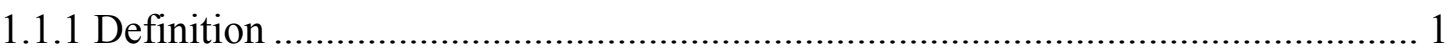

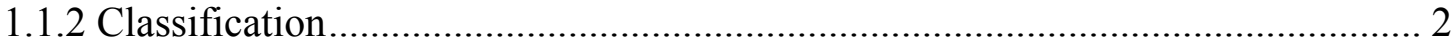

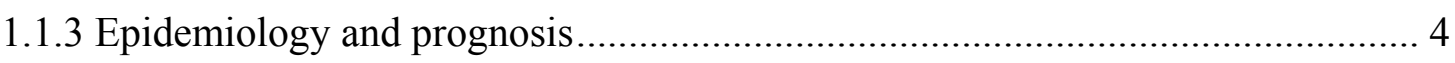

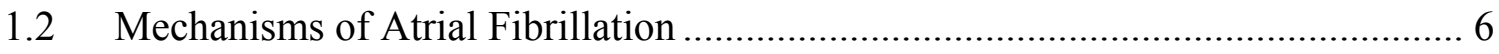

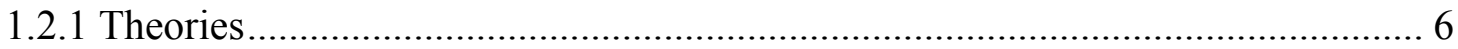

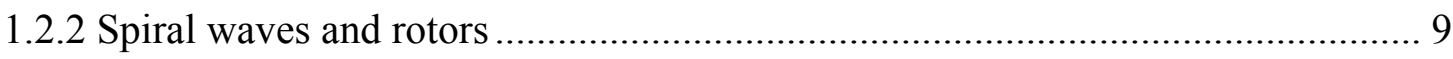

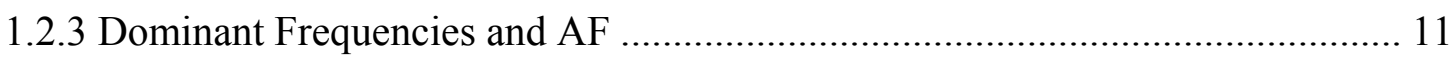

1.2.4 Complex fractionated atrial electrograms (CFAEs) and DF .......................... 13

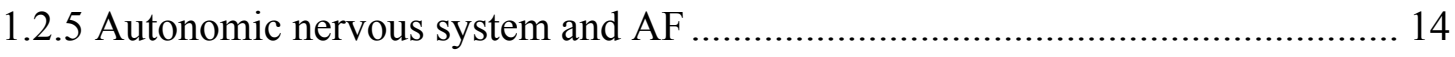

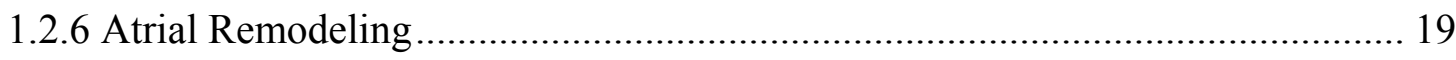

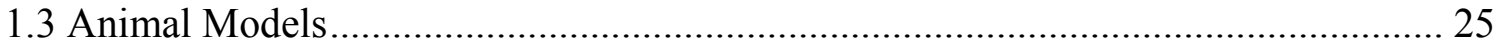

1.3.1 Atrial tachycardia remodeling (ATR) animal model .................................... 26

1.3.2 Vagal stimulation (VS) animal model .................................................... 28

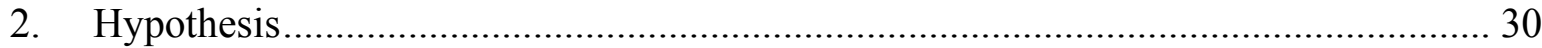

3. Differences in atrial fibrillation properties under vagal nerve stimulation versus atrial

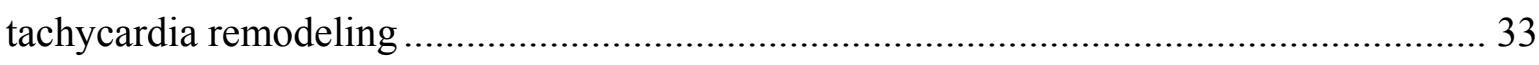

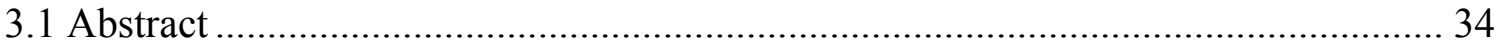

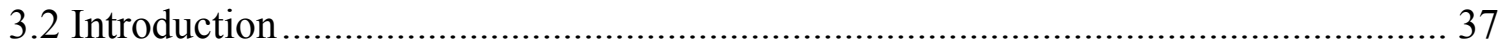

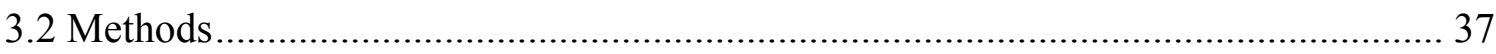

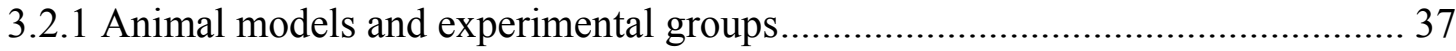

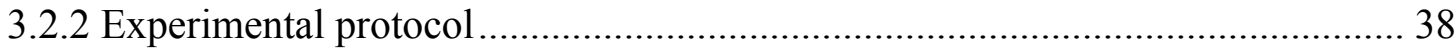

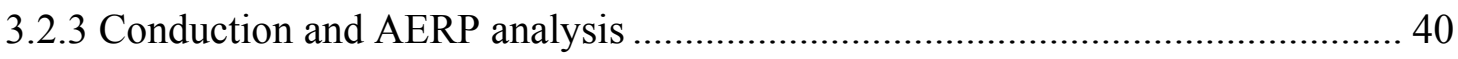




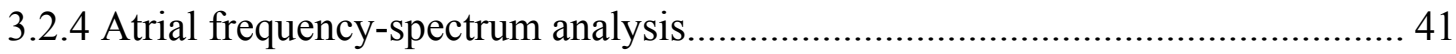

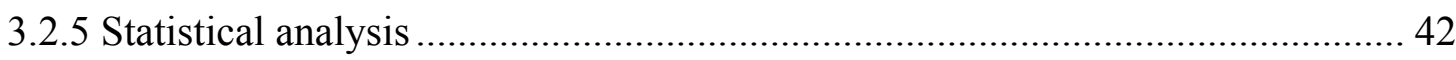

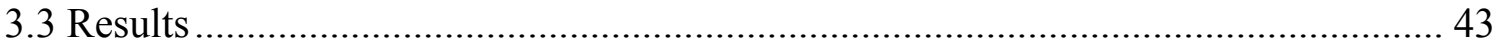

3.3.1 Electrophysiological variables and properties of atrial fibrillation...................... 43

3.3.2 Regional changes in electrophysiological properties.......................................... 44

3.3.3 Local conduction abnormalities ....................................................................... 44

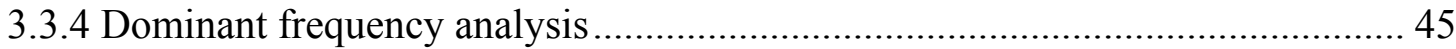

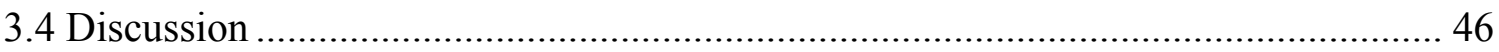

3.4.1 Atrial electrophysiological consequences of vagal-nerve stimulation and ATR 46

3.4.2 Novel findings and potential underlying mechanisms ........................................ 48

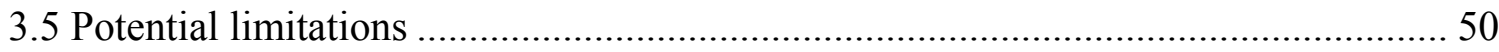

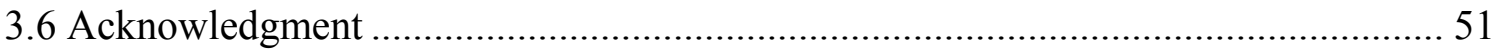

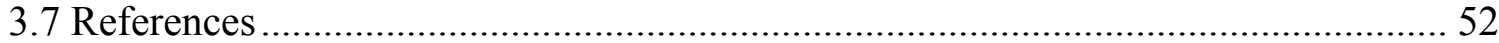

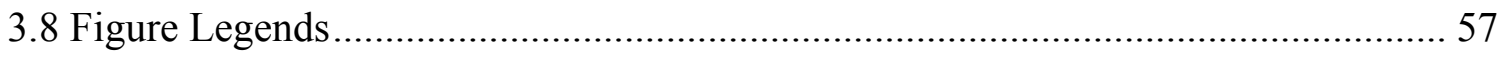

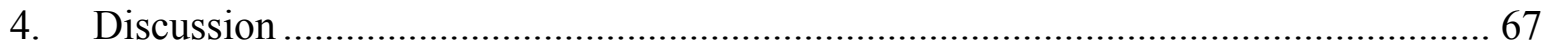

4.1 Electrophysiological properties of VS and ATR substrate ……………………......... 67

4.2 Leading circle model, spiral wave theory and our study ......................................... 70

4.3 Role of autonomic ganglia, spiral waves and rotors ............................................. 72

4.4 Clinical implications ...................................................................................... 75

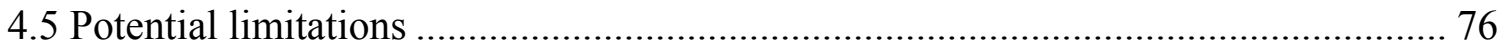

4.6 $\mathrm{I}_{\mathrm{KACh}}, \mathrm{I}_{\mathrm{KACh}, \mathrm{c}}$, muscarinic receptors, $\mathrm{DF}$ and future research ................................... 77

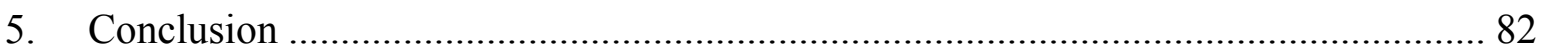

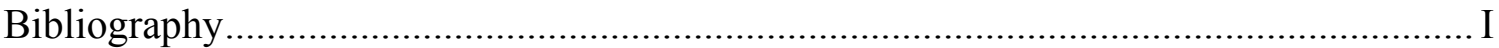




\section{List of figures}

Fig. 1 Patterns of AF. page 3

Fig. 2 Example of electrogram and power spectra page 11

Fig. 3 Sympathetic and parasympathetic nervous system page 14

Fig. 4 Anatomic distribution of cardiac autonomic ganglia page 16

Fig. 5 Mean AERP and mean duration of AF under each condition page 59

Fig. 6 Mean CV and mean WL under each condition page 60

Fig. 7 AERP heterogeneity and CV heterogeneity under each condition page 61

Fig. 8 Effects of VS and ATR on electrophysiological indexes in different areas of left and right atrium $\quad$ page 62

Fig. 9 Local conduction differences between groups under LAA and RAA pacing page 63

Fig. 10 Example of electrogram recordings and power spectra under each condition

page 64

Fig. 11 Spatial distribution of mean DFs under each condition page 65

Fig. 12 Overall results of DF analysis. Comparison between groups page 66

Fig. 13 Similarities between anatomical distribution of epicardial autonomic ganglia, DF distribution under VS and ablation lesions following CFAEs.

page 75

Fig. 14 DF analysis between left and right atria under each condition 


\section{List of abbreviations}

AERP: atrial effective refractory period

AF: atrial fibrillation

AFCL: atrial fibrillation cycle length

APD: $\quad$ action potential duration

ASR: $\quad$ atrial structural remodeling

ATR: atrial tachycardia remodeling

AV: $\quad$ atrioventricular

BCL: basic cycle length

CL: $\quad$ cycle length

CTL: control

$\mathrm{CV}: \quad$ conduction velocity

DAF: durée de fibrillation auriculaire

DF: dominant frequency

ECG: electrocardiogram

ERP: $\quad$ effective refractory period

FA: fibrillation auriculaire

FD: $\quad$ fréquences dominantes

HF : heart failure

$\mathrm{I}_{\mathrm{KACh}}: \quad$ inward rectifier potassium current legated to acetylcholine

$\mathrm{I}_{\mathrm{KACh}, \mathrm{c}}$ : $\quad \mathrm{I}_{\mathrm{KACh}}$ constitutively active 


\begin{tabular}{|c|c|}
\hline $\mathrm{I}_{\mathrm{K} 1}$ : & inward rectifier potassium current \\
\hline IVC: & inferior vena cava \\
\hline LA: & left atrial \\
\hline LAA: & left-atrial appendage \\
\hline LBB: & left-atrial side of Bachmann's Bundle \\
\hline LIW: & left-atrial inferior wall \\
\hline LPW: & left-atrial posterior wall \\
\hline mAChKir: & muscarinic $\mathrm{K}^{+}$channel \\
\hline $\mathrm{Pa}:$ & pulmonary artery \\
\hline PRE: & période réfractaire efficace \\
\hline PV: & pulmonary veins \\
\hline RA: & right atrial \\
\hline RAA: & right-atrial appendage \\
\hline RBB: & right-atrial side of Bachmann's Bundle \\
\hline RIW: & right-atrial inferior wall \\
\hline RPV: & right pulmonary vein \\
\hline RPW: & right-atrial posterior wall \\
\hline RTA: & remodelage par tachycardie auriculaire \\
\hline RV: & right ventricular \\
\hline SV: & stimulation vagal \\
\hline SVC: & superior vena cava \\
\hline
\end{tabular}


VS:

vagal stimulation

WL: wavelength 
À mes parents Evangelos et Litsa pour leur soutien continue 


\section{Remerciements}

Je voudrais remercier la fondation Bodossakis pour leur aide économique pendant mes années académiques, le journaliste Nick Gage pour le soutien et les conseils, Madames Louise Fortier, Sylvie Levesque et Marie-Claude Guertin pour leur conseils en Statistique, Madames Nathalie L'Heureux et Chantal St-Cyr pour leur aide aux techniques de laboratoire, la fondation de l'Institut de Cardiologie, les médecins de l'équipe d'électrophysiologie et particulièrement Dr Mario Talajic qui m'a aidé à compléter mon fellowship clinique et expérimentale. Sans la contribution et l'aide substantiel des coauteurs de l'article, cette thèse ne pourrait pas terminer. Enfin un grande merci à mon directeur de recherche Dr Stanley Nattel qui m'a permis de faire partie de son laboratoire et qui m'a aidé pendant toutes les phases du projet. 


\section{Introduction}

\subsection{Atrial Fibrillation}

\subsubsection{Definition}

Atrial fibrillation (AF) is a supraventricular tachycardia characterized by erratic and uncoordinated electrical activation of the atria causing deterioration of atrial mechanical function and irregular heart rhythm ${ }^{1,2}$. On the electrocardiogram, AF is characterized by the substitution of the normally present $\mathrm{P}$ waves with fibrillatory (f) waves that conduct variably to the ventricles, creating the characteristic "irregularly irregular" heart rhythm of $\mathrm{AF}$.

The f waves are small, irregular baseline undulations of variable amplitude and morphology at a rate of $350-600$ beats $/ \mathrm{min}^{3}$. Atrial dimensions and underlying heart disease are the main factors influencing the amplitude of $\mathrm{f}$ waves. Occasionaly, electrical activity is not recognizable on the ECG, but only by atrial endocardial leads recording electrical activity of even higher frequency. It is believed that $f$ waves don't represent total atrial activity but depict only the larger vectors generated by the variable electrical atrial activation at any given moment ${ }^{3}$. However, if each atrial impulse were conducted to the ventricle the extremely rapid ventricular rate would lead to ineffective cardiac contraction and sudden death ${ }^{4}$. The filtering properties of the atrioventricular (AV) node, which has a 
limited impulse-carrying capacity, prevent such an event. Thus, the ventricular response to $\mathrm{AF}$ depends on the interaction between atrial rate and filtering $\mathrm{AV}$ node function, the level of vagal and sympathetic tone, the presence or absence of accessory pathways, and the action of drugs ${ }^{1,4}$.

Although AF can occur in patients without any evident heart problems (lone AF), it is generally associated with structural heart diseases such as congestive heart failure, valvular disease, ischemic heart disease, pericardial diseases, congenital defects and hypertensive or other cardiomyopathies. Atrial dilation and increased atrial pressure are the most plausible causes of AF promotion in such patients. However, the precise mechanistic links are incompletely defined ${ }^{4}$. Non-cardiac causes include electrolyte disturbances, ethanol intoxication, thyroid dysfunction, pulmonary disease, septic disease or febrile illnesses 5 .

\subsubsection{Classification}

Various classifications have been proposed. According to ACC/AHA/ESC guidelines "the clinician should distinguish a first-detected episode of AF (fig. 1), recognizing that there may be uncertainty about the duration of the episode and about previous undetected episodes"1 . If the patient had 2 or more episodes AF is recurrent. If an episode lasts longer than 7 days then $\mathrm{AF}$ is characterized as persistent. If $\mathrm{AF}$ terminates spontaneously or even after pharmacological or electrical cardioversion in less than 7 days 
time then it should be classified as paroxysmal. AF lasting longer than a year becomes permanent.

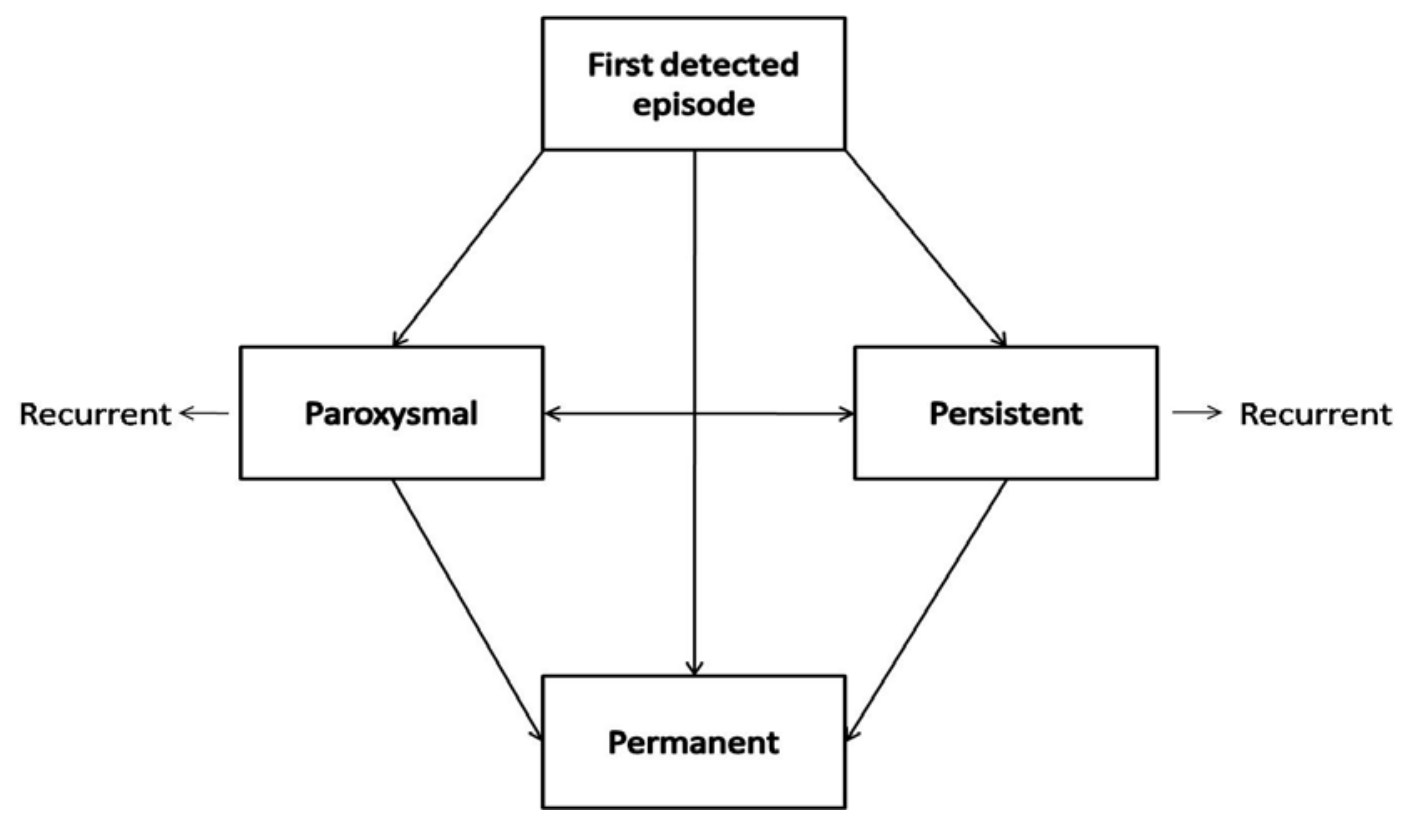

Fig. 1 Patterns of AF. Paroxysmal AF for episodes lasting less than 7 days, persistent AF for episodes lasting between 7 days and one year and permanent AF for episodes greater than a year (adapted from Fuster et $\mathrm{al}^{1}$ )

These categories are not mutually exclusive. A patient can present several times with paroxysmal and occasionally persistent $\mathrm{AF}$ and vice versa. It is practical to categorize the patient according to the most frequent presentation.

The term "lone AF" applies to arrhythmic episodes in young individuals (generally $<60$ years old) without evidence of cardiopulmonary disease ${ }^{1,6}$. It represents one of the 
most intriguing forms of AF, comporting interesting pathophysiological implications. It generally has a favorable prognosis.

\subsubsection{Epidemiology and prognosis}

Prevalence of a disease is defined as the proportion of a population affected by the disease at a point in time. The estimated prevalence of $\mathrm{AF}$ is $0.4 \%$ to $1 \%$ in the general population $^{1,7}$. It increases to $9 \%$ in subjects 80 years or older. AF prevalence is higher in men when compared to women at all ages. Nevertheless, due to the higher mean age, women comprise a larger proportion of the older groups ${ }^{8,9}$.

AF prevalence is expected to increase proportionally with the increase of mean age of population. In USA the percentage of subjects older than 65 years is estimated to increase substantially by the year 2050 to more than $20 \%$ of the general population ${ }^{9}$. Considering that $75 \%$ of patients with AF are 65 years or older and the median age of U.S patients with AF is 75 years $^{7-9}$, we would expect a considerable rise of AF prevalence in USA and proportionally in other countries with similar lifestyle.

The incidence of a disease is the rate at which new cases present in a population during a specified time period. In prospective studies the incidence of AF increases from less than $0.1 \%$ per year in patients under 40 years to more than $1.5 \%$ in women and $2 \%$ in

men older than 80 years old ${ }^{1,10,11}$. Furthermore, in the Framingham study the age-adjusted incidence increased in a span of less than 30 years, suggesting a greater impact of AF in the 
near future ${ }^{1,11}$. The lifetime risk for development of AF was 1 in 4 for individuals 40 years of age and older ${ }^{9,12}$. Thus, the burden of AF in the population, being already high, increases from year to year, comporting increases in costs, physical damage and mortality.

$\mathrm{AF}$ is associated with an increased risk of stroke, heart failure (HF) and all cause mortality $^{1}$. In the Framingham Heart Study, it was associated with 1.5 to 1.9 fold excess mortality after adjustment for preexisting cardiovascular conditions. Main causes of mortality are thromboembolic events and/or HF.

The ventricular rate in AF is determined by the interaction between the high atrial rate and the filtering function of $\mathrm{AV}$ node ${ }^{4}$. High ventricular rates can per se cause severe congestive HF after several weeks or months ${ }^{13}$, whereas high heart rate in patients with HF can be deleterious and increase mortality. HF promotes AF and vice versa. Patients with either condition that develop the alternate have a poor prognosis ${ }^{1}$. Moreover, loss of effective atrial contraction leads to blood stasis in the atria and formation of clots that tend to propagate to the brain and other vital organs. The rate of ischemic stroke among patients with non valvular AF averages 5\% per year with a relative risk 6 times higher of that of people without $\mathrm{AF}^{1}$. About $36 \%$ of ischemic strokes in individuals aged 80 to 89 years old are attributed to $\mathrm{AF}^{9}$. 


\subsection{Mechanisms of Atrial Fibrillation}

\subsubsection{Theories}

$\mathrm{AF}$ is the most common arrhythmia in clinical practice. Therefore, researchers focused early on this arrhythmia and theories regarding its mechanisms have been put forward almost 100 years ago $^{4,5}$. The principal mechanisms described were 1) the automatic focus activity 2) the single circuit reentry and 3) the multiple-circuit reentry.

\subsubsection{Rapid ectopic activity and single circuit reentry theories}

Focal activity and single circuit reentry theories include the existence of a source producing high frequency wavefronts that interact with the spatially variable refractory and conductive properties of atrial tissue. A single rapid firing focus would be expected to produce a regular tachycardia. However, if the atrial rate is too rapid the atria cannot respond in a 1:1 fashion and a chaotic atrial rhythm will result. Haissaguere et al showed that $\mathrm{AF}$ is frequently initiated by rapid focal ectopic activity coming from the pulmonary veins $(\mathrm{PV})^{14}$. While PV seem the most frequent source of ectopic activity, rapid foci have been found also in superior vena cava (SVC), ligament of Marshall, left posterior free wall, crista terminalis and coronary sinus ${ }^{1}$.

Seemingly, special conditions are necessary in order for a single-circuit reentry to stabilize and maintain AF. A microreentrant circuit, with exiting impulses firing at extremely high rates, encounters functional conduction barriers in the atria that obstacle a 
1:1 conduction. Fibrillatory conduction can be due to spatially variable refractory periods or to the structural properties of atrial tissue ${ }^{5,15}$. Schuessler et al. demonstrated in an isolated right atrial (RA) preparation that, with increasing concentrations of acetylcholine (ACh), a single, relatively stable, high frequency circuit resulted in fibrillatory conduction $^{16}$. Studies from Mandapati et al. reinforced the concept that localized left atrial (LA) sources, which may be single microreentrant circuits, would be the basis for AF in isolated animal hearts ${ }^{17}$. Furthermore, Berenfeld et al. demonstrated in the same animal model that there exists a frequency in the sheep RA below which electrical activity is organized and above which it is disorganized like $\mathrm{AF}^{15}$. Consequently, although a dominant frequency (DF) of fibrillation in LA would be conducted in the RA with decreasing values, such frequency would be high enough to disorganize electrical propagation in RA. Similar DF differences between LA and RA have been observed either clinically or experimentally in other studies ${ }^{18,19}$.

\subsubsection{Multiple-circuit reentry}

Over the past 50 years the hypothesis of multiple circuit reentry has been the dominant conceptual model of $\mathrm{AF}^{4}$. According to Moe and coworkers ${ }^{20}$, fractionation of wavefronts propagating through the atria results in multiple reentrant self- perpetuating wavelets. The number of wavelets at any time depends on the atrial mass, the refractory period and the conduction velocity (CV) in different parts of the atria. Large atrial mass, short refractory period and delayed conduction are conditions that increase the number of 
wavelets favoring sustained AF. However, a sufficient number of these wave fronts must always find excitable tissue in order for the arrhythmia to persist.

Based on these concepts and in subsequent experimental work Allessie and colleagues $^{21,22}$ developed the "leading circle" model of functional reentry. The wavelength (WL) is the distance travelled by the electrical impulse during the time of effective refractory period (ERP) and equals the product of the ERP with the $\mathrm{CV}$. If the dimensions of the tissue involved are shorter than the WL, the presuppositions of reentry are missing, as the electrical impulse encounters unexcitable tissue and consequently extinguishes. Normal size atrium can permit only a small number of leading circles, which tend to extinguish. On the contrary, a dilated atrium can host multiple leading circles promoting sustained AF. Based on this notion, the Maze procedure was designed to divide the atrium into regions too small to support reentry ${ }^{23}$. The great efficacy of this procedure strengthened the multiple circuit reentry concept ${ }^{5}$. Additionally, interventions that decrease WL such as vagal stimulation (VS) (which reduces atrial effective refractory period [AERP]) permit more leading circles to coexist and promote $\mathrm{AF}$, while interventions that increase WL, such as antiarrhythmic drugs that increase AERP, suppress AF by reducing the number of possible circuits ${ }^{24}$. Accordingly, most of antiarrhythmic drugs in use prevent the recurrence of $\mathrm{AF}$ by prolonging the $\mathrm{WL}^{22,25,26}$.

However, AERP is not uniformly distributed in the atria and it has been demonstrated that higher heterogeneity of AERP promotes $\mathrm{AF}^{27}$. Shorter regional AERP and consequently shorter WL would need a circuit of small size for reentry to occur. As the 
firing heart rate of reentrant tachycardia increases with decreasing circuit size, the smallest circuit size (or smallest WL) should control the overall atrial electrical activity ${ }^{24}$. Such notion would be compatible with single circuit reentry with a DF that is conducted with decreasing frequency to the remaining atrium. Thus, single circuit reentry or multiple circuit reentry could be the two faces of the same coin; that is, two expressions of the same mechanism that unfortunately we still try to understand.

\subsubsection{Spiral waves and rotors}

Experimental work in the last decades has sustained the theory of spiral wave activity as responsible for sustained reentrant activity in excitable systems such as the heart $^{24,28,29}$. While in the leading circle model the electrical impulse excitation follows a circle with an unexcitable core (continuously excited by centripetal waves), according to the spiral wave theory the electrical impulse pursues a spiral trajectory continuously changing direction. There is a source sink relationship where the source represents the excited and depolarized tissue and the sink denotes the excitable tissue $\mathrm{e}^{30,31}$. If the source is too small it will extinguish itself in the vast sink; if it is too big it won't find excitable tissue to continue its activity. The maintenance of the spiral wave requires an angle of curvature which is determined by tissue excitability and source-sink relationships. Low excitability (for example an increase in ERP or reduction in $\mathrm{I}_{\mathrm{Na}}$ ) or propagation strength (reduced $\mathrm{CV}$ ) limit the curvature and enlarge the spirals with subsequent termination of $\mathrm{AF}^{24}$. Thus, inhibition of $\mathrm{Na}^{+}$current should enlarge the spirals and terminate $\mathrm{AF}$ as Na-channel 
blockers do. On the contrary, according to the leading circle they would have the opposite effect: the $\mathrm{CV}$ reduction would decrease the $\mathrm{WL}$ and would promote $\mathrm{AF}$, which is not what has been observed clinically $y^{32,33}$ and experimentally ${ }^{34,35}$.

Furthermore, experimental work demonstrated the existence of spiral waves during AF with optical ${ }^{36}$ and high density conventional mapping ${ }^{24,37}$. A mathematical model of atrial activity with representations of atrial ionic and conduction properties in a 2dimensional grid indicated also a spiral wave activity during $\mathrm{AF}^{38}$. Moreover, recent studies of cholinergic $\mathrm{AF}$ in the isolated sheep heart demonstrated that high frequency sources in the PV region dominate and drive the fibrillatory activity throughout both atria ${ }^{39,40}$. This and other experimental studies, ${ }^{17,36,40}$ has led to the hypothesis that "patients with AF have a focal or reentrant mechanism as the initiating cause of arrhythmia, while perpetuation of AF may depend on the uninterrupted periodic activity of a small number of discrete generators (rotors), most often localized in the LA and established by the interaction of propagating waves with anatomical heterogeneities in the atria", ${ }^{, 39}$. The results of one of the first studies using rapid atrial pacing in dogs to promote AF support such a hypothesis $^{41}$. Ablation of the area with the shortest cycle length (CL) during AF had a profound antiarrhythmic effect in that model. Clinical studies ${ }^{42-44}$ demonstrated that ablation in PV region and posterior wall, that is areas showing the fastest activity during $\mathrm{AF}$ as measured by $\mathrm{CL}$ in coronary sinus electrograms, prolonged at first the $\mathrm{CL}$ and subsequently terminated the arrhythmia. The areas of shortest CL would correspond to the generators (rotors) responsible for the maintenance of AF. Consequently, based on these 
works researchers focused recently their interest on the study of atrial electrical activity and its spectral properties during AF.

\subsubsection{Dominant Frequencies and AF}

The theorem of Fourier tells that any time series, such as a cardiac electrogram, can be represented exactly as the superposition of sinusoidal waves with different frequencies and amplitudes ${ }^{45}$. Consequently, an atrial electrogram can be decomposed in its spectral components creating a power spectrum where the sinusoidal wave of major amplitude shows a dominant peak (fig. 2). The frequency of that sinusoidal wave constitutes the dominant frequency (DF) and conceptually represents the inverse of the most frequent and dominant $\mathrm{CL}$ in the registration of an atrial electrogram $(\mathrm{DF}=1 \mathrm{sec} / \mathrm{CL} \mathrm{sec})$. For example atrial flutter, which is an atrial arrhythmia with regular CL, has generally a DF of $5 \mathrm{~Hz}$ that would be equal to $1 \mathrm{sec}$ divided by the classical CL of $0.2 \mathrm{sec}$ ( 300 beats per minute).
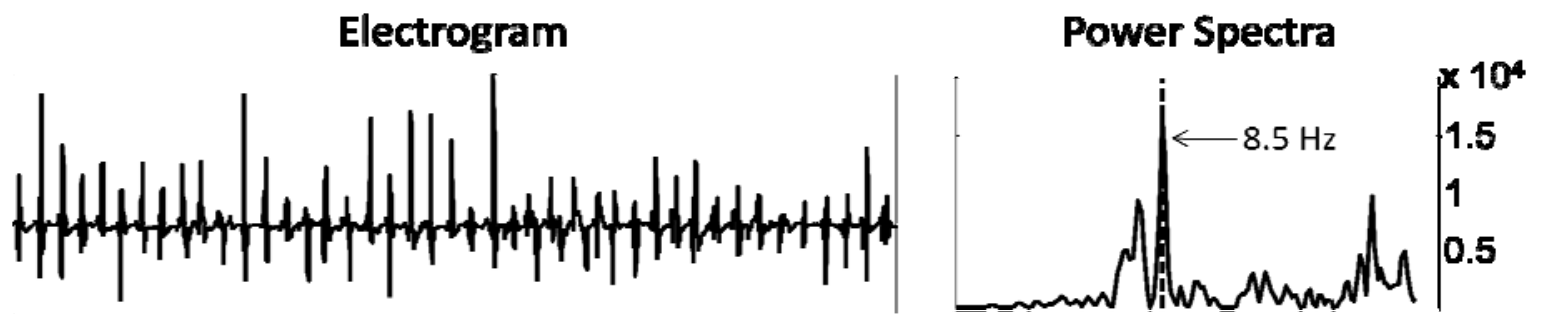

Fig. 2 Example of atrial electrogram recording and its corresponding power spectra. The dominant frequency of $8.5 \mathrm{~Hz}$ corresponds to the frequency with the highest power. 
Studies in isolated sheep hearts that have analyzed AF in frequency domains have provided evidence that AF has a high degree of spatiotemporal periodicity and high frequency rotors are responsible for maintaining $\mathrm{AF}^{17,36,40}$. Such rotors emanate generally from the PV region suggesting that these structures have an important role in maintaining $\mathrm{AF}^{45}$. Sanders et $\mathrm{al}^{46}$ creating $\mathrm{DF}$ maps from recordings of 120 points in both atria, correlated the DF distribution with ablation points and they found that ablation at PVs harboring high DF-sites resulted in an increase in $\mathrm{CL}$ of $\mathrm{AF}$ in either paroxysmal or permanent AF. However, arrhythmia termination during ablation occurred only in $88 \%$ of paroxysmal AF patients. In $87 \%$ arrhythmia termination was associated with ablation in high DF-sites.

Moreover, there is substantial evidence from animal and human studies that during AF dominant frequencies are higher in LA than in the RA ${ }^{18,19,39,47}$. According to studies in isolated sheep heart, most of the high frequency sources exist in the LA and at a critical frequency, a gradient develops between LA and RA. In a recent study, Atienza et al ${ }^{48}$ demonstrated that elimination of LA to RA frequency gradients during ablation predicts long-term maintenance of sinus rhythm in AF patients. All these data clearly indicate that high-DF sites play a role in the maintenance of AF in a significant number of patients. 


\subsubsection{Complex fractionated atrial electrograms (CFAEs) and DF}

There is evidence that high DF areas likely represent either rotors or triggered activity that is driving $\mathrm{AF}^{17}$. In the clinical setting new electogram based measures of fractionation and rate have recently been proposed to guide AF ablation ${ }^{49}$. Several studies describe AF termination after ablation of sites with $\mathrm{CFAEs}^{49-51}$. CFAES were originally defined by Nademanee ${ }^{49}$ as either 1) electrograms with two or more deflections or continuous electrical activity over a 10 second period or 2) electrograms with a mean $\mathrm{CL}<$ $120 \mathrm{msec}$ over a 10 second recording period.

Kalifa et $\mathrm{al}^{52}$ studying AF in isolated sheep hearts showed that the most fractionated activity was found in the periphery of high frequency sources, while a similar correlation between DF areas and fractionated electrograms was demonstrated by Everett et $\mathrm{al}^{53}$ in various animal models. Recently, Zlochiver et $\mathrm{al}^{54}$ presented a very interesting work, providing insights into the mechanisms underlying CFAEs. They showed that complex electrogram signals can be divided into strictly periodic components (presumably due to underlying rotors) and residual components deriving from meandering of spiral wave sources $^{55}$. Registrations farther from rotors have weaker signals, that is more residual components coming from spiral wave meandering. Interestingly, a recent study correlated the sites of fragmented electrograms with those of ganglionated plexi of the autonomic nervous system ${ }^{56}$. 


\subsubsection{Autonomic nervous system and AF}

Autonomic nervous system plays a very important role in regulating heart rhythm. It is divided in two major portions: the craniosacral parasympathetic division and the thoracolumbar sympathetic division. Both divisions originate in nuclei within the central nervous system with preganglionic fibers that exit from the brain stem or spinal cord and terminate in ganglia ${ }^{57}$.

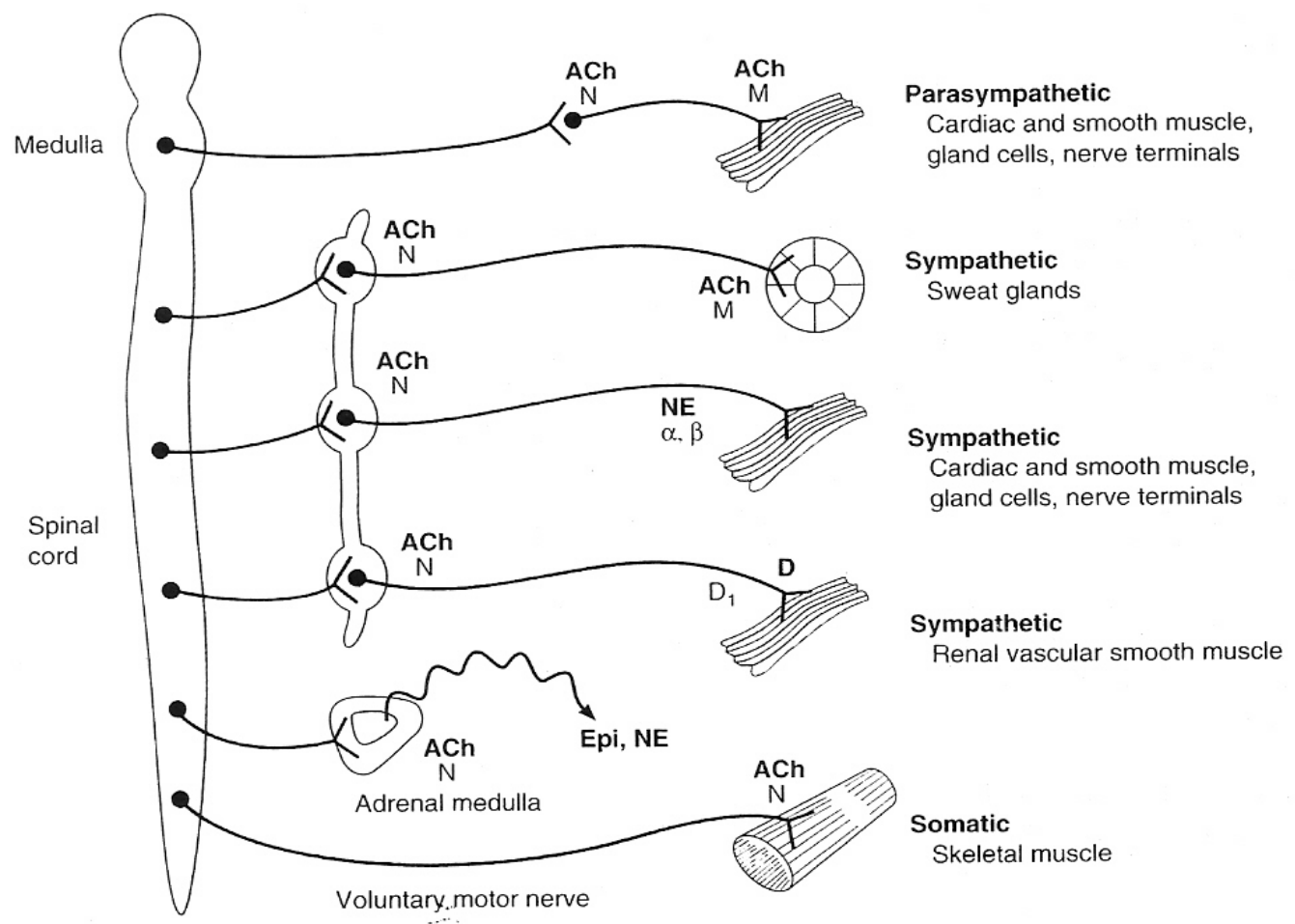

Fig. 3 Distribution of parasympathetic and sympathetic fibers from central nervous system to ganglia and subsequently to peripheral organs. Sympathetic preganglionic fibers terminate in ganglia of the paravertebral chain, while parasympathetic preganglionic fibers terminate in peripheral ganglia in straight relationship with the organs and tissues innervated (adapted from Katzung ${ }^{57}$ ). 
Sympathetic cardiac preganglionic fibers leave the central nervous system through thoracic nerves and terminate in ganglia located in the paravertebral chains (superior cervical ganglion, middle cervical ganglion, vertebral ganglion, cervicothoracic (stellate) ganglion $)^{58-60}$. Parasympathetic cardiac preganglionic fibers leave the central nervous system through the vagal nerves and terminate on ganglion cells distributed diffusely in a complex system of ganglia located in fat pads or near the superficial vessels of the heart (fig. 3). In the same complex system of ganglia and fat pads terminate also the postganglionic sympathetic fibers constituting a plexus of cardiac nerves with multiple bifurcations and synapses among them. According to Chiou et $\mathrm{al}^{61}$ there are three fat pads around the heart that constitute the primary stations of the preganglionic parasympathetic fibers. Most efferent vagal fibers travel through a fat pad located between the SVC and aortic root and then project to the right pulmonary vein (RPV) fat pad (adjacent to the right pulmonary vein-atrial junction), or the inferior vena cava (IVC) fat pad (at the junction of inferior vena cava and left atrium). Notably the RPV fat pad would innervate the sinus node, while the IVC pad would innervate the AV node. However, a few vagal fibers bypass the SVC fat pad and go directly to either of the other two pads. The vagal postganglionic neurons to the sinus node are located in the RPV fat pad (adjacent to the RPV-atrial junction), while the vagal postganglionic neurons innervating the AV node are located in the IVC fat pad (at the junction of IVC and LA). However, fibers coming from the fat pads terminate in a complex system of intrinsic cardiac neurons located in small ganglia 
scattered mainly on the posterior surfaces of the atria and superior aspect of the ventricles, including AV groove and circumscribing most of the main heart vessels ${ }^{59,62,63}$ (fig. 4).
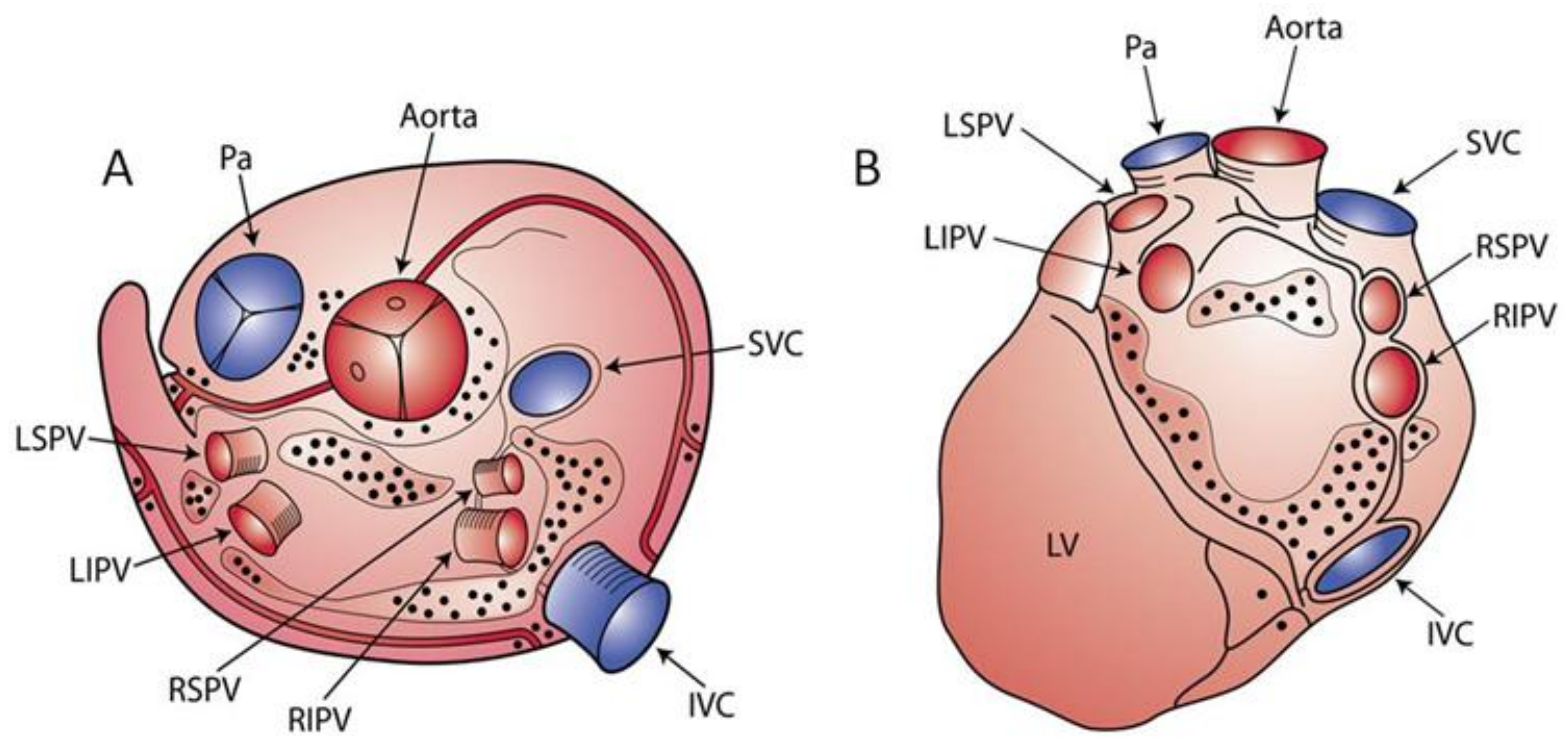

Fig. 4 Schematic representation of anatomical distribution of ganglia of the autonomous intrinsic cardiac nervous system on the epicardial surface. Most of the ganglia are located in the posterior atrial surface and superior atrial and ventricular surface circumscribing main heart vessels. A: Superior view. B: Posterior view IVC= Inferior vena cava, LIPV= Left Inferior Pulmonary Vein, LSPV= Left Superior Pulmonary Vein, LV= Left Ventricle, $\mathrm{Pa}=$ Pulmonary Artery, RIPV= Right Inferior Pulmonary Vein, RSPV= Right Superior Pulmonary Vein, SVC $=$ Superior Vena Cava (adapted from Armour et $\mathrm{al}^{62,64}$ and Yuan et $\left.\mathrm{al}^{64}\right)$. 
Although epicardial fat pads and ganglionated plexuses contain mainly vagal ganglia, some sympathetic nerve fibers and even sympathetic neurons exist inside this complex system $^{65}$. Whereas, electrical stimulation of the fat pads elicits a predominantly vagal response, parasympathetic blockade by atropine reveals the sympathetic excitation. Consequently, RF ablation or surgical removal of fat pads damages both vagal and sympathetic innervation ${ }^{65}$.

Vagus nerves exert a negative dromotropic and chronotropic effect on the sinus and AV nodes while sympathetic stimulation has a positive effect. Right VS primarily slows heart rate while right stellate ganglion stimulation increases heart rate. Conversely, left vagal or left stellate stimulation exerts its negative or positive dromotropic effects mainly on AV conduction ${ }^{66}$. However, both sympathetic and parasympathetic systems act contemporaneously and the final effect depends on the interaction between them. Thus, VS produces a greater reduction in heart rate in the presence of tonic sympathetic stimulation (accentuated antagonism), while changes in AV conduction during concomitant sympathetic and VS are the algebraic sum of the changes occurring independently if we stimulate only each one of the branches of autonomic nervous system ${ }^{66}$. Furthermore, cardiac responses to brief vagal bursts begin after a short latency and dissipate quickly, while cardiac responses to sympathetic stimulation commence and dissipate rather slowly. So, VS influences beat to beat regulation, obtaining rapid responses to vagal influences, while sympathetic stimulation produces a slow temporal response. Such phenomena are manifested also in the measurement of heart rate variability in long electrocardiographic 
recordings. In the power spectra of such recordings (obtained with Fast Fourier Trasformation as we saw in the DF section) the high frequency (HF) component corresponds to rapid modifications of heart frequency and would express the vagal influence on heart rate. On the contrary, the low frequency (LF) component would rather correspond to slow temporal heart rate modifications and would express the sympathetic influence on heart rate.

Parasympathetic stimulation has long been recognized to play an important role in $\mathrm{AF}^{67}$. Coumel suggested that either limb of the autonomic nervous system, particularly the parasympathetic, can generate $\mathrm{AF}^{68}$. He distinguished a clinical form of vagal AF occurring generally in men without structural heart disease after meals or during rest (that is in situations of vagal preponderance). In contrast, adrenergic AF occurres generally in patients with heart disease, hyperthyroidism or pheocromocytoma, with arrhythmic episodes happening in daytime, during stress or exercise.

Vagal AF promotion is related to a spatially heterogeneous reduction in $\mathrm{AERP}^{69}$. VS substantially reduces AERP and even if slightly increases $\mathrm{CV}^{70}$, shortens atrial WL promoting reentry and AF according to the leading circle model ${ }^{65,71}$. The heterogeneous spatial distribution of ganglia containing vagal neurons and the corresponding inhomogeneous distribution of ACh in the atria could be responsible for ERP heterogeneity and consequent AF promotion. Sympathetic stimulation provokes a more homogeneous reduction in AERP still promoting AF, however not as much as $\mathrm{VS}^{71}$. 
Due to the proarrhythmic potential of VS, it has been supposed that denervation of the atria would be beneficial in preventing AF. Chiou et $\mathrm{al}^{61}$ demonstrated that radiofrequency ablation of the three fat pads prevented the inducibility of sustained AF during bilateral VS. Autonomic denervation during AF ablation seems to play an important role for its efficacy ${ }^{72}$, while ablation of autonomic ganglia at the base of the PVs suppresses vagal responses in an experimental model of $\mathrm{AF}^{73}$. As recently suggested ${ }^{56}$, CFAEs may result from activation of the intrinsic cardiac autonomic nervous system and the clinical efficacy of ablation of CFAEs ${ }^{49}$ may result by a partial atrial denervation ${ }^{65}$.

\subsubsection{Atrial Remodeling}

In 1995, Allessie's group published one of the most important works of the last decades $^{74}$, demonstrating that AF changes the electrophysiological properties of the atria in a way to promote its persistence or even its repeated and early initiation after several terminations. "AF begets AF" representing a common clinical scenario in humans, where AF presents initially as paroxysms that become more and more persistent with time, progressing subsequently to chronic AF. The changes in electrophysiological, structural, contractile, neuroreceptorial or endothelial properties of the atrium created by the persistence of AF have been named as atrial remodeling ${ }^{75}$. Two major categories of atrial remodeling have been described: atrial tachycardia remodeling (ATR) occurring after rapid atrial tachyarrhythmias, and atrial structural remodeling (ASR) which is associated with HF 
and other fibrosis promoting conditions ${ }^{76}$. ATR would decrease AERP and ASR would affect $\mathrm{CV}$, both promoting $\mathrm{AF}$ according to the leading circle model.

\subsubsection{Atrial tachycardia remodeling (ATR)}

The alterations in ionic currents and properties of cellular excitability are termed electrical remodeling ${ }^{75}$. The most characteristic changes are ERP reduction and loss of ERP rate-dependence ${ }^{5,74}$ (ERP doesn't become shorter proportionally to the increase in heart rate). Moreover, spatially heterogeneous ERP changes and anisotropic conduction are important in establishing favorable conditions for reentry and subsequently persistence of $\mathrm{AF}^{4,27,75}$.

ATR abbreviates atrial refractoriness by decreasing action potential duration (APD), primarily by $\mathrm{I}_{\mathrm{CaL}}$ downregulation and increased inward rectifier $\mathrm{K}^{+}$currents $^{76}$. $\mathrm{I}_{\mathrm{CaL}}$ is a calcium current passing through the L-type (long-lasting) calcium channels occurring in the later phases of calcium channel opening ${ }^{77}$. AF increases atrial rate $\sim 10$ fold, which increases atrial myocyte $\mathrm{Ca}^{2+}$ loading ${ }^{78}$. Therefore, atrial myocytes put forward different mechanisms in order to protect themselves from $\mathrm{Ca}^{2+}$. Yue et al ${ }^{79}$, studying an animal model of atrial tachycardia pacing to mimic $\mathrm{AF}$, observed a progressive downregulation of the transient outward $\mathrm{K}^{+}$current $\mathrm{I}_{\mathrm{to}}$ and the L-type $\mathrm{Ca}^{2+}$ current $\mathrm{I}_{\mathrm{CaL}}$, leading to $\mathrm{APD}$ shortening and impaired APD rate adaptation with consequent AF promotion. Subsequent work of the same group demonstrated transcriptional messenger RNA (mRNA) downregulation of the $\alpha$-subunit of the L-type $\mathrm{Ca}^{2+}$ channel, as well as of the Kv4.3-Ito $\alpha$ - 
subunit as the causative mechanism ${ }^{80}$. Furthermore, Bosch et al obtained similar findings in human $\mathrm{AF}^{81}$.

Intracellular $\mathrm{Ca}^{2+}$ loading by rapid atrial pacing leads to mitochondrial swelling and may jeopardize cell viability ${ }^{75}$. Declines in $\mathrm{Ca}^{2+}$ gradients between the cell compartments decreases atrial myocyte contractility and underlies the atrial contractile dysfunction observed in clinical $\mathrm{AF}^{75,78}$. Such alterations in intracellular $\mathrm{Ca}^{2+}$ handling and cellular contractility have been named contractile remodeling ${ }^{75,82}$.

The voltage gated transient outward $\mathrm{K}^{+}$current $\mathrm{I}_{\text {to }}$ is consistently decreased in $\mathrm{ATR}^{83}$. Its role in promoting AF is not well established. Ito opposes the inward $\mathrm{Na}^{+}$current in the first phase of action potential. Therefore, a decrease of $I_{\text {to }}$ may facilitate wave propagation by increasing action potential amplitude ${ }^{76}$. Decreases of $\mathrm{I}_{\text {to }}$ are associated with reductions in both mRNA and protein expression of its pore forming Kv4.3 subunit ${ }^{80}$.

Moreover, substantial work in the last decade put in evidence the important role of the inward rectifier channel superfamily $\mathrm{K}_{\mathrm{ir}}$ in atrial cell repolarization and genesis of arrhythmia. Potassium channels of this family set the resting membrane potential of cardiac myocytes $^{77}$. $\mathrm{K}_{\text {ir }}$ passes an outward current when the membrane potential is above the potassium equilibrium potential and thus contributes on the late repolarization phase of the action potential, thereby regaining the resting membrane potential. Conversely, when cell membrane is hyperpolarized, $\mathrm{K}_{\mathrm{ir}}$ passes an inward current in order to maintain the high internal $\mathrm{K}^{+}$activity and keep the resting membrane potential. The main background conductance that controls atrial resting membrane potential is $\mathrm{I}_{\mathrm{K} 1}$, a current passing through 
$\mathrm{K}_{\text {ir }}$ superfamily channels. AF increases expression levels of mRNA of Kir2.1 (channel subunit of $\mathrm{K}_{\mathrm{ir}}$ ), consistent with larger $\mathrm{I}_{\mathrm{K} 1}{ }^{76,}{ }^{84}$. Moreover, an increase in $\mathrm{I}_{\mathrm{K} 1}$ has been observed in either human ${ }^{81,85}$ or animal AF studies ${ }^{86}$, contributing to a faster repolarization, thus reducing further the $\mathrm{APD}^{75}$.

$\mathrm{K}_{\text {ir }}$ superfamily channels include also ligand-operated channels, of which the most noted is the muscarinic operated channel. The muscarinic $\mathrm{K}^{+}$channel (mAChKir) is a heterotetramer of Kir3.1 and Kir3.4 (also known as GIRK1 and GIRK4) ${ }^{87}$. Stimulation of cardiac $\mathrm{M}_{2}$ muscarinic receptors by cholinergic agonists activates $\mathrm{I}_{\mathrm{KACh}}$ (acetylcholineregulated potassium current) which strongly promotes $\mathrm{AF}^{83}$ by stabilizing atrial reentrant rotors $^{38}$. This is consistent with the clinical forms of AF beginning under vagotonic conditions $^{68}$.

Although, other subtypes of muscarinic receptors have also been associated with different $\mathrm{K}^{+}$currents, such currents seem to possess delayed-rectifier properties, distinguishing them from classical $\mathrm{I}_{\mathrm{KAch}}{ }^{88,89}$. A reduction of $\mathrm{I}_{\mathrm{KACh}}$ subunits (Kir3.1 and 3.4) mRNA and proteins in AF patients has been reported ${ }^{83,90,91}$, corresponding to a decreased current response to $\mathrm{M}_{2}$-receptor stimulation ${ }^{84,85}$. Furthermore, Yeh et al ${ }^{92}$ report a decrease of both cholinergic receptor-coupled $\mathrm{K}^{+}$currents and corresponding expression of channel proteins after 1 week rapid atrial pacing. This $\mathrm{I}_{\mathrm{KACh}}$ decrease would lead to an increase in APD and ERP with lower theoretical propensity to AF.

Nevertheless, even if functional $\mathrm{I}_{\mathrm{KACh}}$ is reduced, an increase in a constitutively active form of this current has been described as an important contributor in maintaining 
$\mathrm{AF}^{93,94}$. It has been shown that the inward rectifier potassium current $\mathrm{I}_{\mathrm{K} 1}$ is higher in patients with chronic AF and is associated with smaller muscarinic receptor-mediated $\mathrm{I}_{\mathrm{KACh}}{ }^{84}$. Additionally, patients with chronic AF exhibit an agonist independent constitutive $\mathrm{I}_{\mathrm{KACh}}\left(\mathrm{I}_{\mathrm{KACh}, \mathrm{c}}\right)$ activity that contributes to the enhanced basal inward rectifier current ${ }^{93}$. In animal models, a similar constitutively active $\mathrm{I}_{\mathrm{KACh}, \mathrm{c}}$ current is upregulated and independent of the presence of the agonist $(\mathrm{ACh})^{94}$, while its inhibition in vitro by tertiapin increases APD and suppresses atrial tachyarrhythmias ${ }^{95}$. Whereas $\mathrm{ATR}^{94,} 95$ or chronic $\mathrm{AF}^{84,93}$ decreases agonist stimulated $\mathrm{I}_{\mathrm{KACh}}$, an agonist independent (“constitutive") $\mathrm{I}_{\mathrm{KACh}, \mathrm{c}}$ activity is enhanced ${ }^{93-96}$. Increased $\mathrm{I}_{\mathrm{KACh}, \mathrm{c}}$ was supposed to be secondary to an increase in mAChKir channels that for unknown reasons were becoming independent of ACh binding. However, mRNA and protein expression of Kir3 subunits are unchanged in experimental $\mathrm{ATR}^{94,96}$ whereas they are decreased in chronic $\mathrm{AF}^{76,93}$. Consequently, the increased mAChKir channels hypothesis was rejected. Rather, recent studies proved that AF induced enhancement of $\mathrm{I}_{\mathrm{KACh}, \mathrm{c}}$ is due to increased single channel open probability caused by slowed channel closure ${ }^{96}$, secondary to altered channel phosphorylation ${ }^{97,98}$.

\subsection{Neuroreceptorial remodeling}

Long term rapid atrial pacing creates the above described electrical remodeling. One of the characteristics of such remodeling is an increased heterogeneity in atrial refractoriness. Analogous to studies in ventricular arrhythmias, it has been proposed that a potential mechanism of such spatial dispersion of refractoriness could be the heterogeneity of autonomic innervation ${ }^{99}$. Thus, heterogeneous atrial denervation with application of 
phenol facilitated sustained AF in one study. Consequently, based on the idea that "AF begets AF" there have been studies evaluating the possibility of an autonomic remodeling in animal models of rapid atrial pacing. Jayachandran et al ${ }^{100}$ demonstrated that rapid rates of AF produce a heterogeneous increase in atrial sympathetic innervations, while Chang et $\mathrm{al}^{101}$ showed that there is a significant nerve sprouting and sympathetic hyperinnervation in a canine model of sustained AF. However, it remains unclear if such neural remodeling promotes sustained AF. Recently, Yeh et $\mathrm{al}^{92}$ demonstrated that atrial tachycardia induces downregulation of muscarinic receptors, adding further evidence in favor of a neuroreceptorial remodeling occurring after prolonged atrial tachycardia.

\subsubsection{Atrial structural remodeling (ASR)}

Clinical AF has been associated with atrial fibrosis. ${ }^{102}$ Changes that include increases in extracellular connective tissue composition, cellular size, glycogen accumulation, myolysis, mitochondrial changes, or chromatin redistribution have been termed structural remodeling ${ }^{103}$. Fibrosis is a hallmark of arrhythmogenic structural remodeling ${ }^{104-106}$. Fibrosis occurs generally as a reparative process substituting degenerating myocardium with connective tissue, which causes interstitial expansion.

Atrial fibrosis occurs in a variety of clinical settings such as senescence, cardiac dysfunction, mitral valvular disease, and possibly myocardial ischemia ${ }^{104}$. In a dog-model of congestive HF caused by ventricular tachypacing for 2-5 weeks, promotion of interstitial fibrosis induced sustained $\mathrm{AF}^{105}$. Complete recovery from tachycardia-induced congestive HF after 4-5 weeks of pacing cessation has been demonstrated ${ }^{107,}{ }^{108}$. However, structural 
remodeling with increased interstitial fibrosis remains unmodified, creating a substrate that can support prolonged $\mathrm{AF}^{109}$. The likelihood of $\mathrm{AF}$ increases with increasing extent of fibrosis $^{110}$. Furthermore, Hanna et al showed that ventricular tachypacing-induced congestive HF was associated with substantially more fibrosis in the LA than in the left ventricle $^{111}$. Although, AERP remains unchanged or increased after ventricular tachypacing, prominent conduction abnormalities in association with increased fibrosis create a favorable substrate to reentry according to leading circle model, thus promoting $\mathrm{AF}^{105}$. Consequently, therapeutic approaches targeting the prevention of the fibrous atrial remodeling could have a very important role in fighting the disease.

Several profibrotic factors have been described. TGF $\beta 1$ is an important profibrotic factor $^{112}$. Targeted cardiac TGF $\beta 1$ overexpression produces prominent atrial fibrosis ${ }^{113}$, while TGF $\beta 1$ overexpressing mice show an enhanced susceptibility to $\mathrm{AF}^{114}$. Angiotensin II is another well-established profibrotic molecule. Transgenic mice with cardiac-restricted angiotensin converting enzyme overexpression show marked atrial dilation with focal fibrosis and $\mathrm{AF}^{76,115}$. Recent evidence attributes significant roles also to Platelet Derived Growth Factor (PDGF) and Connective Tissue Growth Factor (CTGF) ${ }^{76}$.

\subsection{Animal Models}

Numerous clinical and experimental studies have been published in an effort to understand the complex pathophysiology of $\mathrm{AF}^{24,116}$. Despite the undoubted progress in explaining causal factors and pathophysiological mechanisms leading to AF, many 
unanswered questions remain ${ }^{4}$. Therefore, many animal models have been developed, assisting continuously in the progress of our knowledge and in the acquisition of new important information ${ }^{41,74,117,118}$. Among them the "atrial tachycardia remodeling" (ATR) animal model and the "vagal stimulation" (VS) animal model are frequently used in order to evaluate new potential therapeutic methods.

\subsubsection{Atrial tachycardia remodeling (ATR) animal model}

Lone AF presents clinically as a paroxysmal form with auto limited episodes. However, by the recurrence and perseverance of new episodes, AF becomes initially persistent, requiring pharmacological or electrical cardioversions, and subsequently chronic or permanent. The longer AF persists the more difficult it becomes to maintain sinus rhythm ${ }^{119}$. Progression from paroxysmal AF to persistent and permanent AF is associated with structural and biochemical changes. As previously mentioned, the alterations in ionic currents and properties of cellular excitability are termed electrical remodeling ${ }^{75,120}$. The changes in myocyte number, chamber size, extracellular connective tissue composition, fibroblast proliferation, glycogen accumulation, mitochondrial composition and chromatin distribution have been termed as structural remodeling ${ }^{75,}$ 103, while the contractile

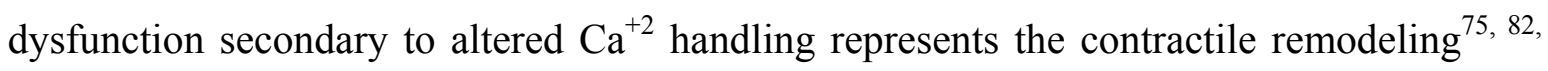
121.

Most of the above knowledge regarding atrial remodeling came from animal models. In 1995 Wijffels et al ${ }^{74}$ showed that AF causes electrophysiological changes of the 
atrial myocardium which promote the maintenance of AF (AF begets AF). Pacemakers sustaining AF by right appendage pacing were implanted in goats. After a week of pacinginduced AF there was a notable shortening of the AERP associated with a remarkable increase in AF duration and inducibility.

Moreover, other experimental work demonstrated that the primary stimulus to remodeling in AF is atrial tachycardia ${ }^{41,117}$. Atrial tachycardia reduces AERP in a spatially heterogeneous fashion, promoting AF by reducing WL and increasing its heterogeneity ${ }^{27}$. Such conditions favor multiple circuit reentry inducing and stabilizing $\mathrm{AF}^{4}$.

Following atrial tachycardia, significant changes in ionic currents and channels occur. There is a progressive reduction of the transient outward potassium current $I_{\text {to }}$ and the L-type $\mathrm{Ca}^{+2}$ current $\mathrm{I}_{\mathrm{Ca}, \mathrm{L}}$, leading to a net shortening of APD and impairment of the APD rate adaptation ${ }^{75,79}$. Furthermore, an increase in $\mathrm{I}_{\mathrm{K} 1}$ has been observed, contributing to a faster repolarization (this current would act in the late phase of repolarization), thus reducing further the $\mathrm{APD}^{75,81,85,86}$.

$\mathrm{I}_{\mathrm{KACh}}$ is the acetylcholine-regulated potassium current. As previously mentioned, it is an inwardly rectifying current generally influencing late repolarization and resting membrane voltage. Stimulation of cardiac $\mathrm{M}_{2}$ muscarinic receptors by cholinergic agonists activates $\mathrm{IK}_{\mathrm{ACh}}$ which strongly promotes $\mathrm{AF}^{83}$. A reduction of $\mathrm{IK}_{\mathrm{ACh}}$ subunits $\mathrm{mRNA}$ or proteins in AF patients has been reported ${ }^{83,90}$. This would lead to an increase in APD and ERP with lower theoretical propensity to AF. Nevertheless, even if functional $\mathrm{IK}_{\mathrm{ACh}}$ is 
reduced, an increase in a constitutively active form of this current has been described as an important contributor in maintaining $\mathrm{AF}^{93,94}$.

The ATR model is one of the animal models used in the present study. In each animal of the ATR group, a pacing lead was inserted into the right ventricular (RV) apex and connected to a subcutaneously-implanted VVI-pacemaker. Radiofrequency ablation of the AV node was performed and the RV-pacemaker was programmed at $80 \mathrm{bpm}$. A pacing lead in the RA appendage (RAA) was connected to a subcutaneously-implanted pacemaker to pace the atria at $400 \mathrm{bpm}$ for 1 week. After 1 week, an electrophysiologic study was done, retrieving all the necessary information for the study.

Recapitulating, ATR animal model gave useful information and clarified many aspects of the complex AF pathophysiology. The similarity of the animal model with real human clinical conditions was ascertained by the similarities in electrophysiological and biochemical variations that occur after atrial tachycardia in the animal model or AF in humans. However, many aspects of the pathophysiology of AF have yet to be clarified, especially concerning the role of the autonomic nervous system in initiating or maintaining the arrhythmia.

\subsubsection{Vagal stimulation (VS) animal model}

The parasympathetic nervous system has long been recognized as an important factor in the onset and maintenance of $\mathrm{AF}^{67}$. A form of vagal $\mathrm{AF}$, occurring after meals or during rest (thus in situations of vagal preponderance), has also been reported ${ }^{68}$. VS 
provokes a spatially heterogeneous ERP abbreviation inducing and maintaining $\mathrm{AF}^{71}$. On the contrary, a similar ERP reduction provoked by sympathetic stimulation doesn't promote AF as much, due to a more homogeneous distribution of ERP in the atria $^{71}$.

The VS model is the second animal model that we used in our study. AF is easily induced and maintained for the whole time that vagus nerves are stimulated in this animal model. Both cervical vagal trunks are isolated, doubly ligated and divided. Bipolar hook electrodes are inserted into each nerve parallel to vagal fibers for several centimeters and subsequently bilateral vagal-nerve stimulation is delivered by a stimulator ${ }^{71}$. VS provokes ACh liberation at the terminal nerve endings. Stimulation of muscarinic receptors by acetylcholine activates $\mathrm{I}_{\mathrm{KACh}}$ resulting in shorter APD and therefore decreased AERP. On the contrary, a small increase in $\mathrm{CV}$ is observed. However, the final result is a net decrease of the WL, creating optimal conditions for microreentry and AF.

A direct relationship of the intensity of VS with the capability of inducing and maintaining AF has been reported ${ }^{69}$. This property promoted the application of VS in many animal models in order to obtain easily an AF episode and performed various experiments. Clinical AF often begins under vagotonic conditions. Nevertheless, it is unknown how comparable this artificial vagal AF could be with the clinical forms of AF. 


\section{Hypothesis}

Both VS and ATR AF are not associated with structural heart disease and consequently they would represent two forms of idiopathic paroxysmal AF. VS and ATR animal models have common electrophysiological and molecular mechanisms in promoting AF. With the VS model we study the influence of the parasympathetic system in creating temporary electrophysiological alterations promoting AF, while with the ATR model we study the effect of atrial tachycardia in inducing more persistent electrophysiological alterations, leading to the perseverance of $\mathrm{AF}$ ( $\mathrm{AF}$ begets $\mathrm{AF}^{74}$ ).

Vagal AF promotion is related to a spatially heterogeneous reduction in AERP and reduced AERP rate adaptation ${ }^{71}$. Similarly to the effects of VS, atrial tachycardia remodeling reduces the AERP, the AERP rate adaptation and the WL while increasing the AERP heterogeneity ${ }^{27,41,74,105,117}$. Nevertheless, the time course of AF promotion due to atrial tachycardia remodeling is slower than that of AERP changes, indicating the involvement of additional mechanisms ${ }^{24}$.

Interestingly, the VS and ATR substrate share some common molecular mechanisms. Stimulation of cardiac $\mathrm{M}_{2}$ muscarinic cholinergic receptors with cholinergic agonists in the VS model elicits a large inward rectifier $\mathrm{K}^{+}$current, $\mathrm{I}_{\mathrm{KAch}}$, which strongly promotes $\mathrm{AF}^{38,83}$. Similarly, constitutively activated inward rectifier $\mathrm{K}^{+}$current $\mathrm{I}_{\mathrm{KAch,c}}$ is also upregulated in cardiomyocytes from AF patients ${ }^{93}$ and contributes to ATR-induced APD abbreviation and atrial-tachyarrhythmia promotion in canine atrium ${ }^{83,95}$. However, 
ATR results in reduction in L-type $\mathrm{Ca}^{+2}$ current $\mathrm{I}_{\mathrm{Ca}, \mathrm{L}}$, which contributes significantly to APD reduction and, accordingly, AERP. Thus, the main difference between VS and ATR model would be the reduction in $\mathrm{Ca}^{+2}$ current $\mathrm{I}_{\mathrm{Ca}, \mathrm{L}}$.

Recently, Pandit et al ${ }^{122}$ demonstrated in a computer model that in two experimental situations with similar APD reduction, an increase in inward rectifier currents accelerates and stabilize rotors more than a reduction in $\mathrm{Ca}^{+2}$ current $\mathrm{I}_{\mathrm{Ca}, \mathrm{L}}$. Even if the two situations produced the same APD reduction, they had a different response in rotor acceleration and stabilization and probably in AF promotion, if such conditions were applied clinically.

Based on the above observations, we hypothesized that similar situations could be reproduced by the VS and ATR animal models. Thus, we wanted to compare the two experimentally induced paradigms of AF in conditions of similar AERP shortening, in an effort to clarify different pathophysiological aspects of AF. Should a similar AERP shortening produce the same electrophysiological properties and similar AF promotion? Are there any electrophysiological differences between the models that can be paralleled to different clinical forms of AF or that can justify a different AF promotion?

In order to clarify such aspects, we followed a 1:1 matching of VS dogs with ATR dogs to ensure similar sex and weight distributions, and similar effects on mean AERP. We adjusted VS parameters in each VS dog according to the mean AERP recorded at 8 RA and left-atrial (LA) sites in the preceding ATR dog (basic cycle length, BCL, $300 \mathrm{~ms}$ ). We obtained the same mean AERP in both models and we obtained epicardial maps of activation that permitted a detailed study of classical electrophysiological variables in 
various anatomical areas. Moreover, DF analysis and its correlation with the electroanatomical properties of the two models gave interesting pathophysiological inputs.

Overall, the purpose of this work was to study the similarities and differences in the electrophysiological mechanisms underlying AF promotion in VS and ATR animal models, search for possible mechanisms that could explain such results, and finally try to correlate these models with clinical AF. 


\title{
3. Differences in atrial fibrillation properties under vagal nerve stimulation versus atrial tachycardia remodeling
}

\author{
Grigorios Katsouras, MD, ${ }^{1}$ Masao Sakabe, $\mathrm{MD}, \mathrm{PhD},{ }^{1}$ \\ Philippe Comtois, $\mathrm{PhD},{ }^{2}$ Ange Maguy, $\mathrm{PhD},{ }^{1}$ Brett Burstein, $\mathrm{PhD},{ }^{1}$ \\ Peter G. Guerra, MD, ${ }^{1}$ Mario Talajic, $M D,{ }^{1}$ Stanley Nattel, $\mathrm{MD}^{1}$ \\ ${ }^{1}$ Department of Medicine, ${ }^{2}$ Department of Physiology and Research Center, Montreal Heart \\ Institute and Université de Montréal, 5000 Belanger Street, Montreal, Quebec, Canada, \\ H1T 1 C8
}

There are no conflicts of interest.

Short title: Vagal versus atrial tachycardia AF substrate

Word count: 4,994 (excluding short title, word count and abbreviation list)

Financial support: Supported by the Canadian Institutes of Health Research (MOP 44365) and the Fondation Leducq ENAFRA network grant (07/CVD-03).

Address for correspondence: Stanley Nattel, 5000 Belanger Street East, Montreal, Quebec H1T 1C8, Canada. Tel.: 514-376-3330; Fax: 514-376-1355. E-mail: 


\subsection{Abstract}

BACKGROUND There are many similarities between atrial effects of atrialtachycardia remodeling (ATR) and vagal-nerve stimulation (VS): both promote atrial fibrillation (AF), reduce atrial effective refractory period (AERP) and AERP rateaccommodation, enhance AERP-heterogeneity and increase inward-rectifier $\mathrm{K}^{+}$-current. OBJECTIVE To compare the consequences of ATR and VS at similar levels of AERP abbreviation in dogs.

METHODS ATR-dogs $(\mathrm{n}=6)$ were subjected to 7-day atrial-tachypacing at $400 \mathrm{bpm}$, with radiofrequency-induced atrioventricular block and ventricular-demand pacing (80 bpm) to control ventricular response. VS was applied in 6 matched dogs with stimulation-parameters selected to produce similar mean AERP-values to ATR-dogs. RESULTS ATR and VS produced similarly-short AERPs (79 \pm 12 and $80 \pm 12 \mathrm{~ms}$ respectively), AERP rate-adaptation loss and AERP heterogeneity increases. Although both ATR and VS increased AF duration, VS was significantly more effective in AFpromotion, with mean AF duration of $992 \pm 134$ seconds, versus $440 \pm 240$ seconds $(P<0.05)$ under ATR. The greater AF-promoting effect of VS was associated with greater mean dominant-frequency values during AF (11.7 \pm 1.8 versus $10.0 \pm 1.3 \mathrm{~Hz}$ ATR, $P<0.05)$. VS greatly enhanced the spatial dominant-frequency variability, increasing the coefficient of variation to $15.2 \pm 1.9 \mathrm{~Hz}$, versus $8.9 \pm 1.5 \mathrm{~Hz}$ for ATR $(P<0.05)$, primarily by increasing per-dog maximum dominant-frequency $(15.4 \pm 0.6 \mathrm{~Hz}$, versus $12.5 \pm 0.6$ for ATR, $P<0.01)$.

CONCLUSION For matched AERP-values, VS promotes AF more strongly than ATR. Despite similar AERP-changes, VS produces considerably greater increases in dominant-frequencies, particularly maximum values, consistent with previous 
suggestions that inward-rectifier $\mathrm{K}^{+}$-current enhancement is particularly effective at accelerating and stabilizing spiral-wave rotors that maintain AF.

KEYWORDS: Atrial remodeling; Arrhythmia mechanisms; Reentry; Autonomic function; Biophysics; Electrophysiology 


\begin{abstract}
AERP: atrial effective refractory period
AF: atrial fibrillation

ATR: atrial-tachycardia remodeling

BCL: basic cycle length

CTL: control

$\mathrm{CV}$ : conduction velocity

DF: dominant frequency

ERP: effective refractory period
\end{abstract}

Abbreviation List

LA: left atrial

LAA: left-atrial appendage

LBB: left-atrial side of Bachmann's Bundle

LIW: left-atrial inferior wall

LPW: left-atrial posterior wall

RA: right atrial

RAA: right-atrial appendage

RBB: right-atrial side of Bachmann's Bundle

RIW: right-atrial inferior wall

RPW: right-atrial posterior wall

$\mathrm{RV}$ : right ventricular

VS: vagal stimulation

WL: wavelength 


\subsection{Introduction}

Numerous studies have addressed the complex pathophysiology of atrial fibrillation (AF). ${ }^{1}$ Animal models have been used for over 100 years and have provided extensive relevant information. ${ }^{2}$ The atrial-tachycardia remodeling (ATR) paradigm, by which rapid atrial activation promotes $\mathrm{AF}$, has provided important insights into $\mathrm{AF}$ mechanisms. ${ }^{1-3}$ Vagotonic AF has also been widely used, particularly to study pharmacological control. $^{2}$

There are many similarities in the atrial properties associated with vagal versus ATR-induced AF-promotion. Both involve reduced atrial effective refractory period (AERP) and AERP rate-adaptation, ${ }^{3,4}$ and both manifest increased spatial AERPheterogeneity. ${ }^{5,6}$ Vagal effects on AERP and AF are due to enhancement of the

acetylcholine-regulated $\mathrm{K}^{+}$-current $\mathrm{I}_{\mathrm{KACh}}{ }^{7}$ and a significant portion of the ATR-effect is due to enhanced constitutively-active $\mathrm{I}_{\mathrm{KACh}}\left(\mathrm{I}_{\mathrm{KACh}, \mathrm{c}}\right){ }^{8}$ These similarities in electrophysiological effects and ionic-current changes suggest common mechanisms of AF promotion. We therefore designed the present study to compare directly ATRrelated and vagal $\mathrm{AF}$ at matched levels of AERP-shortening.

\subsection{Methods}

\subsubsection{Animal models and experimental groups}

Animal-handling procedures were approved by the local Animal Research Ethics Committee. Twelve mongrel dogs were studied in two groups: 1) 6 vagalstimulation (VS) dogs; 2) 6 dogs subjected to 1 -week ATR as previously described. ${ }^{8}$ 
ATR dogs were initially anesthetized with sodium pentobarbital $(30 \mathrm{mg} / \mathrm{kg} \mathrm{IV}$, additional $4 \mathrm{mg} / \mathrm{kg}$ doses as needed). A pacing lead was inserted into the right ventricular (RV) apex and connected to a subcutaneously-implanted VVI-pacemaker. Radiofrequency ablation of the atrioventricular node was performed and the RVpacemaker was programmed at $80 \mathrm{bpm}$. A pacing lead in the right atrial (RA) appendage (RAA) was connected to a subcutaneously-implanted pacemaker to pace the atria at $400 \mathrm{bpm}$ for 1 week.

\subsubsection{Experimental protocol}

On study days, dogs were anesthetized with morphine $(2 \mathrm{mg} / \mathrm{kg} \mathrm{sc})$ and $\alpha$ chloralose (120 mg/kg iv, followed by $29.3 \mathrm{mg} / \mathrm{kg} / \mathrm{h})$, and ventilated mechanically. Body temperature was maintained at $37^{\circ} \mathrm{C}$. In the ATR group the RA-pacemaker was deactivated. A median thoracotomy was performed and a pericardial cradle created. Four bipolar Teflon-coated stainless steel electrodes were inserted into the RAA and left atrial (LA) appendages (LAA) for recording and stimulation. Five silicon plaques containing 240 bipolar electrodes were sewn over the atrial epicardial surface. ${ }^{9}$ A programmable stimulator was used to deliver 2-ms twice-threshold current pulses. Signals were filtered $(10-900 \mathrm{~Hz})$ and digitized (12-bit resolution, 2-kHz sampling). In vagal dogs, a bipolar RV electrode and VVI-pacemaker were used to demand-pace the ventricles at $80 \mathrm{bpm}$. 


\subsubsection{Experimental design}

VS dogs were matched 1:1 with ATR dogs to ensure similar sex and weight distributions, and similar effects on mean AERP. We first performed an open-chest electrophysiological study in each ATR dog, then matched the subsequent VS dog for sex and weight. We adjusted vagal-stimulation parameters in each VS dog according to the mean AERP recorded at $8 \mathrm{RA}$ and left-atrial (LA) sites in the preceding ATR dog (basic cycle length, BCL, $300 \mathrm{~ms}$ ).

\subsubsection{Vagal stimulation}

Both cervical vagal trunks were isolated, doubly ligated and divided. Bipolar hook electrodes (stainless steel, insulated with Teflon except for the distal 10-15 mm) were inserted into each nerve parallel to vagal fibers for several centimeters. ${ }^{5}$ Bilateral vagal-nerve stimulation (0.2-ms pulse-width) was delivered by a Grass SD-9F stimulator (Quincy, MA). Vagal stimulation voltage and frequency were selected to produce the target AERP (average values $3.9 \pm 0.7 \mathrm{~V}$ and $12.2 \pm 0.6 \mathrm{~Hz}$ ). After vagalstimulation parameters were established based on AERP, vagal stimulation was applied for 30 seconds and the sinus-node slowing response to vagal stimulation was assessed over the last 15 seconds (average baseline sinus cycle-length $360 \pm 8.5 \mathrm{~ms}$, cycle-length during vagal stimulation $792 \pm 105 \mathrm{~ms}$ ). This response was verified periodically during each experiment and vagal-stimulation parameters readjusted if necessary to produce a constant bradycardic response.

\subsubsection{Electrophysiological study}

AERP was measured at multiple BCLs in the RAA and LAA and at a BCL of $300 \mathrm{~ms}$ at 6 additional RA and LA sites: posterior wall (RPW, LPW), inferior wall 
(RIW, LIW) and the Bachmann bundle (RBB, LBB). AERP was determined with 10 basic stimuli (S1) followed by a premature extrastimulus (S2) with 5-ms decrements. The longest S1-S2 failing to capture defined the AERP. The mean of 3 AERP values at each BCL was used for analysis. If AERP values differed by $>10 \mathrm{~ms}, 2$ additional AERP measurements were obtained and the mean of all determinations was taken to represent AERP. AF was induced with atrial burst-pacing at $10 \mathrm{~Hz}$ and 4xthresholdcurrent. To estimate mean $\mathrm{AF}$ duration in each dog, $\mathrm{AF}$ was induced 10 times. $\mathrm{AF} \geq 20$ min was considered sustained and was cardioverted with a synchronized direct-current shock. A 20-min rest period was then allowed before experimentation was resumed. After 2 cardioversions, no further AF inductions were performed.

\subsubsection{Conduction and AERP analysis}

Epicardial mapping was conducted with the Cardiomap system (Research Center, Sacre-Coeur Hospital and Biomedical Engineering Institute, École Polytechnique and Université de Montréal, Montreal, Quebec). Activation data were analyzed off-line with computer-determined peak amplitude criteria for activation, and were reviewed manually. Electrogram timing was compared with QRS complexes to exclude ventricular electrograms.

Conduction velocity (CV) was determined by analyzing activation at four electrode sites in the direction of rapid propagation in the RAA, RPW, RBB, LBB and LAA $^{5,9,10}$ Distance from the proximal site was plotted against activation time and CV was determined by linear regression ( $r>0.99$ required for analysis). Because of variable conduction in the left inferior-posterior wall and right inferior wall, CV could not 
always be measured accurately in LPW, LIW and RIW, which were therefore not included in the analysis. Local wavelengths (WLs) were calculated as the product of local CV and local ERP. CV and AERP heterogeneity were quantified by calculating coefficients of variation of 5 regional $\mathrm{CV}$ values $\left(\mathrm{COV}_{\mathrm{CV}}=\mathrm{SD}_{\mathrm{CV}} / \mathrm{mean}_{\mathrm{CV}} \times 100 \%\right)$ and 8 regional AERP values $\left(\mathrm{COV}_{\mathrm{AERP}}=\mathrm{SD}_{\mathrm{AERP}} /\right.$ mean $\left._{\mathrm{AERP}} \times 100 \%\right)$

To evaluate spatial conduction-inhomogeneities, phase maps were constructed, based on previously-described methods. ${ }^{10}$ In brief, activation-time differences between each electrode and its neighboring sites were normalized to interelectrode distances and maximum values at each site were taken to indicate local phase delays. A phase-delay histogram was then constructed and values corresponding to the $5^{\text {th }}, 50^{\text {th }}$ and $95^{\text {th }}$ percentiles designated P5, P50 and P95 respectively. P50 represents the median phasedelay and is an overall conduction index. The P5-95 expresses the range of phase delays and the variation coefficient (P5-95/P50) is a conduction-heterogeneity index independent of $\mathrm{CV}$.

\subsubsection{Atrial frequency-spectrum analysis}

Spectral characteristics of activation at each site during AF were studied as previously described..$^{9,11,12}$ Periodogram estimation was performed on 4-second samples to analyze frequency content in the 0.5 to $80 \mathrm{~Hz}$ band. The mean of each signal was first subtracted to remove the DC-part of the signal. A split-cosine, bell-tapering window was applied, with $5 \%$ of data points being tapered. An estimate of the signal spectrum was obtained by using a smoothed periodogram with a weighting parameter M. ${ }^{12} \mathrm{M}$ was determined semiautomatically with an unbiased risk estimator method to 
choose the tuning parameter $\mathrm{M}$ for the smoothed periodogram. The dominant frequency (DF) at each recording-site was defined as the frequency of the highest peak of the smoothed periodogram. ${ }^{9}$ The variability in DFs was assessed in each dog based on the coefficient of variation $\left(\mathrm{COV}_{\mathrm{DF}}=\mathrm{SD}_{\mathrm{DF}} /\right.$ mean $\left._{\mathrm{DF}} \times 100 \%\right)$.

\subsubsection{Statistical analysis}

All results are expressed as mean \pm SEM. Statistical comparisons between ATR and vagal-stimulation means were performed by unpaired t-tests, except in cases of repeated-measures data (such as AERP at multiple BCLs and AERP, CV and WL in multiple atrial regions), in which 2-factor ANOVA (ATR versus vagal-stimulation as one factor and the repeated-measure index such as BCL or region) was applied. All data satisfied statistical criteria for normal distribution (Kolmogrov-Smirnov test) except for AF durations, which were normally-distributed after log-transformation and were so analyzed. To test for differences between coefficients of variation, we performed an F-test of the variance ratio according to Lewontin. ${ }^{13}$ A two-tailed $P<0.05$ was considered statistically-significant. The control (baseline) values before vagal stimulation are shown as reference values for vagal and ATR conditions, but are not compared statistically. 


\subsection{Results}

\subsubsection{Electrophysiological variables and properties of atrial fibrillation}

Matching was effective: there were 2 male and 4 female dogs in each group, the mean weight averaged $29.2 \pm 5.9$ versus $26.9 \pm 7.6 \mathrm{~kg}(P=\mathrm{NS})$ for ATR and VS groups respectively, and mean AERP values at 8 sites (BCL of $300 \mathrm{~ms}$ ) were $79 \pm 12$ and $80 \pm 12$ ms respectively ( $P=\mathrm{NS}$ ), versus $117 \pm 12 \mathrm{~ms}$ under control conditions. There were no differences between vagal-nerve stimulation and ATR in terms of AERP and AERP rate-adaptation over a wide range of BCLs (Figure 5A). However, mean AF durations were significantly greater under vagal-stimulation than with ATR (Figure 5B). In addition, sustained AF requiring cardioversion occurred under vagal-stimulation in 6 of 6 dogs versus only 2 of 6 ATR dogs $(P=0.06$, Fisher exact test $)$.

Both vagal-stimulation and ATR were associated with slightly larger overall CVs (by about 10\% compared to control), based on the average of all regional values (Figure 6A), but there were no differences between vagal and ATR values. Similarly, wavelength (WL) was shorter in both groups than in control (Figure 6B), but there were no significant differences between ATR and vagal-stimulation values. AERP heterogeneity was larger under both vagal-stimulation and ATR, with $\operatorname{COV}_{\mathrm{AERP}}$ of $26.8 \pm 4.1 \%$ and $23.2 \pm 10.6 \%$ respectively, compared to $11.3 \pm 4.7 \%$ under control conditions (Figure 7A), but vagal-stimulation and ATR values were not significantly different. No significant differences were observed between groups for $\mathrm{COV}_{\mathrm{CV}}$ (Figure 7B). Thus, in both VS and ATR groups, after achieving a similar AERP, we observed similar CV values, similar WLs, and similar AERP heterogeneity. Nevertheless, AF 
duration was significantly more enhanced under vagal-nerve stimulation than with ATR. We therefore examined regional changes in atrial properties.

\subsubsection{Regional changes in electrophysiological properties}

A quantitative analysis of the regional electrophysiological effects of vagalstimulation and ATR is shown in Figure 8. AERP was smaller under both vagalstimulation and ATR than for control over a wide range of atrial sites (Figure 8A), but there was no statistical significance for the factor vagal-stimulation versus ATR. Regional values for $\mathrm{CV}$ are shown in Figure 8B. Regional $\mathrm{CV}$ values were not significantly different between ATR and vagal-stimulation conditions. Similarly, for WL, ATR and vagal-stimulation values were not significantly different from each other. Overall, regional differences in conduction, refractoriness and WL failed to provide any explanation for the different effects of vagal-stimulation versus ATR on AF duration.

\subsubsection{Local conduction abnormalities}

In an attempt to understand the ATR versus vagal-stimulation differences in AF promotion, we performed an analysis of local conduction properties with the use of phase-delay histograms, which may reveal pathophysiologically-significant changes even in the absence of global conduction alterations. ${ }^{10}$ The P50, reflecting average interelectrode activation-time differences, was not significantly different between vagalstimulation and ATR (Figure 9A). Similarly, no significant changes occurred in P5-95 (Figure 9B). The P5-95/P50 (heterogeneity index) was not significantly altered during 
RAA pacing, but heterogeneity increased significantly with vagal-stimulation during LAA pacing (Figure 9C), suggesting a greater increase in local conduction heterogeneity under vagal conditions during activation by LA drivers.

\subsubsection{Dominant frequency analysis}

Previous work suggests that DF analysis may provide insights into mechanisms of AF maintenance, and that sites of maximum dominant frequency (DFmax) may constitute

driver regions responsible for AF perpetuation. ${ }^{14,15}$ Consequently, to delineate differences that might account for differential AF sustainability between ATR and vagal-stimulation conditions, we performed $\mathrm{DF}$ analysis at all recording sites during $\mathrm{AF}$ under each condition. Figures 10A, 10B and 10C show representative electrogram recordings, and corresponding panels $\mathrm{D}, \mathrm{E}$ and $\mathrm{F}$ display the respective power spectra obtained after Fast Fourier Transformation. In the examples shown, single dominant peaks are observed with DF values of $8.5,12.6$ and $9.6 \mathrm{~Hz}$ for control, vagal-stimulation and ATR conditions respectively.

To obtain an initial impression of DF patterns in each data set, we averaged the DF values at each electrode site for all dogs in each group. Figure 11 shows the results as heat charts, with mean DF at each site under each condition as a color varying from blue (smallest DF values) to red (largest values). During AF under control conditions, DF values are generally in shades of blue, corresponding to values between 8 and 10.4 Hz. Under vagal-stimulation, much greater variability is seen, with some regions showing values of the same order as control and others with much larger values, up to 
$14 \mathrm{~Hz}$, greatly exceeding those in control. The ATR distribution is more similar to control, but does show some increased values.

Figure 12 provides overall DF data. Mean DF obtained from values at all 240 electrodes in each dog was significantly greater under vagal-stimulation than in ATR (Figure 12A). Similarly, the coefficient of variation of DFs $\left(\mathrm{COV}_{\mathrm{DF}}\right)$ was significantly greater under vagal-stimulation than for ATR (Figure 12B), indicating a greater heterogeneity in atrial DF values under vagal-stimulation. The DFmax values associated with potential driver regions were significantly greater under vagalstimulation compared with ATR conditions (Figure 12C), which were similar to control. Minimum DF values in each dog showed no significant variations between conditions.

\subsection{Discussion}

In the present study we compared the atrial electrophysiological consequences of vagal nerve stimulation and ATR at comparable levels of AERP abbreviation. Despite similar effects on absolute AERP, AERP distribution and AERP rate-dependence, as well as on conduction indexes, vagal-stimulation proved to be more effective than ATR in promoting AF maintenance.

\subsubsection{Atrial electrophysiological consequences of vagal-nerve stimulation and ATR}

The parasympathetic system has long been recognized to play an important role

in AF promotion. ${ }^{16}$ Vagal activation decreases atrial cardiomyocyte action potential 
duration and hyperpolarizes atrial action potentials by inducing an acetylcholinedependent $\mathrm{K}^{+}$-current, $\mathrm{I}_{\mathrm{KACh}}{ }^{7}$ Vagal $\mathrm{I}_{\mathrm{KACh}}$ activation is spatially-heterogeneous, owing to spatially-variable distributions of vagal nerve endings and cholinergic receptors, resulting in spatially-heterogeneous actions that are believed to be important in AFpromotion. ${ }^{5,7,17}$ The classical notion of the mechanism of vagal AF has been multiplecircuit reentry promoted by strong WL shortening, increasing the number of simultaneous functional atrial reentry circuits. ${ }^{1,18}$ More recent studies have emphasized the importance of cholinergically mediated acceleration of high-frequency rotor sources corresponding to DFmax regions, with fibrillatory activity due largely to wavefrontbreakup related to structural and functional properties. ${ }^{7,19,20}$

The electrophysiological substrate maintaining AF in ATR-tissue is complex and evolves over time. ${ }^{21}$ At 1 week of ATR, spatially heterogeneous AERP changes predominate. $^{22}$ Reductions in L-type $\mathrm{Ca}^{2+}$-current $\left(\mathrm{I}_{\mathrm{CaL}}\right)$ play an important role, but increases in inward-rectifying $\mathrm{K}^{+}$-currents, including $\mathrm{I}_{\mathrm{K} 1}$ and $\mathrm{I}_{\mathrm{KACh}, \mathrm{c}}$ are also significant. $^{8,21}$ The electrophysiological consequences of ATR share many similarities with those of vagal nerve stimulation: shortened AERP, reduced AERP rate dependence and enhanced AERP variability. These similarities were all observed in the present study (Figures 5 and 7). This outcome is perhaps not surprising, given that both interventions enhance inwardly rectifying $\mathrm{K}^{+}$-currents: muscarinic receptor-activated $I_{K A C h}$ in the case of vagal nerve stimulation; $I_{K 1}$ and $I_{K A C h, c}$ in the case of ATR. The main difference between vagal-stimulation effects and ATR is $\mathrm{I}_{\mathrm{CaL}}$-downregulation, which plays a prominent role in $\mathrm{ATR}^{1,23}$ but is not produced by vagal-nerve stimulation. 


\subsubsection{Novel findings and potential underlying mechanisms}

To our knowledge, this is the first study to compare directly the electrophysiology of ATR-induced AF promotion with that of vagal-nerve stimulation under matched effective refractory period conditions. The result was in some sense surprising: despite indistinguishable changes in many electrophysiological parameters, vagal nerve stimulation was significantly more effective in promoting AF-maintenance than was ATR. However, the data regarding effects on DF values and distribution, in combination with recent work regarding the biophysics of AF maintenance, ${ }^{7,14,19,20,24}$ shed considerable light on the potential basis for the discrepancy between ATR and vagal stimulation effects. The stability and persistence of cholinergic AF is closely related to the dynamics of rapidly rotating spiral wave generators. ${ }^{7,14,19,20}$ Cholinergic activation enhances the rate of spiral wave rotation, reduces spiral tip meander and prevents termination by annihilation against competing sources or tissue boundaries. Similarly, the stability of reentry in ATR-remodeled atrial substrates depends on primary rotor dynamics. $^{24}$

Pandit et al. studied the determinants of ATR effects on rotor dynamics in detail ${ }^{24}$ with the use of a previously developed mathematical model of remodeled human atrial $\mathrm{APs}^{25}$ incorporated in a 2-dimensional sheet of atrial tissue. They compared the previously developed model (in which action-potential abbreviation results primarily from $\mathrm{I}_{\mathrm{CaL}}$ reduction), which the authors called "CAF1", with a revised model incorporating a 100\%-increase in $\mathrm{I}_{\mathrm{K} 1}$ inward rectifier current (called "CAF2"), based on experimental data. Although both CAF1 and CAF2 action potentials accelerated and stabilized atrial rotors, the effect was larger with CAF2. ${ }^{24}$ Because the CAF2 action 
potential duration was shorter, the authors also compared CAF2 with modified CAF1 action potentials having a greater decrease in $\mathrm{I}_{\mathrm{CaL}}$, to achieve durations similar to CAF2. The modified CAF1 model accelerated and stabilized rotor activity relative to CAF1 simulations, but not to the same extent as CAF2. Based on further analyses, the authors concluded that for the same degree of action potential abbreviation, inward-rectifier $\mathrm{K}^{+}$current enhancement produces stronger rotor acceleration and stabilization than $\mathrm{I}_{\mathrm{CaL}}{ }^{-}$ reduction, because in addition to abbreviating action potentials, $\mathrm{I}_{\mathrm{K} 1}$ enhancement also hyperpolarizes atrial cell membranes. Membrane hyperpolarization removes voltagedependent $\mathrm{Na}^{+}$current inactivation, increases the source $\mathrm{Na}^{+}$current and permits faster and more stable rotor activity. During vagal stimulation, AERP reduction is accomplished solely by inward-rectifier $\left(\mathrm{I}_{\mathrm{KACh}}\right)$ current enhancement, whereas in ATR, AERP is decreased by a combination of $\mathrm{I}_{\mathrm{CaL}}$ reduction and inward-rectifier $\left(\mathrm{I}_{\mathrm{K} 1}\right.$ and $\mathrm{I}_{\mathrm{KACh}}$ ) current enhancement.

Thus, based on the study by Pandit et $\mathrm{al}^{24}$, one would expect a greater degree of rotor stabilization and acceleration in the vagal stimulation condition (in which AERP abbreviation results from inward-rectifier current enhancement alone) than in the ATR condition (in which AERP abbreviation results from a lesser degree of inward-rectifier current enhancement combined with $\mathrm{I}_{\mathrm{CaL}}$ reduction). The relative changes in $\mathrm{DF}$ observed with vagal stimulation versus ATR support this reasoning. DF-maps during AF showed more acceleration (Figure 11), and mean DF values were significantly greater (Figure 12A) under vagal stimulation than in ATR. In addition, there was greater variability in DF under vagal stimulation, as evident in DF-maps and $C_{D V}$ values (Figure 12B). The DF variability enhancement was due to much larger DFmax 
values under vagal stimulation, whereas minimum DF values were not affected (Figure 12C). These observations are consistent with previous experimental observations concerning the importance of regional heterogeneity in vagal effects on AF, with spatially-heterogeneous vagal effects resulting in zones of strong vagal action adjacent to zones of minimal or no vagal effect. ${ }^{5}$

The prominent changes in DFmax under vagal stimulation agree with previous experimental observations suggesting that DFmax regions represent driver rotors that maintain AF and determine its stability. ${ }^{14,19,20,26,27}$ Our findings are therefore consistent with the notion that rotor wave dynamics are key determinants of the stability of $\mathrm{AF}^{28,29}$ Similar to our results, Everett et $\mathrm{al}^{30}$ noted that infusion of the cholinergic agonist methacholine produced greater increases in DFs and DF spatiotemporal variability compared with several other $\mathrm{AF}$ models, including ventricular tachypacing-induced heart failure, atrial tachypacing, and acute mitral regurgitation. The DF distribution of vagally induced AF in our study is surprisingly similar to the distribution of ablation lesions performed by Nademanee et $\mathrm{al}^{31}$ targeting complex fractionated electrograms in paroxysmal AF patients. Although we cannot exclude a fortuitous coincidence, the similarity suggests a potentially important participation of vagal mechanisms in paroxysmal AF, as previously suggested by other investigators. ${ }^{32}$

\subsection{Potential limitations}

The conventional mapping system that we used has several limitations. The spatiotemporal resolution is insufficient to reliably track individual rotors. We sampled only the epicardial surface, and atrial tissue has a complex 3-dimensional structure that 
can participate in AF maintenance. ${ }^{33}$ One advantage of our system is that it allows for the gathering of data in the in situ heart under physiological conditions, without potential distortion from tissue excision, perfusion with crystalloid non-blood containing solutions and potentially toxic dyes, ultraviolet light energy and electromechanical uncouplers that are needed for higher-resolution optical mapping.

We matched dogs on the basis of weight and sex. However, because our dogs were random-source mongrels, we did not know their age or breed, introducing potential uncontrolled sources of intergroup variability.

We studied ATR after 7 days of atrial tachypacing. A longer period of tachypacing (6 weeks) produced larger changes in DF values and heterogeneity versus control in the work of Everett et $\mathrm{al}^{30}$ than those that we observed in the present study. The clinical counterpart of our models may therefore be a relatively short duration of AF (corresponding to weaker ATR) versus a situation of strong vagal tone. This consideration may also account for the lack of clear increase in DF with ATR, despite the fact that patients with persistent $\mathrm{AF}$ have higher DF values than patients with paroxysmal AF. ${ }^{34}$ However, our primary objective was to compare the 2 paradigms under matching intensities in terms of mean atrial effective refractory period conditions, which we did succeed in accomplishing.

\subsection{Acknowledgment}

The authors thank Nathalie l'Heureux for technical assistance and France Theriault for secretarial help with the manuscript. 


\subsection{References}

1. Nattel S. New ideas about atrial fibrillation 50 years on. Nature 2002;415:219226.

2. Nattel S, Shiroshita-Takeshita A, Brundel BJJM, Rivard L. Mechanisms of atrial fibrillation: lessons from animal models. Prog Cardiovasc Dis 2005;48:9-28.

3. Wijffels MC, Kirchhof CJ, Dorland R, Allessie MA. Atrial fibrillation begets atrial fibrillation. A study in awake chronically instrumented goats. Circulation 1995;92:1954-1968.

4. Wang Z, Pagé P, Nattel S. _Mechanism of flecainide's antiarrhythmic action in experimental atrial fibrillation. Circ Res 1992;71:271-287.

5. Liu L, Nattel S. Differing sympathetic and vagal effects on atrial fibrillation in dogs: role of refractoriness heterogeneity. Am J Physiol 1997;273:H805-H816.

6. Fareh S, Villemaire C, Nattel S. Importance of refractoriness heterogeneity in the enhanced vulnerability to atrial fibrillation induction caused by tachycardia-induced atrial electrical remodeling. Circulation 1998;98:2202-2209.

7. Kneller J, Zou R, Vigmond EJ, Wang Z, Leon LJ, Nattel S. Cholinergic atrial fibrillation in a computer model of a two-dimensional sheet of canine atrial cells with realistic ionic properties. Circ Res 2002;90:E73-E87.

8. Cha TJ, Ehrlich JR, Chartier D, Qi XY, Xiao L, Nattel S. Kir3-based inward rectifier potassium current: potential role in atrial tachycardia remodeling effects on atrial repolarization and arrhythmias. Circulation 2006;113:1730-1737. 
9. Lemola $\mathrm{K}$, Chartier $\mathrm{D}$, Yeh $\mathrm{YH}$, et al. Pulmonary vein region ablation in experimental vagal atrial fibrillation: Role of pulmonary veins versus autonomic ganglia. Circulation 2008;117:470-477.

10. Li D, Fareh S, Leung TK, Nattel S. Promotion of atrial fibrillation by heart failure in dogs: Atrial remodeling of a different sort. Circulation 1999;100:87-95.

11. Lemola K, Ting M, Gupta $\mathrm{P}$, et al. Effects of two different catheter ablation techniques on spectral characteristics of atrial fibrillation. J Am Coll Cardiol 2006;48:340-348.

12. Lee T. A stabilized bandwidth selection method for kernel smoothing of the periodogram. Signal Processing 2001;81:419-430.

13. Lewontin R. On the measurement of relative variability. Systematic Zool $1966 ; 15: 141-142$.

14. Mandapati R, Skanes A, Chen J, Berenfeld O, Jalife J. Stable microreentrant sources as a mechanism of atrial fibrillation in the isolated sheep heart. Circulation 2000;101:194-199.

15. Sanders P, Berenfeld O, Hocini M, et al. Spectral analysis identifies sites of highfrequency activity maintaining atrial fibrillation in humans. Circulation 2005;112:789-797.

16. Garrey WE. Auricular fibrillation. Physiol Rev 1924;4:215-250.

17. Yeh Y-H, Lemola K, Nattel S. Vagal atrial fibrillation. Acta Cardiol Sin $2007 ; 23: 1-12$

18. Smeets JL, Allessie MA, Lammers WJ, Bonke FI, Hollen J. The wavelength of the cardiac impulse and reentrant arrhythmias in isolated rabbit atrium. The role of 
heart rate, autonomic transmitters, temperature, and potassium. Circ Res 1986;58:96-108.

19. Chen J, Mandapati R, Berenfeld O, Skanes AC, Gray RA, Jalife J. Dynamics of wavelets and their role in atrial fibrillation in the isolated sheep heart. Cardiovasc Res 2000;48:220-232.

20. Kalifa J, Tanaka K, Zaitsev AV, et al. Mechanisms of wave fractionation at boundaries of high-frequency excitation in the posterior left atrium of the isolated sheep heart during atrial fibrillation. Circulation 2006;113:626-633.

21. Nattel S, Burstein B, Dobrev D. Atrial remodelling and atrial fibrillation: Mechanisms and implications. Circulation: Arrhythmia and Electrophysiology 2008;1:62-73.

22. Gaspo R, Bosch RF, Talajic M, Nattel S. Functional mechanisms underlying tachycardia-induced sustained atrial fibrillation in a chronic dog model. Circulation 1997;96:4027-4035.

23. Yue L, Feng J, Gaspo R, Li GR, Wang Z, Nattel S. Ionic remodeling underlying action potential changes in a canine model of atrial fibrillation. Circ Res $1997 ; 81: 512-525$.

24. Pandit SV, Berenfeld O, Anumonwo JMB, et al. Ionic determinants of functional reentry in a 2-D model of human atrial cells during simulated chronic atrial fibrillation. Biophys J 2005;88:3806-3821.

25. Courtemanche M, Ramirez RJ, Nattel S. Ionic targets for drug therapy and atrial fibrillation-induced electrical remodeling: Insights from a mathematical model. Cardiovasc Res 1999;42:477-489. 
26. Berenfeld O, Mandapati R, Dixit S, et al. Spatially distributed dominant excitation frequencies reveal hidden organization in atrial fibrillation in the Langendorffperfused sheep heart. J Cardiovasc Electrophysiol 2000;11:869-879.

27. Sarmast F, Kolli A, Zaitsev A, et al. Cholinergic atrial fibrillation: $I_{K, A C h}$ gradients determine unequal left/right atrial frequencies and rotor dynamics. Cardiovasc Res 2003;59:863-873.

28. Jalife J, Berenfeld O, Mansour M. Mother rotors and fibrillatory conduction: a mechanism of atrial fibrillation. Cardiovasc Res 2002;54:204-216.

29. Zou R, Kneller J, Leon LJ, Nattel S. Substrate size as a determinant of fibrillatory activity maintenance in a mathematical model of canine atrium. Am J Physiol (Heart Circ Physiol) 2005;289:H1002-H1012.

30. Everett TH 4th, Wilson EE, Verheule S, Guerra JM, Foreman S, Olgin JE. Structural atrial remodeling alters the substrate and spatiotemporal organization of atrial fibrillation: a comparison in canine models of structural and electrical atrial remodeling. Am J Physiol Heart Circ Physiol 2006;291:H2911-H2923.

31. Nademanee K, McKenzie J, Kosar E, et al. A new approach for catheter ablation of atrial fibrillation: mapping of the electrophysiologic substrate. J Am Coll Cardiol 2004;43:2044-2053.

32. Coumel P. Autonomic influences in atrial tachyarrhythmias. J Cardiovasc Electrophysiol 1996;7:999-1007.

33. Schuessler RB, Kawamoto T, Hand DE, et al. Simultaneous epicardial and endocardial activation sequence mapping in the isolated canine right atrium. Circulation 1993;88:250-263. 
34. Stiles MK, Brooks AG, Kuklik P, et al. High-density mapping of atrial fibrillation in humans: relationship between high-frequency activation and electrogram fractionation. J Cardiovasc Electrophysiol. 2008;19:1245-53. 


\subsection{Figure Legends}

Figure 5. A. Mean \pm SEM atrial effective refractory period (AERP) in the RA appendage as a function of BCL. B. Mean \pm SEM AF duration. $* P<0.05$ ATR versus vagal-stimulation (vagal).

Figure 6. Effects of vagal-stimulation (vagal) and ATR on electrophysiological indices A. Conduction velocity (CV). B. Wavelength (WL).

Figure 7. A. Atrial effective refractory period (AERP) heterogeneity expressed as the coefficient of variation $\left(\mathrm{COV}_{\mathrm{AERP}}\right)$. B. Conduction velocity (CV) heterogeneity expressed as the coefficient of variation $\left(\mathrm{COV}_{\mathrm{CV}}\right)$. $\mathrm{COV}$ $(\mathrm{SD} /$ mean $\times 100)$ was used as an index of variability.

Figure 8. Effects of vagal-stimulation and ATR on electrophysiological indexes in different areas of left and right atrium. A. AERP $\quad$ B. CV C. WL. LAA=Left-atrial appendage; LPW= left-atrial posterior wall; LIW= leftatrial inferior wall; $\mathrm{LBB}=$ left-atrial side of Bachmann's Bundle; $\mathrm{RBB}=$ right-atrial side of Bachmann's Bundle; RPW= right-atrial posterior wall; $\mathrm{RIW}=$ right-atrial inferior wall; $\mathrm{RAA}=$ right-atrial appendage. ${ }^{*} P<0.05$ for ATR versus vagal-stimulation (vagal).

Figure 9. Results of phase-delay analysis during pacing from the left-atrial appendage (LAA) or right-atrial appendage (RAA) under control, vagalstimulation and ATR conditions at a BCL of 300 ms. A. Median of local phase differences (P50), B. Absolute heterogeneity (P5-95), C. Heterogeneity Index (P5-95/P50). $* P<0.05$ for ATR versus vagalstimulation (vagal). 
Figure 10. Examples of electrogram recordings and of corresponding power spectra obtained at a single electrode under each condition. The dominant frequency (DF) corresponds to the frequency with the highest power. Larger DFs were consistently seen under vagal-stimulation compared to the other conditions studied.

Figure 11. Spatial distribution of mean DFs under each condition at each of the 240 bipolar electrode positions, based on mean values at each point for all dogs studied. Missing data points correspond to sites at which values were available for fewer than 3 dogs under the condition shown. A. Atrial electrode-locations are shown for each set of electrodes. B, C, and D. Mean DFs at each electrode-site are represented by a color scale (right) for each condition. $\mathrm{LA}=$ Left-atrial appendage; $\mathrm{LPW}=$ left-atrial posterior wall; LIW= left-atrial inferior wall; LBB= left-atrial side of Bachmann's Bundle; $\mathrm{RBB}=$ right-atrial side of Bachmann's Bundle; $\mathrm{RPW}=$ right-atrial posterior wall; $\mathrm{RIW}=$ right-atrial inferior wall; $\mathrm{RA}=$ right-atrial appendage.

Figure 12. Overall results of dominant-frequency (DF) analysis. Comparison between groups of: A. Mean \pm SEM DFs for each animal, obtained by averaging all DFs in each animal and then calculating mean \pm SEM for each condition. B. Mean $\pm \mathrm{SEM}$ of coefficient of variation $\left(\mathrm{COV}_{\mathrm{DF}}\right)$ of $\mathrm{DFs}$ for all electrodesites in each animal. C. Mean \pm SEM maximum (max) and minimum (min) DF values in each animal under each condition. $* P<0.05, * * P<0.01$ for ATR versus vagal-stimulation. 

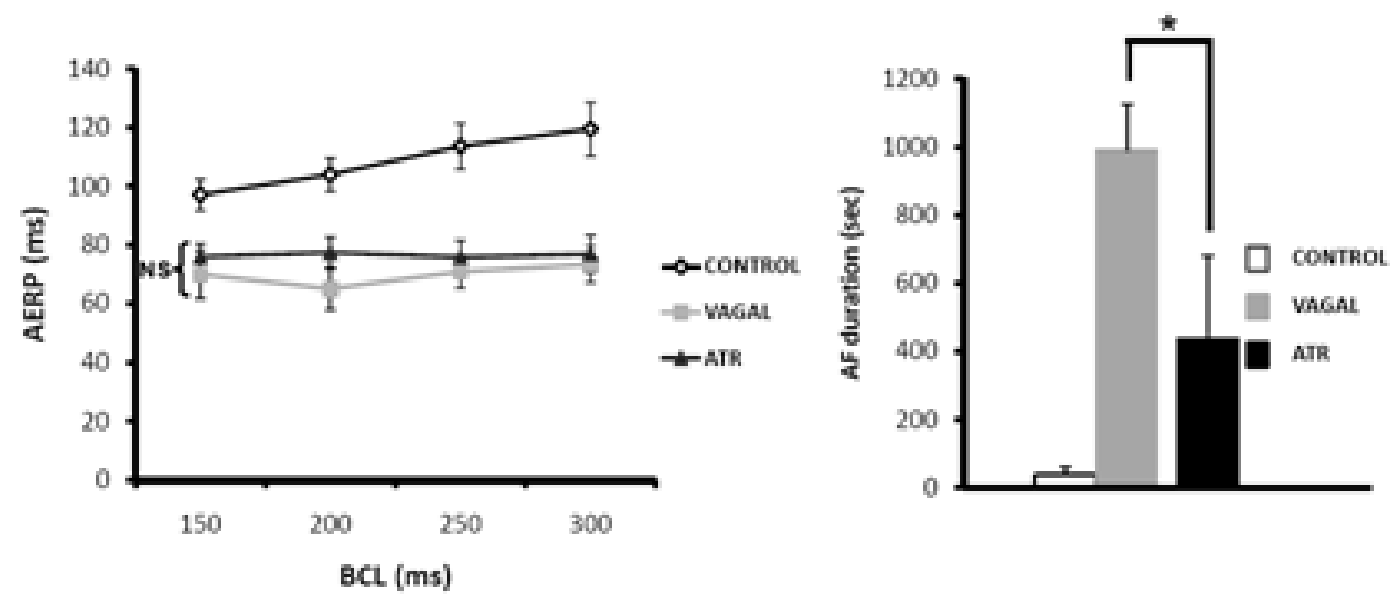

Figure 5 
A

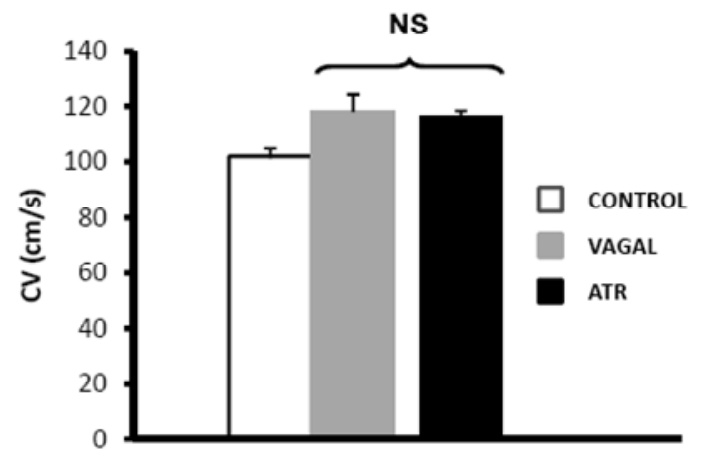

B

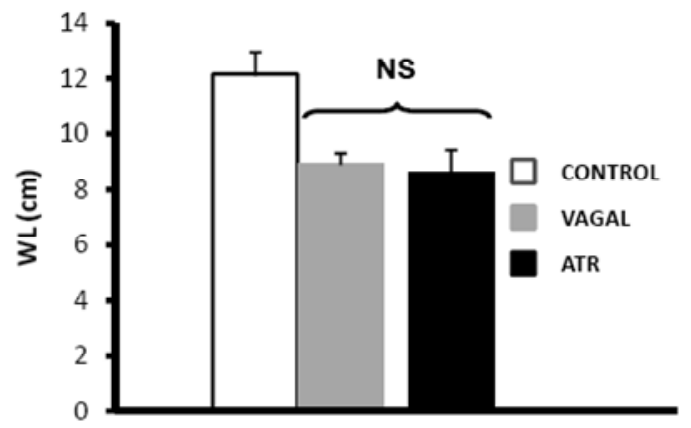

Figure 6 

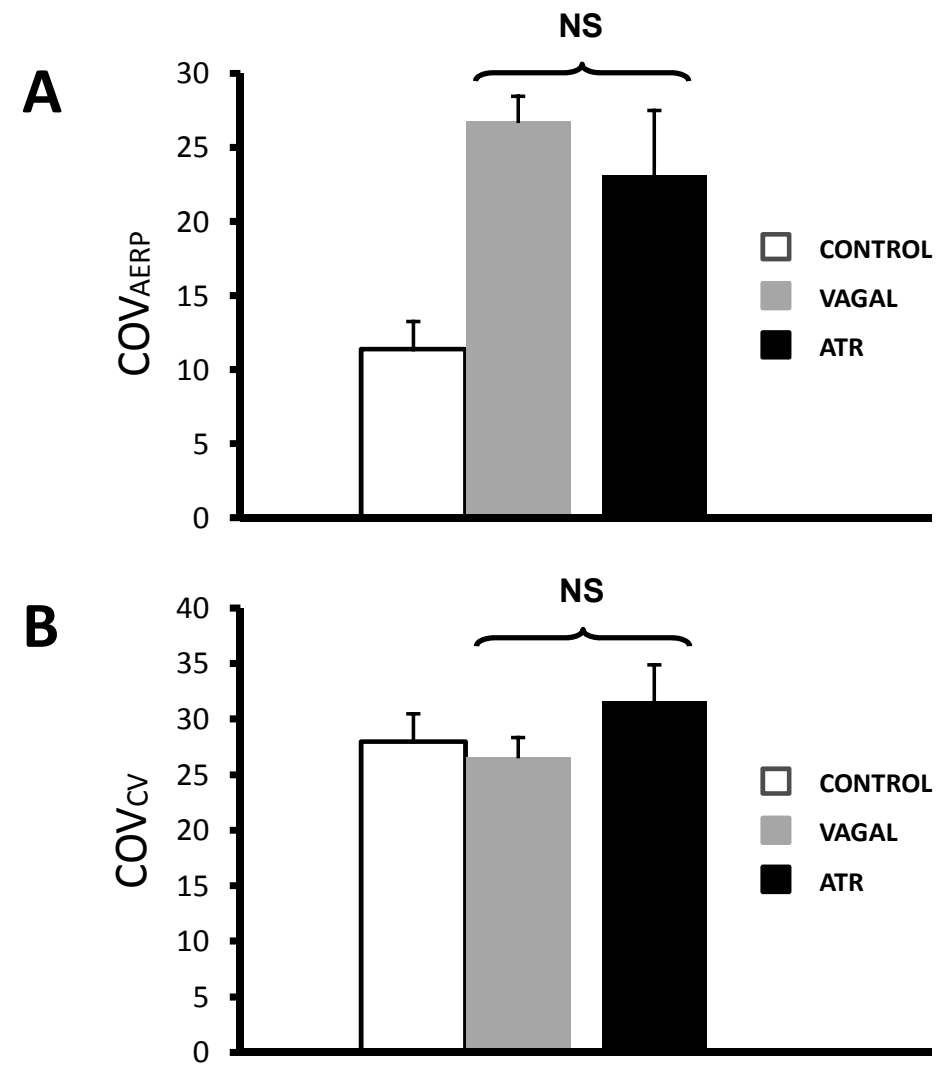

Figure 7 

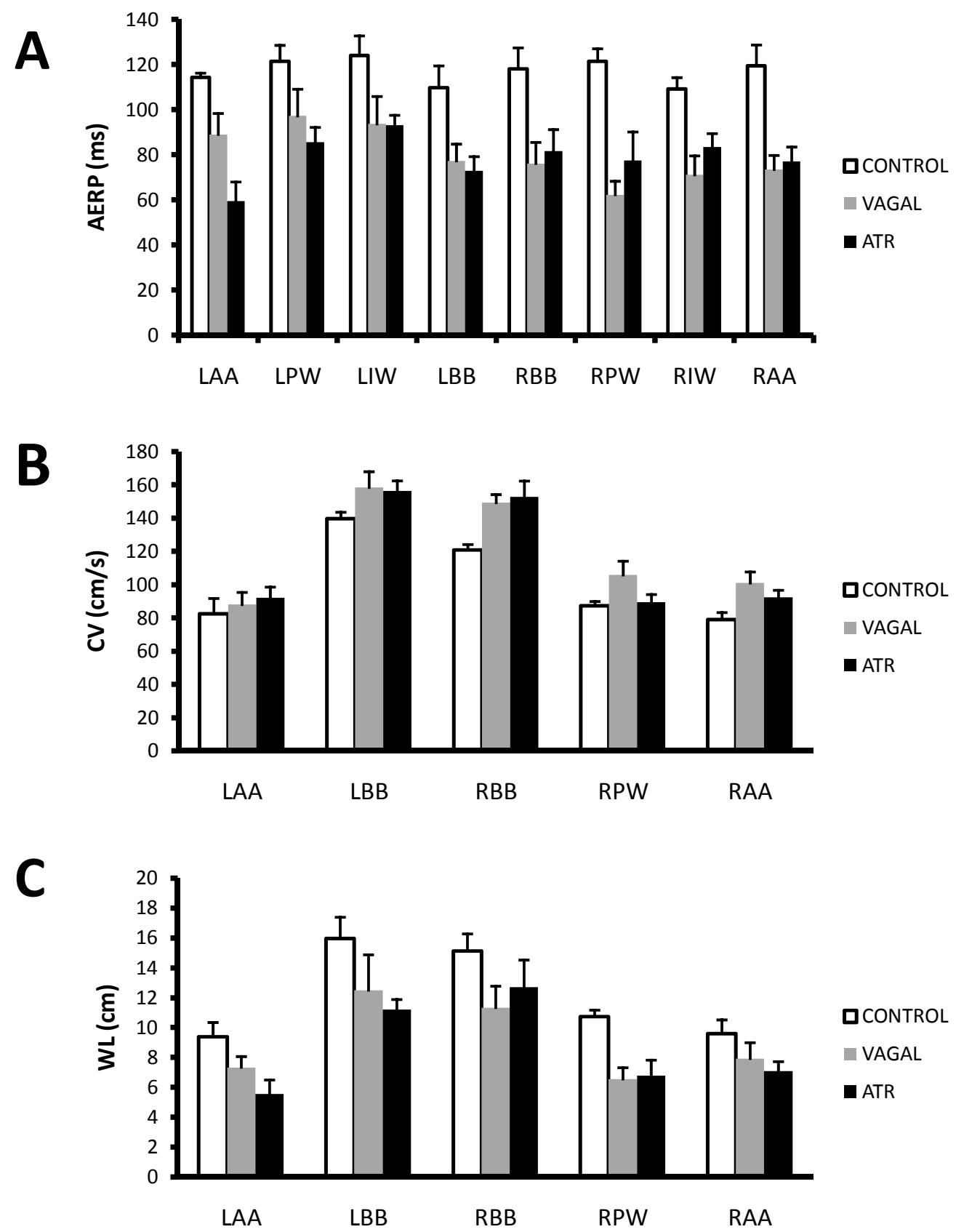

Figure 8 
LAA PACING

RAA PACING
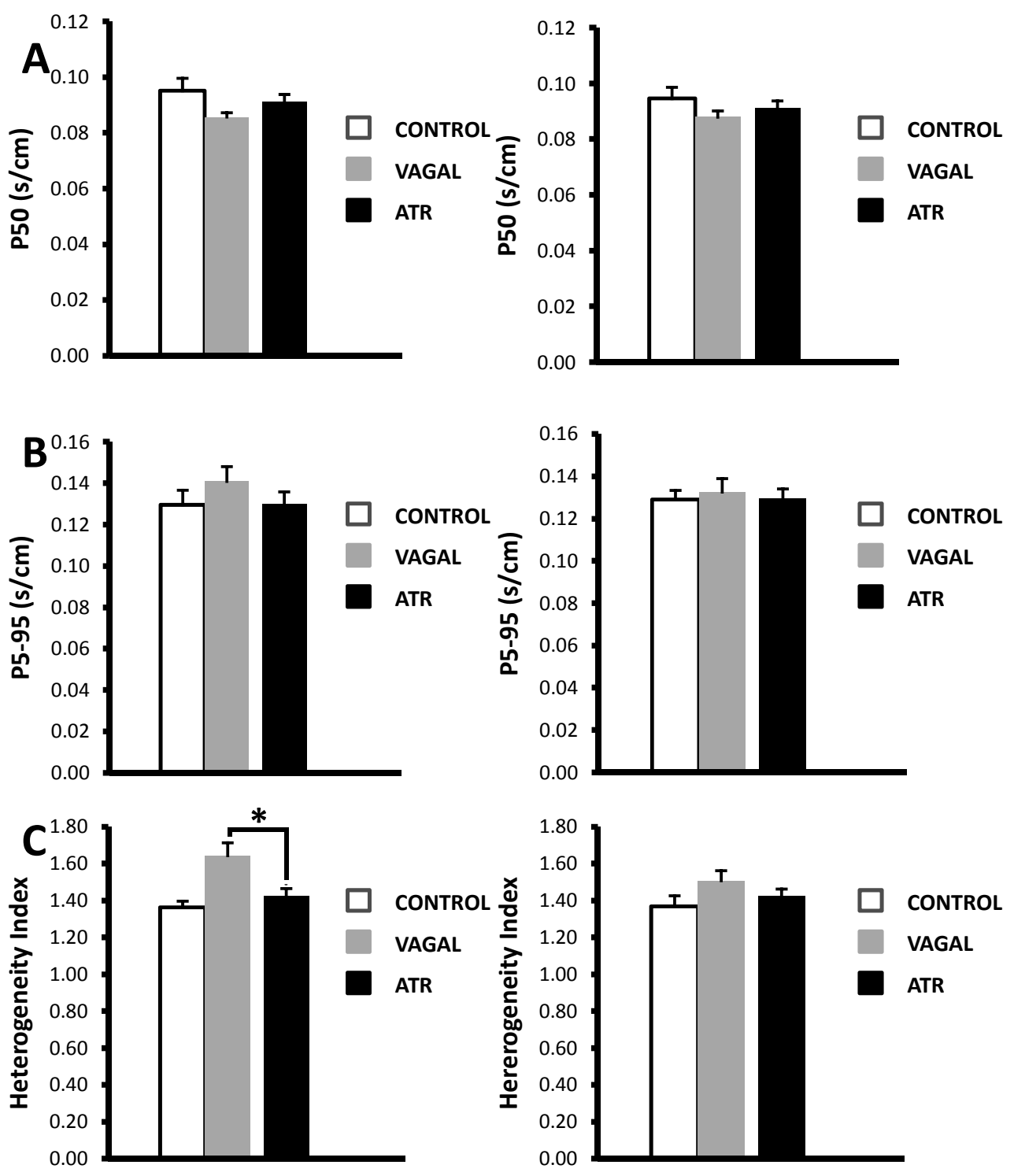

Figure 9 


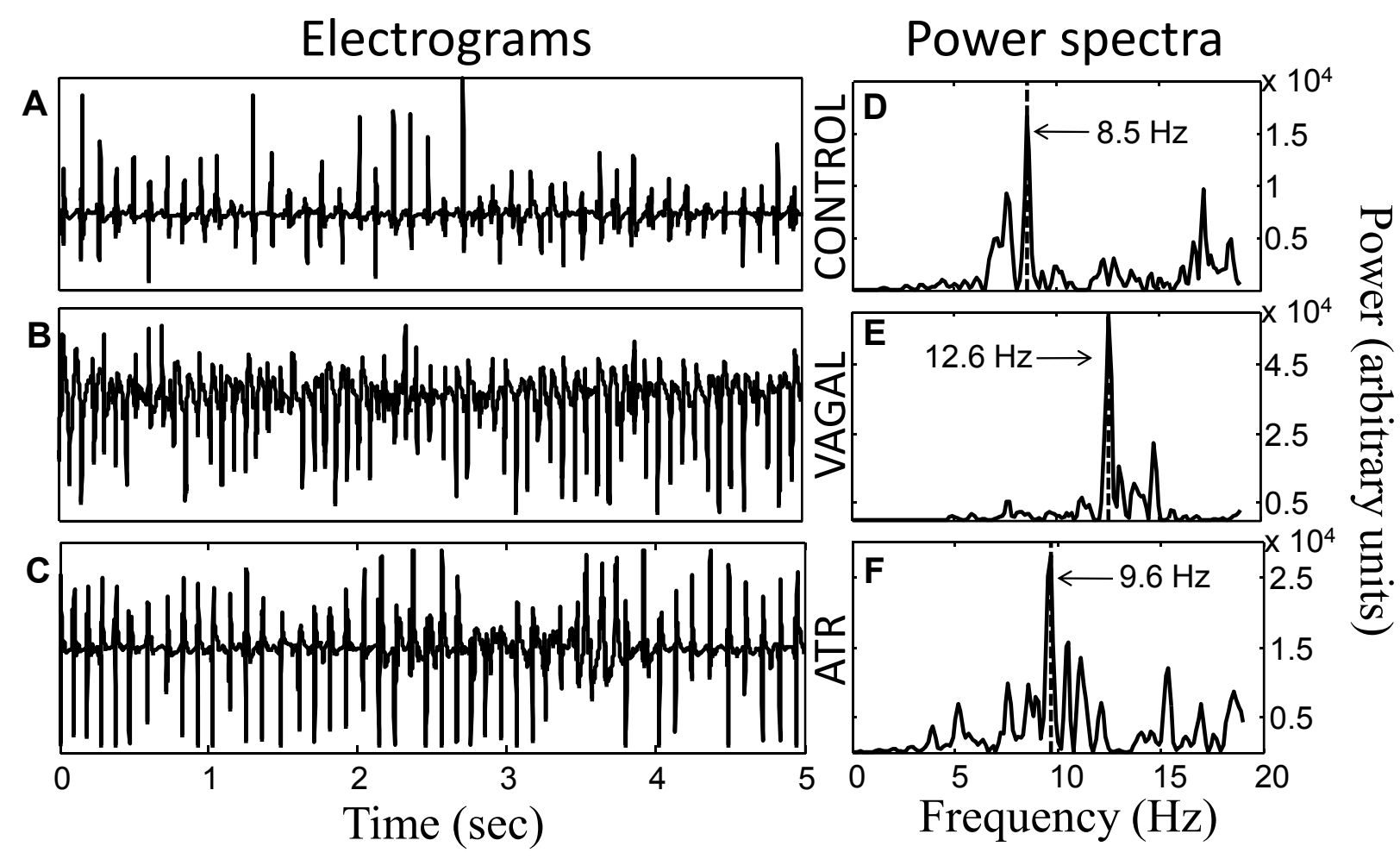

Figure 10 

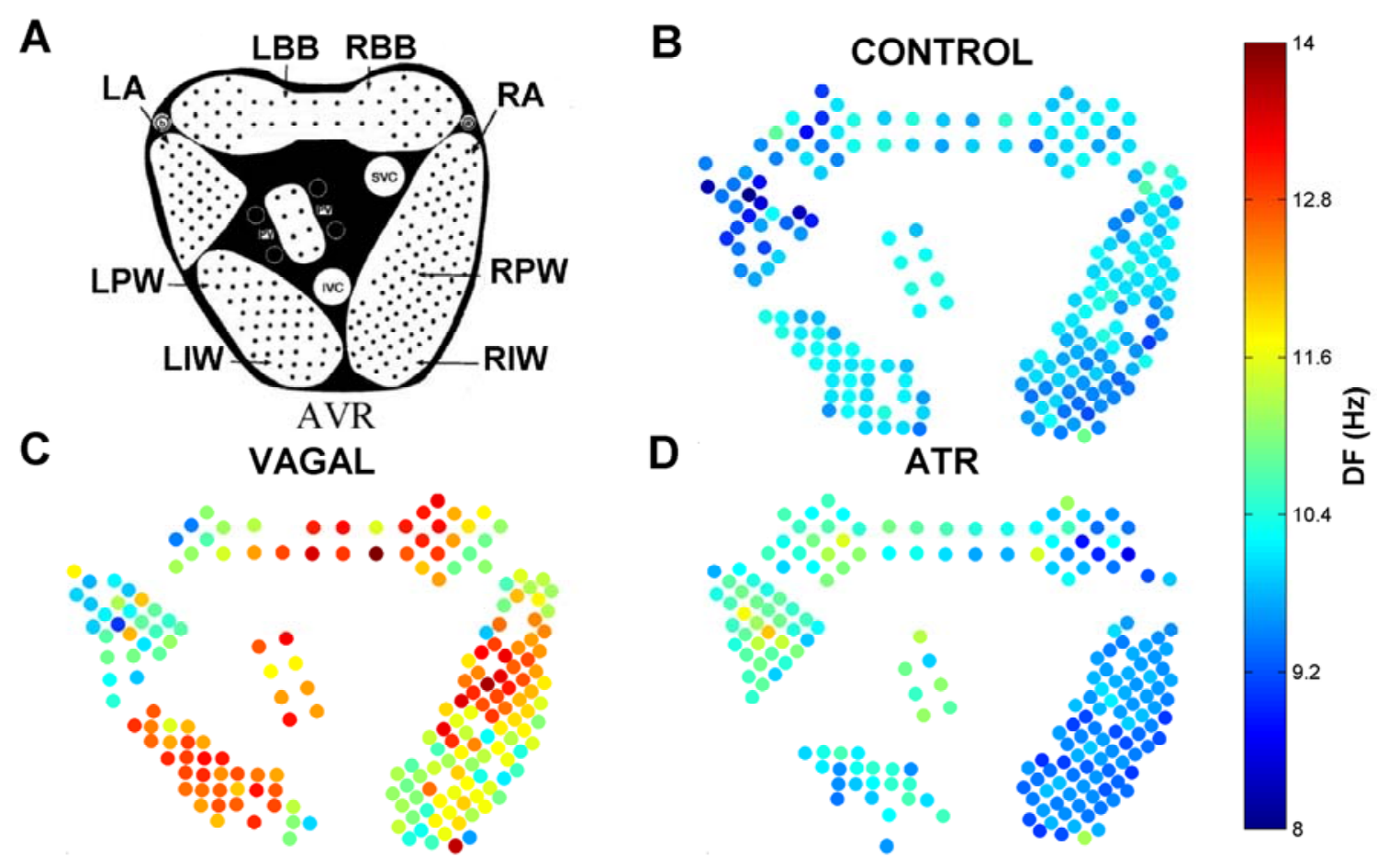

Figure 11 

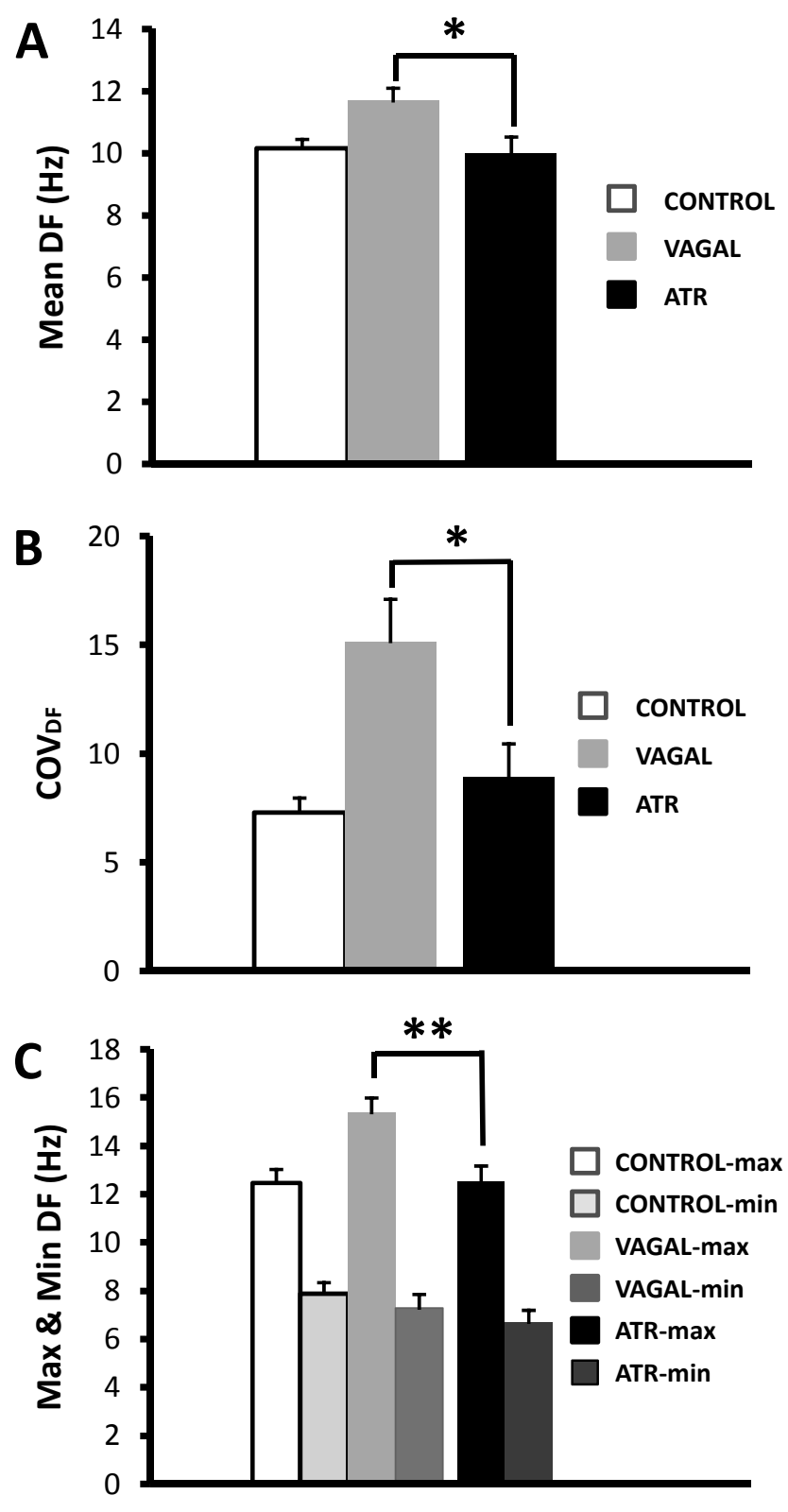

Figure 12 


\section{Discussion}

In the present study we compared the VS and ATR AF substrates having as a presupposition a similar atrial ERP. Despite observing similar CV and WL, we showed that VS AF is faster and more persistent comparing to ATR AF. This occurred independent of changes in the classical electrophysiological variables, which have been considered to date as the main contributors in the electrophysiological remodeling following $\mathrm{AF}^{74}$. VS dogs however presented a heterogeneous distribution of higher DF as well as a higher heterogeneity in local conduction. These results suggest that the heterogeneous anatomical distribution of vagal ganglia and the VS-induced cellular hyperpolarization are important contributors to AF-maintaining rotor stabilization and acceleration. Thus, the similarity of the substrates is only superficial, indicating analogous differences in respective clinical forms or phases of AF.

\subsection{Electrophysiological properties of VS and ATR substrate}

The parasympathetic system has long been recognized to play an important role in AF promotion ${ }^{67}$. Vagal AF is related to a spatially heterogeneous reduction in atrial ERP producing a substrate that is very propitious for $\mathrm{AF}^{71}$. $\mathrm{AF}$ has been induced in

different experimental models with either infusion of ACh in the sinus node artery ${ }^{123}$ or by direct stimulation of the vagal cervical nerves. Similarly, atrial tachycardia remodeling reduces the atrial ERP, the ERP rate adaptation and the WL while increasing the ERP heterogeneity ${ }^{27,41,74,105,117 .}$

In our study, we obtained the same mean ERP reduction comparing to CTL in both models of AF (fig. 5A). The coefficient of variation (CoV) of ERP, used as an index of heterogeneity, was also higher in both AF groups (fig. 7A). Additionally, the 
study of other basic electrophysiological variables didn't highlight significant differences between VS and ATR dogs.

In both groups, we obtained an increase in CV and a decrease in the WL of similar proportions, comparing always to CTL (fig. 6). Whereas a VS increase in CV is in accordance with previous studies ${ }^{70,71}$, there is still controversy concerning the ATR effect on $\mathrm{CV}^{75}$. The varying results regarding $\mathrm{CV}$ changes in ATR substrate may point to the existence of multiple factors and changes that can affect $\mathrm{CV}$. A decreased $\mathrm{I}_{\mathrm{Na}}$ would tend to decrease $\mathrm{CV}^{124}$, while a decreased ERP or an increased connexin expression ${ }^{75,125,126}$ would have the opposite effect.

Gaspo et $\mathrm{al}^{117,124}$ showed a reduction in CV in ATR dogs. However, CV measurements were done in the RPW, where we also didn't find significant differences in $\mathrm{CV}$ between CTL and ATR. Our results are in accordance with Fareh et $\mathrm{al}^{27}$ and Wijfells et $\mathrm{al}^{74}$, where pacing techniques similar to ours (from left and right atrial appendage) were used for the calculation. Furthermore, animal and human studies ${ }^{125,126}$ showed an increased connexin (Cx40) expression especially in the lateral cell membrane, potentially contributing to anisotropic impulse conduction, while other studies $^{127,128}$ found $\mathrm{Cx} 40$ significantly reduced in patients with persistent AF.

Although we ascertained an increase in $\mathrm{CV}$, there was a significant decrease of WL (WL=ERPxCV) in both AF groups (fig. 6B). The WL reduction could explain the inducibility of AF in VS and ATR, according to Allessie's leading circle model ${ }^{4,21}$, but it doesn't justify the promotion of persistence of AF in VS compared to ATR. Overall, VS and ATR groups shared similar differences in all main electrophysiological variables, but had a different effect on the persistence of AF. 
Nevertheless, the evaluation of local conduction abnormalities by phase delay analysis revealed important differences between the two AF substrates. Whereas, in ATR group, according to previous studies ${ }^{105,}{ }^{129}$, phase delay analysis didn't demonstrate significant differences with CTL, the heterogeneity index, measured in phase delay maps created under left auricular pacing, was significantly higher in the VS group compared with ATR (fig. 9C). A similarly higher heterogeneity index in the VS group, though not significantly $(\mathrm{p}=0.06)$, was also observed during right auricular pacing. Therefore, the enhanced anisotropic conduction and subsequent heterogeneity of repolarization in the VS group would establish more favorable conditions for reentry and justify the observed promotion of permanent $\mathrm{AF}^{4,75}$.

Of particular interest is also the observation, that the difference in conduction heterogeneity seems more important when measured during left auricular pacing (heterogeneity index of VS vs ATR during left auricular pacing $\mathrm{p}<0.05$, while during right auricular pacing $\mathrm{p}=0.06$ ). Wang et $\mathrm{al}^{69}$ showed that the ability of atrial extrastimuli to induce $\mathrm{AF}$ varied with the stimulation site, while Lammers et al ${ }^{130}$ found that premature extrasystoles enhance heterogeneity of conduction which leads to leading circle reentry. In 1998 Haissaguerre et al demonstrated that the pulmonary vein muscle sleeves are the most frequent source of ectopic beats which initiate $\mathrm{AF}^{14}$. Furthermore, in a recent study based on previously developed mathematical and anatomical models ${ }^{131,132}$, Gong et al suggested that the atria are more vulnerable to premature beats originating in the pulmonary veins (PV) than the RA ${ }^{133}$. These authors studied the window of vulnerability, or range of intervals, in which ectopic beats from different anatomical points can induce AF. They found that for ectopic foci in the RA, especially 
those closer to the sinoatrial node, such as the superior vena cava and crista terminalis, the size of the window of vulnerability for the induction of AF was markedly smaller than that of the PV ectopic foci. Accordingly, our results of conduction heterogeneity were congruent with the previous study. Thus, the increased heterogeneity in conduction, which was found predominantly during left pacing in VS dogs (fig. 9C), could be the expression of a higher vulnerability of the VS substrate in left atrial ectopic beats. However, induction of AF in our study was performed only with right atrial pacing and, therefore we don't have data of vulnerability differences between left and right atrium, which could further support or refute this hypothesis.

\subsection{Leading circle model, spiral wave theory and our study}

Over the past 50 years, multiple circuit reentry has been the dominant pathophysiological theory of $\mathrm{AF}^{4}$. Moe and coworkers ${ }^{20}$ developed the multiple wavelet reentry theory according to which AF is characterized by a large number of propagating wave fronts. However a sufficient number of these wave fronts must always find excitable tissue in order for the arrhythmia to persist.

Based on these concepts and in subsequent experimental work Allessie and colleagues $^{21,22}$ developed the "leading circle" model of functional reentry. The WL is the distance travelled by the electrical impulse during the time of ERP and equals the product of the ERP with the CV. If the dimensions of the tissue involved are shorter than the WL, the presuppositions of reentry are missing, as the electrical impulse encounters unexcitable tissue and consequently extinguishes. Accordingly, most antiarrhythmic drugs in use prevent the recurrence of AF by prolonging the $\mathrm{WL}^{22,25,26}$. 
However, experimental work in the last decades has sustained the theory of spiral wave activity as responsible for sustained reentrant activity in excitable systems such as the heart ${ }^{24,28,29}$. While in the leading circle model the electrical impulse excitation follows a circle with an unexcitable core (continuously excited by centripetal waves), according to the spiral wave theory the electrical impulse pursues a spiral trajectory continuously changing direction. There is a source sink relationship where the source represents the excited and depolarized tissue and the sink denotes the excitable tissue $^{30,31}$. If the source is too small it will extinguish itself in the vast sink; if it is too big it won't find excitable tissue to continue its activity. The maintenance of the spiral wave requires an angle of curvature which is determined by tissue excitability and source-sink relationships. Low excitability (for example an increase in ERP or reduction in $\mathrm{I}_{\mathrm{Na}}$ ) or propagation strength (reduced $\mathrm{CV}$ ) limit the curvature and enlarge the spirals with subsequent termination of $\mathrm{AF}^{24}$. Thus, inhibition of $\mathrm{Na}$ current should enlarge the spirals and terminate AF as Na-channels blockers do. On the contrary, according to the leading circle they would have the opposite effect: the CV reduction would decrease the WL and would promote AF, which is not what has been observed clinically ${ }^{32,33}$ and experimentally ${ }^{34,35}$. Comtois et $\mathrm{al}^{31}$ have recently studied in a mathematical and experimental model the mechanism by which $\mathrm{I}_{\mathrm{Na}}$ blockade terminates vagal AF. Arrhythmia termination was related to decreased source $\mathrm{Na}^{+}$-current in the face of large $\mathrm{I}_{\mathrm{KACh}}$-related sinks (source-sink relationship), leading to destabilization of primarygenerator rotors and their subsequent annihilation. This was indirectly expressed also by the reduction in maximum DF values observed in AF after Na-channel blockade. 
The previous results are in agreement with the results of our study. Both VS and ATR AF substrate presented similar electrophysiologic modifications. ERP reduction was artificially equal in both substrates. Despite the fact that CV was similarly increased and WL was similarly reduced in both substrates, we found significant differences in AF properties. AF duration was significantly longer and DFs and conduction heterogeneity were significantly higher in VS dogs. Such phenomena couldn't be explained by the leading circle model as the WL was similar in both substrates.

On the contrary, the increase in $\mathrm{I}_{\mathrm{KACh}}$ related to VS would hyperpolarize the diastolic membrane potential, leading to a reduction of the duration of action potential, as well as a faster recovery and subsequent increased availability of $\mathrm{Na}^{+}$channels. According to experimental animal and computer models ${ }^{122,}{ }^{134}$, such an increase in inward rectifier $\mathrm{K}^{+}$current would lead to an increase in rotor frequency and a propensity to stabilization of rotors resulting in AF promotion. The analogies with our VS model are obvious. Furthermore, the higher DFs in VS dogs is another indirect index of the rotor frequency increase, testifying to the aptness of the spiral wave reentry theory in our model.

\subsection{Role of autonomic ganglia, spiral waves and rotors}

DF analysis demonstrated higher values in the VS group comparing to ATR group (fig. 12A). DF heterogeneity, expressed as a coefficient of variation, was also higher in VS group (12B). Consequently, there was a clear association in our study between higher and heterogeneously distributed DF values and increased duration of AF in the VS group. Our results are similar to previous work where AFCL was examined ${ }^{71,}$ 
117. Moreover, recent studies showed high DF values after electric or ACh induced stimulation of cardiac autonomic ganglia ${ }^{38,53,73,134,135}$. However, to our knowledge this is the first study comparing the spectral properties of VS AF with ATR AF.

In their classical work Wijffels et $\mathrm{al}^{74}$ remarked that $\mathrm{AF}$ was self-terminating when $\mathrm{CL}>120 \mathrm{msec}$, while an exponential increase in the AF duration was observed for AF $C L<120 \mathrm{msec}$ (equivalent a $8.3 \mathrm{~Hz}$ ). According to emerging experimental evidence $^{17,36}$, perpetuation of AF may depend on the uninterrupted activity of a small number of discrete generators (rotors), established by the interaction of propagating waves with anatomical heterogeneities in the atria ${ }^{39}$. As few as 1 rapidly discharging rotor may be sufficient to maintain fibrillatory activity during cholinergic $\mathrm{AF}^{17,36,38,136}$. Our results are congruent with the above notions. Rapidly firing drivers and higher DF promote AF maintenance in the VS group in comparison with ATR.

Stimulation of cardiac $\mathrm{M}_{2}$ muscarinic cholinergic receptors by cholinergic agonists elicits a large inward rectifier $\mathrm{K}^{+}$current, $\mathrm{I}_{\mathrm{KACh}}$, which strongly promotes $\mathrm{AF}^{38,}$ 83. In a mouse knockout model lack of $\mathrm{I}_{\mathrm{KACh}}$ prevented $\mathrm{AF}^{137}$. On the contrary, as we discussed in the paper, according to experimental animal and computer models, an increase in an inward rectifying $\mathrm{K}^{+}$current, such as $\mathrm{I}_{\mathrm{K} 1}$ or $\mathrm{I}_{\mathrm{KACh}}$ tend to increase rotor frequency and stabilization ${ }^{122,134}$. The increase in an inward rectifier $\mathrm{K}^{+}$current hyperpolarizes the diastolic membrane voltage, resulting in the observed reduction of the duration of action potential, as well as a faster recovery and subsequent increased availability of $\mathrm{Na}^{+}$channels. The final result would be the acceleration and stabilization of rotors, promoting the permanence of AF. 


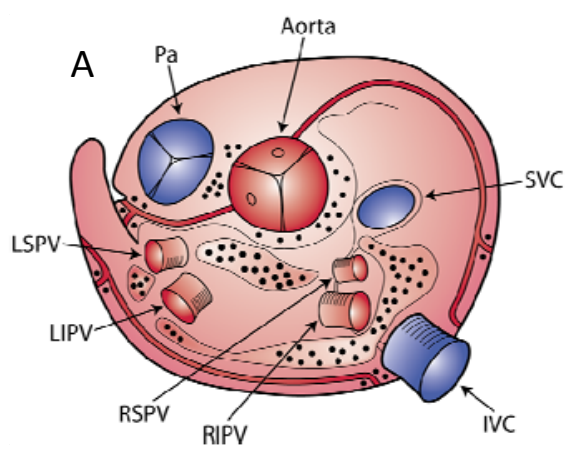

B
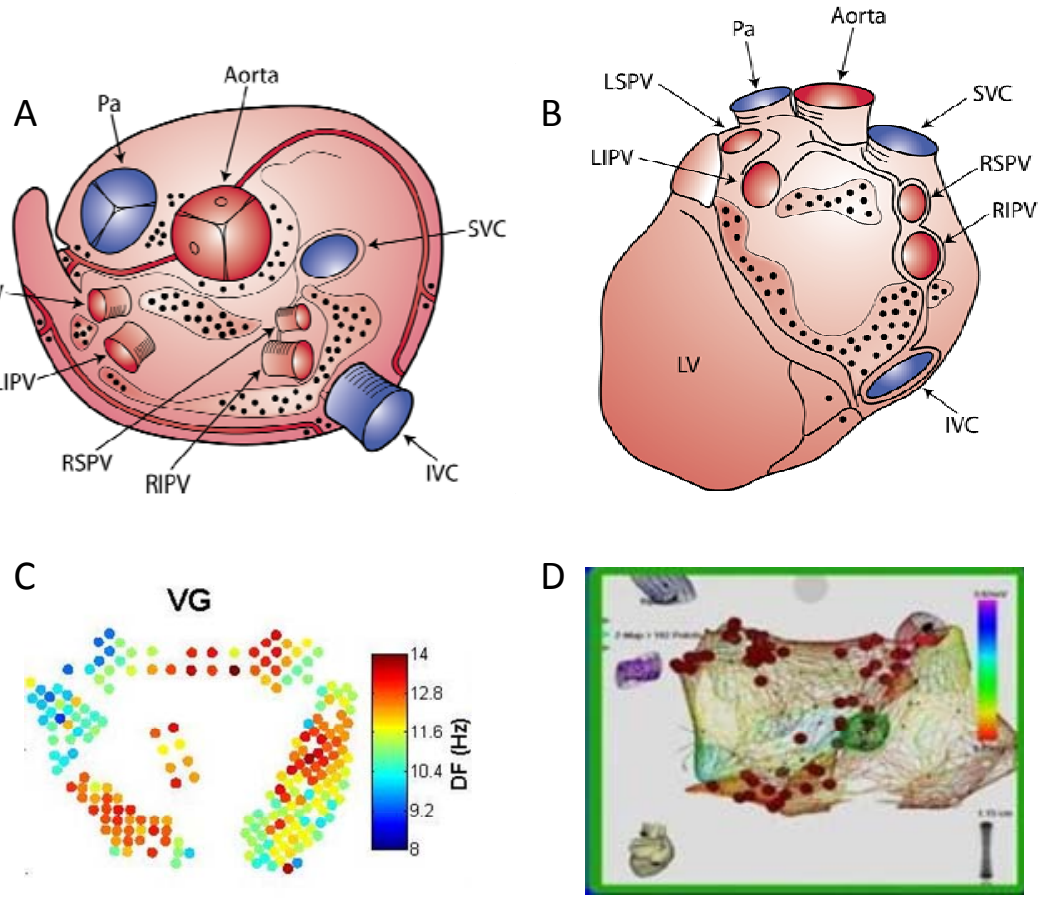

Fig. 13. Anatomical distribution of ganglia of the autonomous intrinsic cardiac nervous system A: superior view B: posterior view (adapted from Armour et $\mathrm{al}^{62}$ ). Analogous distribution of C: DFs in VS induced AF and D: ablation lesions following CFAEs (Nademanee et $\mathrm{al}^{49}$.) 


\subsection{Clinical implications}

Previous studies showed a left to right gradient in DF in patients with paroxysmal $\mathrm{AF}$ but not persistent $\mathrm{AF}^{18,19,39,47}$. It has been found that higher DFs with lower spatiotemporal periodicity are present in patients with persistent $\mathrm{AF}^{46,47}$. In analogy, we observed higher DFs and permanent AF only in the VS group. Accordingly, we found a similar tendency in left to right DFs gradient in the ATR group (after 1 week pacing) which is comparable with the paroxysmal AF groups in human studies. Ablation of PVs results in a loss in the left-to-right DF gradient in patients with paroxysmal $\mathrm{AF}$ and in fewer $\mathrm{AF}$ episodes ${ }^{47}$. However, in an animal model, $\mathrm{AF}$ promotion by VS was not influenced by the presence or absence of $\mathrm{PVs}^{73}$. Consequently, parasympathetic activation seems of primordial importance in prolonging AF, suggesting a possible role even in the persistent clinical forms of AF.

The distribution of DFs in VS induced AF (fig. 13C) in our study is surprisingly analogous to the distribution of the ablation lesions performed by Nademanee et $\mathrm{al}^{49}$, following the allocation of complex fractionated electrograms (CFAE) (fig. 13D), in patients with paroxysmal or persistent AF. Such distribution is also analogous to the

distribution of vagal ganglia according to Armour et $\mathrm{al}^{62}$ (fig. 13A and B). Kalifa et $\mathrm{al}^{52}$ studying AF in isolated sheep hearts showed that the most fractionated activity was found in the periphery of high frequency sources, while a similar correlation between DF areas and fractionated electrograms was demonstrated by Everett et $\mathrm{al}^{53}$ in various animal models. As recently suggested ${ }^{56}$, CFAEs may result from activation of the intrinsic cardiac autonomic nervous system and the clinical efficacy of ablation of $\mathrm{CFAEs}^{49}$ may result by a partial atrial denervation ${ }^{65}$. Thus, as our results suggest, ACh release from epicardial ganglia after vagal stimulation would accelerate and stabilize 
different rotors maintaining AF. Therefore, DFs would correspond to the regions of vagal ganglia, which are also the regions of CFAEs.

Our results reinforce the idea of ablation of vagal ganglia in order to reduce

duration and number of $\mathrm{AF}$ episodes ${ }^{138}$. However, the importance and the timing of such ablation (simultaneously with PV ablation to prevent recurrences and remodeling, or in a second procedure) have still to be defined. Furthermore, studying the vagal effects after different periods of ATR would probably clarify significant aspects of the pathophysiological modifications that occur in the passage between paroxysmal and permanent AF and could suggest interesting possible therapeutic solutions.

\subsection{Potential limitations}

The same animal group (6 dogs) was used for the electrophysiologic evaluation in baseline conditions and under VS. This resulted in fewer animals sacrificed, but, on the other hand, it could have affected partially our results under VS. The elapsed time between the start of the operation and the actual VS was considerable due to the electrophysiologic measurements in baseline conditions. This could have influenced the autonomic tone of the animals. Nevertheless, our results were similar to previous studies ${ }^{69,71}$ where 2 separate groups of animals were used.

Electrophysiological variables were measured at a CL of $300 \mathrm{msec}$. CV was measured in left and right atrial areas after pacing from the LAA or RAA respectively. This method permitted the measurement in lines of electrodes vertical to isochronal lines. However, RIW, LPW, and LIW CV couldn't be measured accurately in every dog, because of variable conduction in these areas, and therefore they were excluded 
from the analysis. Consequently, mean CV and WL were similar in VS and ATR group for the analyzed areas, but we cannot exclude that differences could exist in the 3 notanalyzed areas.

Moreover, our mapping system samples quite extensively the epicardial atrial surfaces, but does not provide information about septal activation or the activation of subendocardial structures. Therefore, our results regarding the anatomical distribution of DFs are valid for the epicardial surface, but not for the respective endocardial surface, where ablation techniques are mostly applied. However, the similarity of our results in ATR group (left DF predominance) with clinical studies using endocardial mapping $^{18,46,47}$, as well as the analogy of VS DFs distribution with CFAE distribution in human and animal studies ${ }^{19,49,52,134}$ support the validity of our results even for the endocardium.

\section{6 $I_{\mathrm{KACh}}, I_{\mathrm{KACh}, \mathrm{c}}$, muscarinic receptors, DF and future research}

Human AF leads to an increase in $\mathrm{I}_{\mathrm{K} 1}{ }^{81}$ and similar changes have also been observed in animal studies ${ }^{95}$. Consequently, we would expect an increase in DF even in the ATR model that however we didn't detect. A possible explanation would have its scientific base in autonomic nervous remodeling based mainly in dissimilar anatomic distribution of autonomic ganglia and receptors between left and right atria, as well as diverse receptor downregulation. 
Kir3.1 and Kir 3.4 are channel subunits that form the acetylcholine regulated channel $\mathrm{I}_{\mathrm{KAch}}$. Decreases in both $\mathrm{mRNA}^{84}$ and protein $^{90}$ of these subunits have been reported in human and animal AF, corresponding to a decreased current response to M2 receptor stimulation ${ }^{83,84}$. Furthermore, all three muscarinic receptor subtypes (M2, M3, M4) which are coupled to $\mathrm{K}^{+}$currents in atrial cells from LA and PV undergo an ATR downregulation process ${ }^{92}$. However, contradiction exists about the distribution of muscarinic receptors in the different atrial regions ${ }^{139,} 140$ and the proportion of downregulation in each atrial area is unknown. Our results (fig. 11 and fig. 13) indicate that the distribution of mean DFs in the VS group follows almost precisely the anatomic allocation of atrial ganglia, as previously described by Armour et $\mathrm{al}^{62,64}$. In ATR dogs, the driver zones showed variable location and their distribution was less clear.

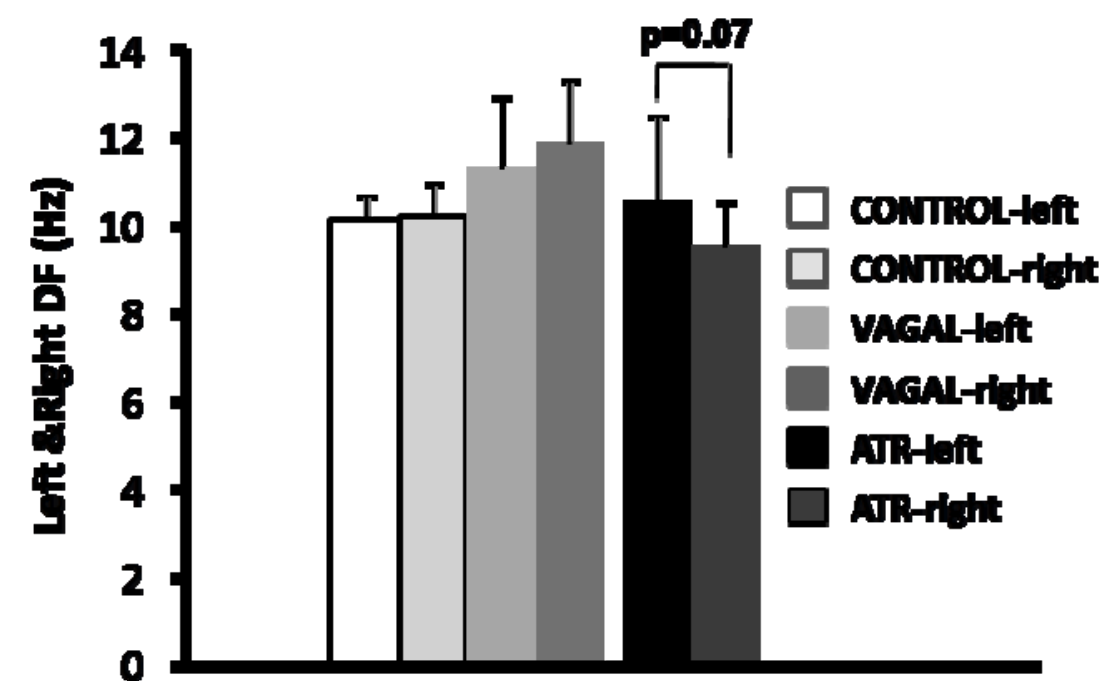

Fig. 14 Mean \pm SEM DFs for left atrium and right atrium for each animal, obtained by averaging all DFs in each animal and then calculating mean \pm SEM for each condition. 
Although the LAA is almost deficient in ganglia, we noticed somewhat higher values in DF in ATR dogs. A comparison of mean DFs in left and right atrium showed a tendency toward higher DFs in left atrium ( $p=0.07$ not significant), while there wasn't such tendency in the analogous comparison in VS or CTL group (fig. 14). According to these results, we formulated the hypothesis that, in the ATR group, the downregulation of the muscarinic receptors would be higher in the anatomical areas overlapped by neural ganglia. AF would promote parasympathetic activation as an autonomic nervous reaction to higher atrial and/or ventricular frequencies. Consequently, as a result of the activation of $\mathrm{I}_{\mathrm{KACh}}$, an internalization of muscarinic receptors would follow with subsequent desensitization of this $\mathrm{K}^{+}$current $^{141}$. Downregulation of the receptors would probably be higher in the place where higher amounts of Ach were liberated such as regions underlying the neural ganglia. An index of this regionally specific downregulation would be the different distribution of DFs in our experiment: various and heterogeneous, following ganglia distribution in VS group (fig. 11C); more homogeneous in frequency values but with a left predominance in ATR group (fig. 11D). Physiologically, this would correspond to a homeostatic response of the organism in the face of neural heterogeneity which as a conseguence reduces the sustainability of AF. Evidence of that is the shorter duration of AF in ATR group in comparison to VS.

Further support comes from studies which suggest that in ATR, in concert with a reduction in an $\mathrm{ACh}$ stimulated $\mathrm{I}_{\mathrm{KACh}}$, there is an increase in a constitutively active form of this current $\left(\mathrm{I}_{\mathrm{KACh}, \mathrm{c}}\right)^{75,93-95}$. $\mathrm{I}_{\mathrm{KACh}}$ channels can be constitutively active in the absence of cholinergic agonist stimulation ${ }^{83,93-95}$. There is evidence that $\mathrm{I}_{\mathrm{KAch}}$ and Kir3 channels $\left(\mathrm{K}_{\mathrm{ACh}}\right)$ may be greater in the left than the right atrium ${ }^{134}$. Accordingly, VS and ACh 
infusion would create higher driver rotors in the richer in $\mathrm{I}_{\mathrm{KACh}}$ channels left atrium. However, we noticed the opposite effect; no difference in DF was observed between left and right DFs (fig. 14), while mean DFs in the RA appendage tended to be higher than LA appendage in VS group $(\mathrm{p}=0.06)$. In order to interpret these results, we should consider the notion that the muscarinic receptor and $\mathrm{K}_{\mathrm{ACh}}$ channels are two separate entities, with a $\mathrm{G}$ protein playing the role of intermediary ${ }^{142}$. Thus, vagal nervous stimulation would result probably in higher local concentrations of $\mathrm{ACh}$ in discrete atrial regions containing muscarinic receptors with variable effect and different anatomical distribution. Therefore, VS would be highly arrhythmogenic, because of the anatomical imbalance in the distribution of neural ganglia, while downregulation of the muscarinic receptors with respective channels could be partly beneficial. However, the existing anatomical imbalance in $\mathrm{K}_{\mathrm{ACh}}$ channels would still be proarrhythmic because of the constitutive $\mathrm{I}_{\mathrm{KH}}$ current $^{83}$. Moreover, the inhibition of such current with tertiapin has been proved beneficial in the suppression of sustained tachyarrhythmias in ATR animals ${ }^{95}$.

On the other hand, rapid right atrial pacing produces a heterogeneous increase in

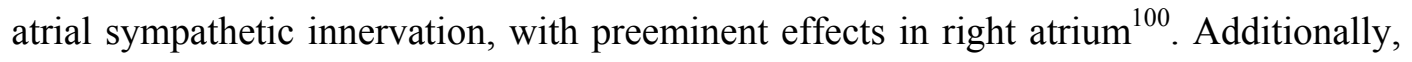
Chang et $\mathrm{al}^{101}$ in a canine model of sustained AF showed that there is a significant nerve sprouting and sympathetic hyperinnervation that is higher in the right atrium compared to left atrium. Consequently, we cannot exclude that right atrial pacing could have caused significant ACh discharge from neural elements in the vicinity of the stimulation site, thus promoting downregulation of muscarinic receptors and channels with parallel sympathetic nerve sprouting mostly in RA. Nevertheless, the above studies showed 
significant nerve sprouting and sympathetic hyperinnervation even in LA, while in control dogs it seemed that the RA also tended to have a higher nerve density than the LA and septum. Furthermore, there was no correlation between the duration of pacing and the density of cardiac nerves in either RA or LA.

In conclusion, we need more information to prove our hypothesis. While numerous studies ${ }^{19,39,47}$ demonstrated a left to right gradient in DF in accordance with the same tendency presented in ATR in our study, there isn't any work to our knowledge which studied the effect of direct VS in ATR conditions. Such a study would help us clarify the importance of parasympathetic stimulation in persistent or chronic AF. Moreover, comparing regional densities of muscarinic receptors and $\mathrm{I}_{\mathrm{KACh}}$ currents after either right or left atrial pacing could clarify important aspects of a supposed neuroreceptorial remodeling. 


\section{Conclusion}

For a comparable AERP, VS AF is faster and more persistent than AF with an ATR substrate. These results are consistent with modeling work suggesting that VS-induced hyperpolarization is an important contributor to AF-maintaining rotor stabilization and acceleration. Important differences in local conduction and higher heterogeneity in VS AF contribute also significantly in the different pathophysiological manifestations of the two substrates. In addition, our study adds further evidence that spiral wave theory probably interprets better the complex AF phenomena compared to leading circle concept. According to the latter, for similar AERP and WL we shouldn't find any differences in AF promotion.

Furthermore, during VS, the spatial distribution of high DFs during AF follows strictly the anatomic distribution of epicardial ganglia and shows high heterogeneity. An interesting correlation of CFAEs with DFs and consequently vagal ganglia was also suggested by the electroanatomical mapping performed in our study. Therefore, based also

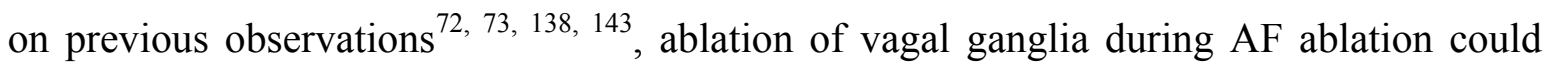
also be advantageous.

A higher heterogeneity in VS DFs was also noted, while in the ATR model there was a tendency to higher DFs in the LA, in accordance with previous animal and human studies $^{18,19,39}$. We hypothesized a continuous vagal activation in the ATR model as a response of the autonomic nervous system to the high heart rate used to produce the model of electrical remodeling. A major downregulation of muscarinic receptors in the areas of vagal ganglia would follow, which would unmask the acetylcholine independent constitutive activity of $\mathrm{I}_{\mathrm{KACh}}$ channels. As long as these channels are more numerous in the 
LA, rotors would have higher frequencies in the LA and consequently DFs would be higher in the LA as observed in our experimental study. Since AF duration is shorter in ATR, such downregulation of receptors seems beneficial. However, further studies are needed to confirm or reject such a hypothesis. In particular, the study of VS in ATR models of different pacing duration would help us clarify various aspects of the neuroreceptorial remodeling and could probably give insights to the pathophysiological passage from paroxysmal AF to more persistent forms. Moreover, the comparison of the electrophysiological and neuroreceptorial effects of left atrial with right atrial pacing could also contribute substantially in the same direction.

Overall, even if VS and ATR AF share many common features, there are important pathophysiological differences, which may correspond to different forms or phases of clinical AF and would need therefore different therapeutic strategies. The role of parasympathetic stimulation in different phases of electrical or structural atrial remodeling merits further consideration in future studies. 


\section{Bibliography}

1. Fuster V, Ryden LE, Cannom DS, et al. ACC/AHA/ESC 2006 Guidelines for the Management of Patients with Atrial Fibrillation: a report of the American College of Cardiology/American Heart Association Task Force on Practice Guidelines and the European Society of Cardiology Committee for Practice Guidelines (Writing Committee to Revise the 2001 Guidelines for the Management of Patients With Atrial Fibrillation): developed in collaboration with the European Heart Rhythm Association and the Heart Rhythm Society. Circulation 2006;114:e257-354.

2. Brugada R, Kääb S. Genetics of Atrial Fibrillation: The Clinician's Perspective. In: Natale A, J J, eds. Atrial Fibrillation From bench to bedside. Totowa: Humana Press; 2008:69-76.

3. Olgin JE, Zipes DP. Specific Arrhythmias: Diagnosis and Treatment. In: Zipes DP, LIbby P, Bonow RO, Braunwald E, eds. BRAUNWALD'S HEART DISEASE: A Textbook of Cardiovascular Medicine. 7th ed. Philadelphia: Elsevier Saunders; 2005:80363.

4. Nattel S. New ideas about atrial fibrillation 50 years on. Nature 2002;415:219-26.

5. Nattel S, Ehrlich J. Atrial Fibrillation. In: Zipes DP, Jalife J, eds. Cardiac Electrophysiology: From cell to bedside. 4th ed. Philadelphia: Saunders; 2004:512-22. 
6. Kopecky SL, Gersh BJ, McGoon MD, et al. The natural history of lone atrial fibrillation. A population-based study over three decades. N Engl J Med 1987;317:669-74.

7. Go AS, Hylek EM, Phillips KA, et al. Prevalence of diagnosed atrial fibrillation in adults: national implications for rhythm management and stroke prevention: the AnTicoagulation and Risk Factors in Atrial Fibrillation (ATRIA) Study. JAMA $2001 ; 285: 2370-5$.

8. Feinberg WM, Blackshear JL, Laupacis A, Kronmal R, Hart RG. Prevalence, age distribution, and gender of patients with atrial fibrillation. Analysis and implications. Arch Intern Med 1995;155:469-73.

9. Padanilam B, Prystowsky EN. Epidemiology of Atrial Fibrillation. The Rising Prevalence. In: Natale A, Jalife J, eds. Atrial Fibrillation From bench to bedside. Totowa: Humana Press; 2008:3-11.

10. Krahn AD, Manfreda J, Tate RB, Mathewson FA, Cuddy TE. The natural history of atrial fibrillation: incidence, risk factors, and prognosis in the Manitoba Follow-Up Study. Am J Med 1995;98:476-84.

11. Wolf PA, Abbott RD, Kannel WB. Atrial fibrillation: a major contributor to stroke in the elderly. The Framingham Study. Arch Intern Med 1987;147:1561-4.

12. Lloyd-Jones DM, Wang TJ, Leip EP, et al. Lifetime risk for development of atrial fibrillation: the Framingham Heart Study. Circulation 2004;110:1042-6. 
13. Fenelon G, Wijns W, Andries E, Brugada P. Tachycardiomyopathy: mechanisms and clinical implications. Pacing Clin Electrophysiol 1996;19:95-106.

14. Haissaguerre M, Jais P, Shah DC, et al. Spontaneous initiation of atrial fibrillation by ectopic beats originating in the pulmonary veins. N Engl J Med 1998;339:659-66.

15. Berenfeld O, Zaitsev AV, Mironov SF, Pertsov AM, Jalife J. Frequency-dependent breakdown of wave propagation into fibrillatory conduction across the pectinate muscle network in the isolated sheep right atrium. Circ Res 2002;90:1173-80.

16. Schuessler RB, Grayson TM, Bromberg BI, Cox JL, Boineau JP. Cholinergically mediated tachyarrhythmias induced by a single extrastimulus in the isolated canine right atrium. Circ Res 1992;71:1254-67.

17. Mandapati R, Skanes A, Chen J, Berenfeld O, Jalife J. Stable microreentrant sources as a mechanism of atrial fibrillation in the isolated sheep heart. Circulation 2000;101:194-9.

18. Lazar S, Dixit S, Marchlinski FE, Callans DJ, Gerstenfeld EP. Presence of left-toright atrial frequency gradient in paroxysmal but not persistent atrial fibrillation in humans. Circulation 2004;110:3181-6.

19. Mansour M, Mandapati R, Berenfeld O, Chen J, Samie FH, Jalife J. Left-to-right gradient of atrial frequencies during acute atrial fibrillation in the isolated sheep heart. Circulation 2001;103:2631-6. 
20. Moe GK, Rheinboldt WC, Abildskov JA. A Computer Model of Atrial Fibrillation. Am Heart J 1964;67:200-20.

21. Allessie MA, Bonke FI, Schopman FJ. Circus movement in rabbit atrial muscle as a mechanism of tachycardia. III. The "leading circle" concept: a new model of circus movement in cardiac tissue without the involvement of an anatomical obstacle. Circ Res 1977;41:9-18.

22. Rensma PL, Allessie MA, Lammers WJ, Bonke FI, Schalij MJ. Length of excitation wave and susceptibility to reentrant atrial arrhythmias in normal conscious dogs. Circ Res $1988 ; 62: 395-410$.

23. Cox JL, Schuessler RB, Boineau JP. The development of the Maze procedure for the treatment of atrial fibrillation. Semin Thorac Cardiovasc Surg 2000;12:2-14.

24. Nattel S, Shiroshita-Takeshita A, Brundel BJJM, Rivard L. Mechanisms of Atrial Fibrillation: Lessons From Animal Models. Progress in Cardiovascular Diseases 2005;48:9-28.

25. Wang J, Bourne GW, Wang Z, Villemaire C, Talajic M, Nattel S. Comparative mechanisms of antiarrhythmic drug action in experimental atrial fibrillation. Importance of use-dependent effects on refractoriness. Circulation 1993;88:1030-44.

26. Wang Z, Page P, Nattel S. Mechanism of flecainide's antiarrhythmic action in experimental atrial fibrillation. Circ Res 1992;71:271-87. 
27. Fareh S, Villemaire C, Nattel S. Importance of refractoriness heterogeneity in the enhanced vulnerability to atrial fibrillation induction caused by tachycardia-induced atrial electrical remodeling. Circulation 1998;98:2202-9.

28. Panfilov AV, Pertsov AM. [Mechanism of spiral waves initiation in active media, connected with critical curvature phenomenon]. Biofizika 1982;27:886-9.

29. Winfree AT. Varieties of spiral wave behavior: An experimentalist's approach to the theory of excitable media. Chaos 1991;1:303-34.

30. Comtois P, Kneller J, Nattel S. Of circles and spirals: bridging the gap between the leading circle and spiral wave concepts of cardiac reentry. Europace 2005;7 Suppl 2:10-20.

31. Comtois P, Sakabe M, Vigmond EJ, et al. Mechanisms of Atrial Fibrillation Termination by Rapidly Unbinding Sodium Channel Blockers. Insights from Mathematical Models and Experimental Correlates. Am J Physiol Heart Circ Physiol 2008.

32. Okishige K, Nishizaki M, Azegami K, Igawa M, Yamawaki N, Aonuma K. Pilsicainide for conversion and maintenance of sinus rhythm in chronic atrial fibrillation: a placebo-controlled, multicenter study. Am Heart J 2000;140:e13.

33. Wijffels MC, Dorland R, Mast F, Allessie MA. Widening of the excitable gap during pharmacological cardioversion of atrial fibrillation in the goat: effects of cibenzoline, hydroquinidine, flecainide, and d-sotalol. Circulation 2000;102:260-7.

34. Kneller J, Kalifa J, Zou R, et al. Mechanisms of atrial fibrillation termination by 
pure sodium channel blockade in an ionically-realistic mathematical model. Circ Res 2005;96:e35-47.

35. Nattel S, Kneller J, Zou R, Leon LJ. Mechanisms of termination of atrial fibrillation by Class I antiarrhythmic drugs: evidence from clinical, experimental, and mathematical modeling studies. J Cardiovasc Electrophysiol 2003;14:S133-9.

36. Skanes AC, Mandapati R, Berenfeld O, Davidenko JM, Jalife J. Spatiotemporal periodicity during atrial fibrillation in the isolated sheep heart. Circulation 1998;98:123648.

37. Ikeda $\mathrm{T}$, Uchida $\mathrm{T}$, Hough $\mathrm{D}$, et al. Mechanism of spontaneous termination of functional reentry in isolated canine right atrium. Evidence for the presence of an excitable but nonexcited core. Circulation 1996;94:1962-73.

38. Kneller J, Zou R, Vigmond EJ, Wang Z, Leon LJ, Nattel S. Cholinergic atrial fibrillation in a computer model of a two-dimensional sheet of canine atrial cells with realistic ionic properties. Circ Res 2002;90:E73-87.

39. Jalife J, Berenfeld O. Dominant frequency mapping to assess the consequences of remodeling in the mechanism of atrial fibrillation. In: Natale A, Jalife J, eds. Atrial fibrillation: from bench to bedside. Totowa: Humana Press; 2008:77-100.

40. Jalife J, Berenfeld O, Mansour M. Mother rotors and fibrillatory conduction: a mechanism of atrial fibrillation. Cardiovasc Res 2002;54:204-16. 
41. Morillo CA, Klein GJ, Jones DL, Guiraudon CM. Chronic rapid atrial pacing. Structural, functional, and electrophysiological characteristics of a new model of sustained atrial fibrillation. Circulation 1995;91:1588-95.

42. Haissaguerre M, Sanders P, Hocini M, et al. Changes in atrial fibrillation cycle length and inducibility during catheter ablation and their relation to outcome. Circulation 2004; 109:3007-13.

43. Pappone C, Rosanio S, Oreto G, et al. Circumferential radiofrequency ablation of pulmonary vein ostia: A new anatomic approach for curing atrial fibrillation. Circulation 2000;102:2619-28.

44. Harada A, Konishi T, Fukata M, Higuchi K, Sugimoto T, Sasaki K. Intraoperative map guided operation for atrial fibrillation due to mitral valve disease. Ann Thorac Surg 2000;69:446-50; discussion 50-1.

45. Berenfeld O. Quantifying activation frequency in atrial fibrillation to establish underlying mechanisms and ablation guidance. Heart Rhythm 2007;4:1225-34.

46. Sanders P, Berenfeld O, Hocini M, et al. Spectral analysis identifies sites of highfrequency activity maintaining atrial fibrillation in humans. Circulation 2005;112:789-97.

47. Lazar S, Dixit S, Callans DJ, Lin D, Marchlinski FE, Gerstenfeld EP. Effect of pulmonary vein isolation on the left-to-right atrial dominant frequency gradient in human atrial fibrillation. Heart Rhythm 2006;3:889-95. 
48. Atienza F, Almendral J, Jalife J, et al. Real-time dominant frequency mapping and ablation of dominant frequency sites in atrial fibrillation with left-to-right frequency gradients predicts long-term maintenance of sinus rhythm. Heart Rhythm 2009;6:33-40.

49. Nademanee K, McKenzie J, Kosar E, et al. A new approach for catheter ablation of atrial fibrillation: mapping of the electrophysiologic substrate. J Am Coll Cardiol 2004;43:2044-53.

50. Rostock T, Rotter M, Sanders P, et al. High-density activation mapping of fractionated electrograms in the atria of patients with paroxysmal atrial fibrillation. Heart Rhythm 2006;3:27-34.

51. Verma A, Novak P, Macle L, et al. A prospective, multicenter evaluation of ablating complex fractionated electrograms (CFEs) during atrial fibrillation (AF) identified by an automated mapping algorithm: acute effects on AF and efficacy as an adjuvant strategy. Heart Rhythm 2008;5:198-205.

52. Kalifa J, Tanaka K, Zaitsev AV, et al. Mechanisms of wave fractionation at boundaries of high-frequency excitation in the posterior left atrium of the isolated sheep heart during atrial fibrillation. Circulation 2006;113:626-33.

53. Everett THt, Wilson EE, Verheule S, Guerra JM, Foreman S, Olgin JE. Structural atrial remodeling alters the substrate and spatiotemporal organization of atrial fibrillation: a comparison in canine models of structural and electrical atrial remodeling. Am $\mathrm{J}$ Physiol Heart Circ Physiol 2006;291:H2911-23. 
54. Zlochiver S, Yamazaki M, Kalifa J, Berenfeld O. Rotor meandering contributes to irregularity in electrograms during atrial fibrillation. Heart Rhythm 2008;5:846-54.

55. Nattel S. Complex fractionated atrial electrograms: can they be made simple? Heart Rhythm 2008;5:855-6.

56. Lu Z, Scherlag BJ, Lin J, et al. Autonomic mechanism for complex fractionated atrial electrograms: evidence by fast fourier transform analysis. J Cardiovasc Electrophysiol 2008;19:835-42.

57. Katzung BG. Introduction to autonomic Pharmacology. In: Katzung BG, ed. Basic and Clinical Pharmacology. 10th ed: McGraw Hill 2007:75-93.

58. Janes RD, Brandys JC, Hopkins DA, Johnstone DE, Murphy DA, Armour JA. Anatomy of human extrinsic cardiac nerves and ganglia. Am J Cardiol 1986;57:299-309.

59. Pauza DH, Skripka V, Pauziene N, Stropus R. Morphology, distribution, and variability of the epicardiac neural ganglionated subplexuses in the human heart. Anat Rec 2000;259:353-82.

60. Kawashima T. The autonomic nervous system of the human heart with special reference to its origin, course, and peripheral distribution. Anat Embryol (Berl) 2005;209:425-38.

61. Chiou CW, Eble JN, Zipes DP. Efferent vagal innervation of the canine atria and sinus and atrioventricular nodes. The third fat pad. Circulation 1997;95:2573-84. 
62. Armour JA, Murphy DA, Yuan BX, Macdonald S, Hopkins DA. Gross and microscopic anatomy of the human intrinsic cardiac nervous system. Anat Rec 1997;247:289-98.

63. Pauza DH, Skripka V, Pauziene N. Morphology of the intrinsic cardiac nervous system in the dog: a whole-mount study employing histochemical staining with acetylcholinesterase. Cells Tissues Organs 2002;172:297-320.

64. Yuan BX, Ardell JL, Hopkins DA, Losier AM, Armour JA. Gross and microscopic anatomy of the canine intrinsic cardiac nervous system. Anat Rec 1994;239:75-87.

65. Zhang Y, Mazgale T. Role of the vagus in AF. Pathophysiology and therapeutic applications. In: Natale A, Jalife J, eds. Atria Fibrillation From bench to bedside. Totowa: Humana Press; 2008:115-31.

66. Rubart M, Zipes DP. Genesis of Cardiac Arrhythmias: Electrophysiological Considerations. In: Zipes DP, LIbby P, Bonow RO, Braunwald E, eds. Braunwald's Heart Disease A textbook of cardiovascular medicine. 7th ed. Philadelphia: Elsevier Saunders; 2005:653-87.

67. Garrey WE. Auricular fibrillation. Physiol Rev 1924;4:215-50.

68. Coumel P. Autonomic influences in atrial tachyarrhythmias. J Cardiovasc Electrophysiol 1996;7:999-1007.

69. Wang J, Liu L, Feng J, Nattel S. Regional and functional factors determining 
induction and maintenance of atrial fibrillation in dogs. Am J Physiol 1996;271:H148-58.

70. Smeets JL, Allessie MA, Lammers WJ, Bonke FI, Hollen J. The wavelength of the cardiac impulse and reentrant arrhythmias in isolated rabbit atrium. The role of heart rate, autonomic transmitters, temperature, and potassium. Circ Res 1986;58:96-108.

71. Liu L, Nattel S. Differing sympathetic and vagal effects on atrial fibrillation in dogs: role of refractoriness heterogeneity. Am J Physiol 1997;273:H805-16.

72. Pappone C, Santinelli V, Manguso F, et al. Pulmonary vein denervation enhances long-term benefit after circumferential ablation for paroxysmal atrial fibrillation. Circulation 2004;109:327-34.

73. Lemola K, Chartier D, Yeh $\mathrm{YH}$, et al. Pulmonary vein region ablation in experimental vagal atrial fibrillation: role of pulmonary veins versus autonomic ganglia. Circulation 2008; 117:470-7.

74. Wijffels MC, Kirchhof CJ, Dorland R, Allessie MA. Atrial fibrillation begets atrial fibrillation. A study in awake chronically instrumented goats. Circulation 1995;92:1954-68.

75. Ehrlich JR, Coutu P, Yeh YH, Qi X, Nattel S. Cellular Electrophysiology and the substrate for atrial fibrillation. In: Natale A, Jalife J, eds. Atrial fibrillation From bench to bedside. Totowa Humana Press; 2008:37-56.

76. Nattel S, Burstein B, Dobrev D. Atrial Remodeling and Atrial Fibrillation: Mechanisms and Implications. Circ Arrhythmia Electrophysiol 2008;1:62-73. 
77. Opie L. Channels, pumps, and exchangers. In: Opie L, ed. Heart Physiology, from cell to circulation. 3rd ed. Philadelphia: Lippincot-Raven; 1998:71-114.

78. Sun H, Chartier D, Leblanc N, Nattel S. Intracellular calcium changes and tachycardia-induced contractile dysfunction in canine atrial myocytes. Cardiovasc Res 2001;49:751-61.

79. Yue L, Feng J, Gaspo R, Li GR, Wang Z, Nattel S. Ionic remodeling underlying action potential changes in a canine model of atrial fibrillation. Circ Res 1997;81:512-25.

80. Yue L, Melnyk P, Gaspo R, Wang Z, Nattel S. Molecular mechanisms underlying ionic remodeling in a dog model of atrial fibrillation. Circ Res 1999;84:776-84.

81. Bosch RF, Zeng X, Grammer JB, Popovic K, Mewis C, Kuhlkamp V. Ionic mechanisms of electrical remodeling in human atrial fibrillation. Cardiovasc Res $1999 ; 44: 121-31$.

82. Schotten U, Duytschaever M, Ausma J, Eijsbouts S, Neuberger HR, Allessie M. Electrical and contractile remodeling during the first days of atrial fibrillation go hand in hand. Circulation 2003;107:1433-9.

83. Nattel S, Maguy A, Le Bouter S, Yeh YH. Arrhythmogenic ion-channel remodeling in the heart: heart failure, myocardial infarction, and atrial fibrillation. Physiol Rev 2007;87:425-56.

84. Dobrev D, Graf E, Wettwer E, et al. Molecular basis of downregulation of G- 
protein-coupled inward rectifying $\mathrm{K}(+)$ current $(\mathrm{I}(\mathrm{K}, \mathrm{ACh})$ in chronic human atrial fibrillation: decrease in GIRK4 mRNA correlates with reduced $\mathrm{I}(\mathrm{K}, \mathrm{ACh})$ and muscarinic receptor-mediated shortening of action potentials. Circulation 2001;104:2551-7.

85. Dobrev D, Wettwer E, Kortner A, Knaut M, Schuler S, Ravens U. Human inward rectifier potassium channels in chronic and postoperative atrial fibrillation. Cardiovasc Res 2002;54:397-404.

86. Cha TJ, Ehrlich JR, Zhang L, Chartier D, Leung TK, Nattel S. Atrial tachycardia remodeling of pulmonary vein cardiomyocytes: comparison with left atrium and potential relation to arrhythmogenesis. Circulation 2005;111:728-35.

87. Dobrzynski H, Marples DD, Musa H, et al. Distribution of the muscarinic K+ channel proteins Kir3.1 and Kir3.4 in the ventricle, atrium, and sinoatrial node of heart. J Histochem Cytochem 2001;49:1221-34.

88. Shi H, Yang B, Xu D, Wang H, Wang Z. Electrophysiological characterization of cardiac muscarinic acetylcholine receptors: different subtypes mediate different potassium currents. Cell Physiol Biochem 2003;13:59-74.

89. Shi H, Wang H, Li D, Nattel S, Wang Z. Differential alterations of receptor densities of three muscarinic acetylcholine receptor subtypes and current densities of the corresponding $\mathrm{K}+$ channels in canine atria with atrial fibrillation induced by experimental congestive heart failure. Cell Physiol Biochem 2004;14:31-40.

90. Brundel BJ, Van Gelder IC, Henning RH, et al. Ion channel remodeling is related to 
intraoperative atrial effective refractory periods in patients with paroxysmal and persistent atrial fibrillation. Circulation 2001;103:684-90.

91. Brundel BJ, Van Gelder IC, Henning RH, et al. Alterations in potassium channel gene expression in atria of patients with persistent and paroxysmal atrial fibrillation: differential regulation of protein and mRNA levels for $\mathrm{K}+$ channels. J Am Coll Cardiol 2001;37:926-32.

92. Yeh YH, Qi X, Shiroshita-Takeshita A, et al. Atrial tachycardia induces remodelling of muscarinic receptors and their coupled potassium currents in canine left atrial and pulmonary vein cardiomyocytes. Br J Pharmacol 2007;152:1021-32.

93. Dobrev D, Friedrich A, Voigt N, et al. The G protein-gated potassium current $\mathrm{I}(\mathrm{K}, \mathrm{ACh})$ is constitutively active in patients with chronic atrial fibrillation. Circulation 2005;112:3697-706.

94. Ehrlich JR, Cha TJ, Zhang L, et al. Characterization of a hyperpolarizationactivated time-dependent potassium current in canine cardiomyocytes from pulmonary vein myocardial sleeves and left atrium. J Physiol 2004;557:583-97.

95. Cha TJ, Ehrlich JR, Chartier D, Qi XY, Xiao L, Nattel S. Kir3-based inward rectifier potassium current: potential role in atrial tachycardia remodeling effects on atrial repolarization and arrhythmias. Circulation 2006;113:1730-7.

96. Voigt N, Maguy A, Yeh YH, et al. Changes in I K, ACh single-channel activity with atrial tachycardia remodelling in canine atrial cardiomyocytes. Cardiovase Res 
$2008 ; 77: 35-43$.

97. Voigt N, Friedrich A, Bock M, et al. Differential phosphorylation-dependent regulation of constitutively active and muscarinic receptor-activated IK,ACh channels in patients with chronic atrial fibrillation. Cardiovasc Res 2007;74:426-37.

98. Michael G, Xiao L, Qi XY, Dobrev D, Nattel S. Remodelling of cardiac repolarization: how homeostatic responses can lead to arrhythmogenesis. Cardiovasc Res 2009;81:491-9.

99. Olgin JE, Sih HJ, Hanish S, et al. Heterogeneous atrial denervation creates substrate for sustained atrial fibrillation. Circulation 1998;98:2608-14.

100. Jayachandran JV, Sih HJ, Winkle W, Zipes DP, Hutchins GD, Olgin JE. Atrial fibrillation produced by prolonged rapid atrial pacing is associated with heterogeneous changes in atrial sympathetic innervation. Circulation 2000;101:1185-91.

101. Chang $\mathrm{CM}$, Wu TJ, Zhou S, et al. Nerve sprouting and sympathetic hyperinnervation in a canine model of atrial fibrillation produced by prolonged right atrial pacing. Circulation 2001;103:22-5.

102. Goette A, Juenemann G, Peters B, et al. Determinants and consequences of atrial fibrosis in patients undergoing open heart surgery. Cardiovasc Res 2002;54:390-6.

103. Thijssen VL, Ausma J, Borgers M. Structural remodelling during chronic atrial fibrillation: act of programmed cell survival. Cardiovasc Res 2001;52:14-24. 
104. Burstein B, Nattel S. Atrial fibrosis: mechanisms and clinical relevance in atrial fibrillation. J Am Coll Cardiol 2008;51:802-9.

105. Li D, Fareh S, Leung TK, Nattel S. Promotion of atrial fibrillation by heart failure in dogs: atrial remodeling of a different sort. Circulation 1999;100:87-95.

106. Allessie M, Ausma J, Schotten U. Electrical, contractile and structural remodeling during atrial fibrillation. Cardiovasc Res 2002;54:230-46.

107. Shinagawa K, Shi YF, Tardif JC, Leung TK, Nattel S. Dynamic nature of atrial fibrillation substrate during development and reversal of heart failure in dogs. Circulation 2002;105:2672-8.

108. Cha TJ, Ehrlich JR, Zhang L, et al. Dissociation between ionic remodeling and ability to sustain atrial fibrillation during recovery from experimental congestive heart failure. Circulation 2004;109:412-8.

109. Ausma J, van der Velden HM, Lenders MH, et al. Reverse structural and gapjunctional remodeling after prolonged atrial fibrillation in the goat. Circulation 2003;107:2051-8.

110. Cardin S, Li D, Thorin-Trescases N, Leung TK, Thorin E, Nattel S. Evolution of the atrial fibrillation substrate in experimental congestive heart failure: angiotensin-dependent and -independent pathways. Cardiovasc Res 2003;60:315-25.

111. Hanna N, Cardin S, Leung TK, Nattel S. Differences in atrial versus ventricular 
remodeling in dogs with ventricular tachypacing-induced congestive heart failure. Cardiovasc Res 2004;63:236-44.

112. Roberts AB, Sporn MB, Assoian RK, et al. Transforming growth factor type beta: rapid induction of fibrosis and angiogenesis in vivo and stimulation of collagen formation in vitro. Proc Natl Acad Sci U S A 1986;83:4167-71.

113. Nakajima H, Nakajima HO, Salcher O, et al. Atrial but not ventricular fibrosis in mice expressing a mutant transforming growth factor-beta(1) transgene in the heart. Circ Res 2000;86:571-9.

114. Olgin JE, Verheule S. Transgenic and knockout mouse models of atrial arrhythmias. Cardiovasc Res 2002;54:280-6.

115. Xiao HD, Fuchs S, Campbell DJ, et al. Mice with cardiac-restricted angiotensinconverting enzyme (ACE) have atrial enlargement, cardiac arrhythmia, and sudden death. Am J Pathol 2004;165:1019-32.

116. Khairy P, Nattel S. New insights into the mechanisms and management of atrial fibrillation. Cmaj 2002;167:1012-20.

117. Gaspo R, Bosch RF, Talajic M, Nattel S. Functional mechanisms underlying tachycardia-induced sustained atrial fibrillation in a chronic dog model. Circulation 1997;96:4027-35.

118. Ortiz J, Niwano S, Abe H, Rudy Y, Johnson NJ, Waldo AL. Mapping the 
conversion of atrial flutter to atrial fibrillation and atrial fibrillation to atrial flutter. Insights into mechanisms. Circ Res 1994;74:882-94.

119. Shiroshita-Takeshita A, Brundel BJ, Nattel S. Atrial fibrillation: basic mechanisms, remodeling and triggers. J Interv Card Electrophysiol 2005;13:181-93.

120. Nattel S, Li D. Ionic remodeling in the heart: pathophysiological significance and new therapeutic opportunities for atrial fibrillation. Circ Res 2000;87:440-7.

121. Sun H, Gaspo R, Leblanc N, Nattel S. Cellular mechanisms of atrial contractile dysfunction caused by sustained atrial tachycardia. Circulation 1998;98:719-27.

122. Pandit SV, Berenfeld O, Anumonwo JM, et al. Ionic determinants of functional reentry in a 2-D model of human atrial cells during simulated chronic atrial fibrillation. Biophys J 2005;88:3806-21.

123. Sharifov OF, Fedorov VV, Beloshapko GG, Glukhov AV, Yushmanova AV, Rosenshtraukh LV. Roles of adrenergic and cholinergic stimulation in spontaneous atrial fibrillation in dogs. J Am Coll Cardiol 2004;43:483-90.

124. Gaspo R, Bosch RF, Bou-Abboud E, Nattel S. Tachycardia-induced changes in Na+ current in a chronic dog model of atrial fibrillation. Circ Res 1997;81:1045-52.

125. Elvan A, Huang XD, Pressler ML, Zipes DP. Radiofrequency catheter ablation of the atria eliminates pacing-induced sustained atrial fibrillation and reduces connexin 43 in dogs. Circulation 1997;96:1675-85. 
126. Polontchouk L, Haefliger JA, Ebelt B, et al. Effects of chronic atrial fibrillation on gap junction distribution in human and rat atria. J Am Coll Cardiol 2001;38:883-91.

127. Kostin S, Klein G, Szalay Z, Hein S, Bauer EP, Schaper J. Structural correlate of atrial fibrillation in human patients. Cardiovasc Res 2002;54:361-79.

128. Wilhelm M, Kirste W, Kuly S, et al. Atrial distribution of connexin 40 and 43 in patients with intermittent, persistent, and postoperative atrial fibrillation. Heart Lung Circ 2006;15:30-7.

129. Shinagawa K, Li D, Leung TK, Nattel S. Consequences of atrial tachycardiainduced remodeling depend on the preexisting atrial substrate. Circulation 2002;105:251-7.

130. Lammers WJ, Kirchhof C, Bonke FI, Allessie MA. Vulnerability of rabbit atrium to reentry by hypoxia. Role of inhomogeneity in conduction and wavelength. Am J Physiol 1992;262:H47-55.

131. Courtemanche M, Ramirez RJ, Nattel S. Ionic mechanisms underlying human atrial action potential properties: insights from a mathematical model. Am J Physiol 1998;275:H301-21.

132. Harrild D, Henriquez C. A computer model of normal conduction in the human atria. Circ Res 2000;87:E25-36.

133. Gong Y, Xie F, Stein KM, et al. Mechanism underlying initiation of paroxysmal atrial flutter/atrial fibrillation by ectopic foci: a simulation study. Circulation 
2007;115:2094-102.

134. Sarmast F, Kolli A, Zaitsev A, et al. Cholinergic atrial fibrillation: I(K,ACh) gradients determine unequal left/right atrial frequencies and rotor dynamics. Cardiovase Res 2003;59:863-73.

135. Takahashi Y, Jais P, Hocini M, et al. Shortening of fibrillatory cycle length in the pulmonary vein during vagal excitation. J Am Coll Cardiol 2006;47:774-80.

136. Sharifov OF, Zaitsev AV, Rosenshtraukh LV, et al. Spatial distribution and frequency dependence of arrhythmogenic vagal effects in canine atria. J Cardiovasc Electrophysiol 2000;11:1029-42.

137. Kovoor P, Wickman K, Maguire CT, et al. Evaluation of the role of I(KACh) in atrial fibrillation using a mouse knockout model. J Am Coll Cardiol 2001;37:2136-43.

138. Schauerte P, Scherlag BJ, Pitha J, et al. Catheter ablation of cardiac autonomic nerves for prevention of vagal atrial fibrillation. Circulation 2000;102:2774-80.

139. Arora R, Ulphani JS, Villuendas R, et al. Neural substrate for atrial fibrillation: implications for targeted parasympathetic blockade in the posterior left atrium. Am J Physiol Heart Circ Physiol 2008;294:H134-44.

140. Huang CX, Zhao QY, Liang JJ, et al. Differential densities of muscarinic acetylcholine receptor and $\mathrm{I}(\mathrm{K}, \mathrm{ACh})$ in canine supraventricular tissues and the effect of amiodarone on cholinergic atrial fibrillation and I(K,ACh). Cardiology 2006;106:36-43. 
141. Yamanushi TT, Shui Z, Leach RN, Dobrzynski H, Claydon TW, Boyett MR. Role of internalization of M2 muscarinic receptor via clathrin-coated vesicles in desensitization of the muscarinic K+ current in heart. Am J Physiol Heart Circ Physiol 2007;292:H173746.

142. Pfaffinger PJ, Martin JM, Hunter DD, Nathanson NM, Hille B. GTP-binding proteins couple cardiac muscarinic receptors to a K channel. Nature 1985;317:536-8.

143. Scherlag BJ, Nakagawa H, Jackman WM, et al. Electrical stimulation to identify neural elements on the heart: their role in atrial fibrillation. J Interv Card Electrophysiol 2005;13 Suppl 1:37-42. 